\title{
Climatic and edaphic influences on the radial growth of eastern redcedar (Juniperus virginiana), Smoke Hole Canyon, West Virginia
}

Joshua A. Wixom

West Virginia University

Follow this and additional works at: https://researchrepository.wvu.edu/etd

\section{Recommended Citation}

Wixom, Joshua A., "Climatic and edaphic influences on the radial growth of eastern redcedar (Juniperus virginiana), Smoke Hole Canyon, West Virginia" (2009). Graduate Theses, Dissertations, and Problem Reports. 846.

https://researchrepository.wvu.edu/etd/846

This Thesis is protected by copyright and/or related rights. It has been brought to you by the The Research Repository @ WVU with permission from the rights-holder(s). You are free to use this Thesis in any way that is permitted by the copyright and related rights legislation that applies to your use. For other uses you must obtain permission from the rights-holder(s) directly, unless additional rights are indicated by a Creative Commons license in the record and/ or on the work itself. This Thesis has been accepted for inclusion in WVU Graduate Theses, Dissertations, and Problem Reports collection by an authorized administrator of The Research Repository @ WVU. For more information, please contact researchrepository@mail.wvu.edu. 


\title{
Climatic and Edaphic Influences on the Radial Growth of Eastern Redcedar (Juniperus virginiana), Smoke Hole Canyon, West Virginia
}

\author{
Joshua A. Wixom \\ Thesis submitted to the \\ Eberly College of Arts and Sciences \\ at West Virginia University \\ in partial fulfillment of the requirements \\ for the degree of
Master of Arts
in Geography
Amy E. Hessl, Ph.D., Chair Rick Landenberger, Ph.D. Richard Thomas, Ph.D. \\ Department of Geology and Geography \\ Morgantown, West Virginia \\ 2009
}

Keywords: tree rings, climatic variability, dendroclimatology, edaphic conditions, cation exchange capacity, sensitivity, moisture stress 


\section{ABSTRACT \\ Climatic and Edaphic Influences on the Radial Growth of Eastern Redcedar (Juniperus virginiana), Smoke Hole Canyon, West Virginia}

\section{Joshua A. Wixom}

The annual variability observed in tree-ring records has been used to reconstruct climate conditions at the local, regional, and global scales. Dendrochronology, the study of tree rings, has typically focused on locations where trees are limited by a single climatic variable (i.e. temperature or moisture availability) at the limits of their range. Individual trees, however, may be limited by one or more variables well within their ecological range. This can occur when individuals are located on ecologically extreme sites where soil moisture and chemistry or increased evapotranspiration impede a tree's ability to grow.

This study examines factors affecting radial growth of eastern redcedar (Juniperus virginiana) from Smoke Hole Canyon, West Virginia. The three study sites (BBS, EAR, and TNC) are well within the distribution of $J$. virginiana, but are typically drier and rockier than other locations in close proximity. Tree-ring series were analyzed for their response and sensitivity to climate. The presence of strip-bark was also recorded. Strip-bark has been observed in other long-lived species of the Cupressaceae family and is thought to increase longevity in species such as J. virginiana. Radial tree growth at each site was positively correlated with March temperature, May precipitation, and June PDSI. May temperature, however, was negatively correlated with growth. Soil chemistry was also related to metrics of tree sensitivity (series intercorrelation, mean sensitivity, and standard deviation), but no strong relationships were observed. Strip-bark trees at BBS were more responsive to climatic variability than whole-bark trees, suggesting strip-bark may play a role in climate sensitivity. The results demonstrate that site-specific conditions do not influence tree sensitivity, but do suggest that further analysis would be useful to determine how biotic and abiotic factors interact at the local scale. 


\section{DEDICATION}

I would like to dedicate this work to my grandfather, Charles B. Wixom. He spent so much time teaching me the value of hard work and the meaning of integrity. His love was absolute and served as an example on which I model my own life. My only wish is that he could be here today to see what I have accomplished and know how much he has inspired me to do great things. 


\section{ACKNOWLEDGEMENTS}

I would first like to thank my advisor, Dr. Amy Hessl, whose support and guidance were instrumental in the development of my academic development and this document. Your desire to see me grow as a student will always be appreciated. I would also like to thank my committee members Drs. Richard Thomas and Rick Landenberger. Their knowledge and comments helped shape my research. I must also recognize my peers R. Stockton Maxwell and Thomas Saladyga. Stockton is my mentor and has spent countless hours helping me to better understand tree rings and all of the valuable information one can learn from them. Tom has been a constant source of motivation and rational thought challenging me to think critically about my research. This work could not have been done without the efforts of our research assistants. Cari Leland was instrumental in helping to collect and process the tree-ring data. Kate McGraw also provided a key role in developing the chronologies for analysis. Eric Lovell's willingness to process my numerous soil samples in a room by himself is a testament to his dedication. Their friendship and hard work will never be taken for granted.

I must also thank my family for their unending love and support throughout this entire process. They have believed in me even when I did not and encouraged me to press on. In particular, my father has been the rock on which I rely and the source of my strength and persistence. No matter the situation he was always willing to lend a hand. He is always there when I need him. My mother has served to remind me that the harder you work the better the result. Without her I would not be where I am today. I must also thank my friends for always believing in me. Your support means the world to me. 


\section{TABLE OF CONTENTS}

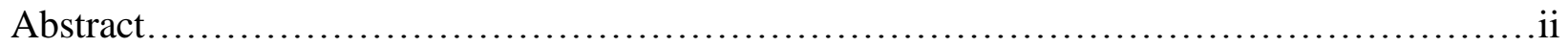

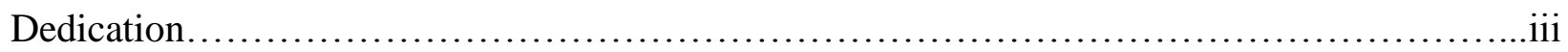

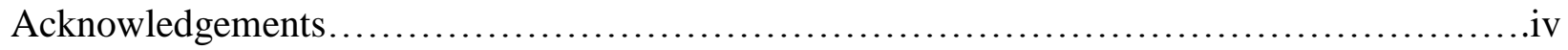

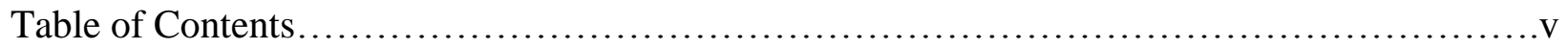

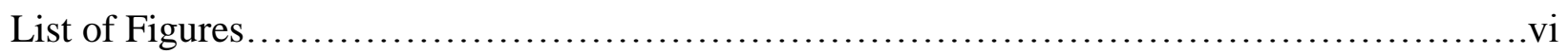

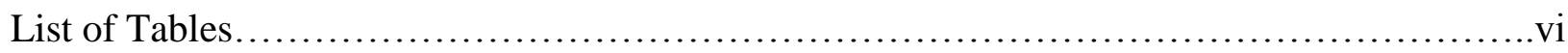

Chapter 1: Introduction................................................................

1.1 Tree Rings and Climate

1.2 Juniperus virginiana

1.3 Edaphic and Site-Specific Influences

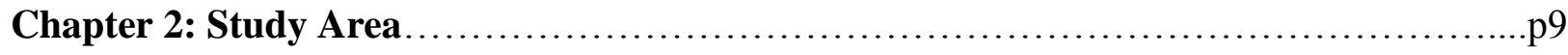

Chapter 3: Methods......................................................... 11

3.1 Tree Ring Sampling

3.2 Tree Ring Analysis

3.3 Soil Sampling

3.4 Soil Analysis

3.5 Data Analysis

Chapter 4: Results. .p18

4.1 Site Chronologies

4.2 Climate Correlations

4.3 Strip-bark: Relationship with Climate Sensitivity

4.4 Tree age and DBH: Relationship with Climate Sensitivity

4.5 Soil Chemistry Effects on Tree Sensitivity

Chapter 5: Discussion.

5.1 Relationship to Climate

5.2 Soil Chemistry and Tree Sensitivity

Chapter 6: Conclusions. .p36

6.1 Climate Response

6.2 Strip-Bark, Tree Age, and Size

6.3 Lack of Relationships with Soil Metrics

6.4 Future Research

References. .p39

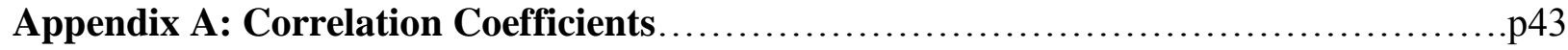

Appendix B: Individual Tree Correlation Coefficients ............................p46

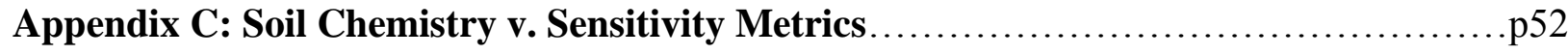

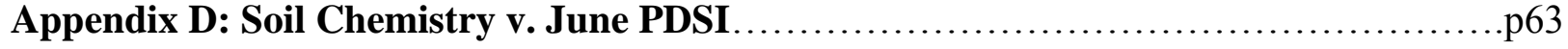

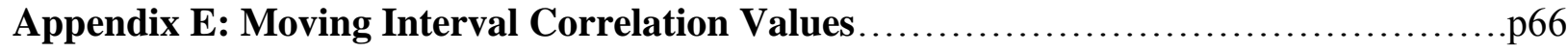




\section{LIST OF FIGURES}

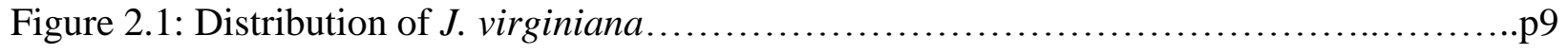

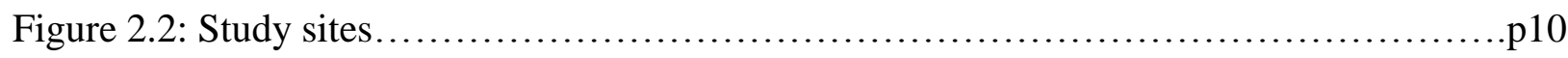

Figure 4.1a: BBS residual chronology ................................................... 18

Figure 4.1b: EAR residual chronology .................................................... 19

Figure 4.1c: TNC residual chronology ................................................... 19

Figure 4.2: Approximate inner ring dates.............................................. 21

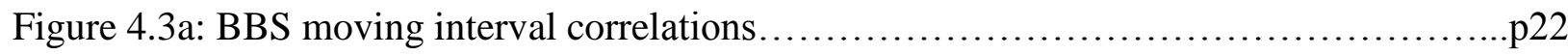

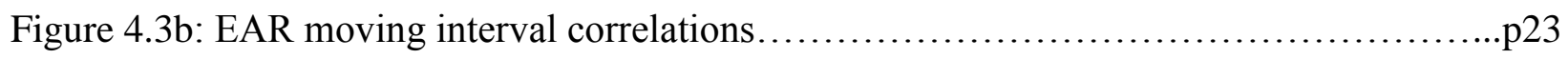

Figure 4.3c: TNC moving interval correlations.......................................p23

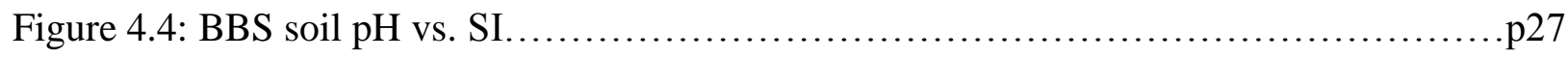

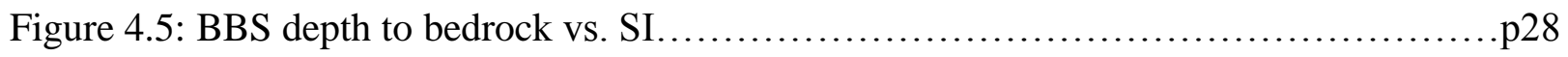

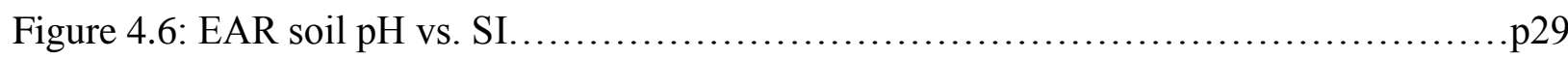

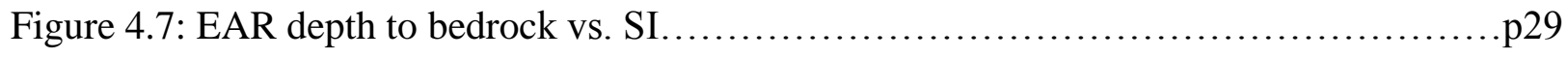

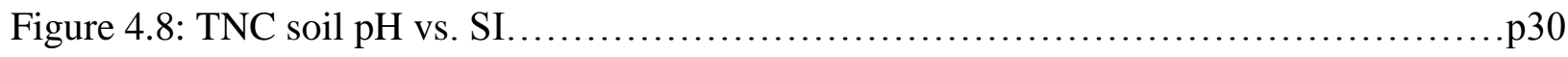

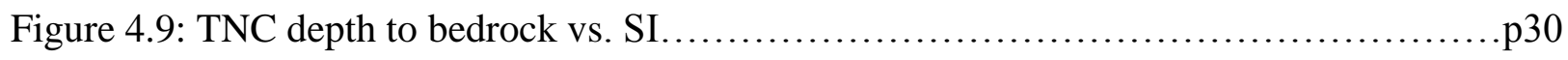

\section{LIST OF TABLES}

Table 2.1: Topographic site characteristics..........................................p 10

Table 3.1: Tree-ring sampling statistics...................................................p 11

Table 3.2: Data collected.................................................................... 17

Table 4.1: COFECHA statistics..................................................... 20

Table 4.2: Correlation of tree-ring metrics and June PDSI...............................p22

Table 4.3a: BBS correlation coefficients.................................................. 24

Table 4.3b: EAR correlation coefficients................................................. 24

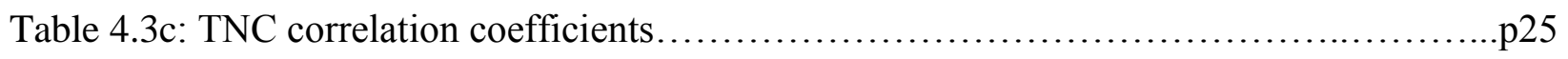

Table 4.4: Strip-bark vs. whole-bark response to June PDSI...............................p26

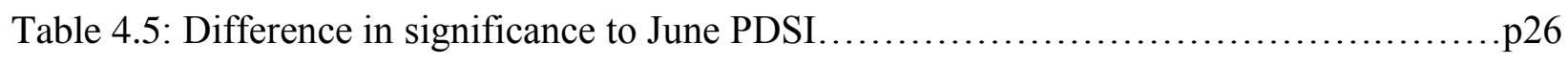




\section{Introduction}

Variations in the growth of annual tree-rings have been used to describe past climatic variability in many regions of the world (Villalba, Veblen, and Ogden 1994). Dendroclimatology, the science that deals with the synthesis of annually dated tree-rings and climate data, allows researchers to produce annually resolved records of historic temperature and precipitation regimes. To do this, however, the climate signal preserved in individual tree-ring series must be isolated from other confounding variables influencing tree growth (i.e. age related growth, disturbance, etc.) using both site selection and statistical methods. For most dendroclimatological studies, trees are chosen from homogenous areas, at or near the limit of their ecological range. Trees that establish near their maximum geographical, latitudinal, or elevational extent are likely to be more responsive to climatic variability. Trees growing at high elevation or high latitude (treeline) tend to be limited by temperature while those growing at lower treeline tend to be limited by moisture (Fritts 1976). Those individuals growing well within their range, however, may still be limited by a single or multiple climatic variables where they are stressed by edaphic conditions (Beadle 1953; Clarkson 1966). For these individuals, a comprehensive understanding of site-specific environmental conditions, including soil chemistry and hydrology, should support any tree-ring analysis, because these variables may affect the way in which individual species respond to climate (Stephenson 1990).

Dendroecological studies must account for intra-site variability, particularly edaphic conditions, since these environmental variables impact the distribution, growth, and longevity of individuals (Clarkson 1966; Stephenson 1990). Historically, sites have been selected based on uniform (though extreme) environmental conditions in order to reduce the "noise" confounding variables add to the record of tree-ring growth. Few attempts have been made to incorporate 
edaphic and other site-specific variables into dendroclimatological studies that explore a tree's radial growth response to climate (Pinto et al. 2007). Climatic drivers undoubtedly interact with variables such as soil moisture capacity, soil depth, and parent material to influence growth response. A robust analysis of site-specific variables should be used to observe the ways in which the edaphic complex impacts the climate sensitivity of individual trees.

Many of the longest-lived tree species occur within the Cupressaceae and Pinaceae families. Bristlecone pine (Pinus aristata Engelm.), the longest lived organism, can live for more than 4,000 years (Schulman 1954; Currey 1965). Western juniper (Juniperus occidentalis Hook.) can live for more than 2,000 years (Miles and Worthington 1998) and northern white cedar (Thuja occidentalis L.) has been found to live for more than 1,000 years (Kelly and Larson 1997). However, not all individuals of these species are long-lived. Where trees are near their elevational or range limits, they tend to grow slowly and live longer. These individuals also tend to be ideal for climate reconstruction since their growth is often limited by a single climate variable. Often, where individuals form an edaphic climax, but are not necessarily at the elevational or range limit for that species, trees are both long-lived and sensitive to climate. Examples of long-lived edaphic climax species include: Pinus aristata Engelm. growing on limestone (LaMarche 1969), Thuja occidentalis L. on dolomitic limestone (Larson et al. 2000), and Juniperus virginiana on dolomitic limestone (Kucera and Martin 1957). Many of these species utilize specialized physiological mechanisms to maintain growth. Strip-bark is often an indicator of old-growth trees growing within stands at higher elevations (Bunn et a. 2003). The mechanism helps trees stressed by local site conditions (i.e. moisture availability) adapt to adverse climate conditions. Strip-bark also allows a tree to continue to grow even if it has been 
damaged by wind, ice, or rock fall. It is not clear, however, if trees with strip-bark are more sensitive to climate than full-bark trees (Bunn et al. 2003).

Individual tree response to climatic variability has yielded promising but limited insight into species-specific relationships with the environment (Bunn et al. 2003). Previous dendroclimatological studies have shown J. virginiana to be sensitive to moisture availability on rock outcrops (Hawley 1937, Larson 1997). Where J. virginiana forms an edaphic climax, it has the potential to be a good recorder of climatic variability (Butler and Walsh 1988; Copenheaver et al. 2005). Yet, few studies have analyzed the influences of the edaphic complex on the climate sensitivity of individual trees. Identifying site-specific limiting factors will enhance the general understanding of $J$. virginiana growing on isolated rock outcrop and cliff communities. This is of particular importance, because $J$. virginiana can be found growing across a wide range of edaphic conditions which can exert different influences on tree sensitivity. The purpose of this study is to (i) determine what climatic factors influence the radial growth of Juniperus virginiana growing on limestone in West Virginia and (ii) examine the relationship between tree growth and climate among individuals. The working hypotheses are:

H1: Summer drought is most strongly related to Juniperus virginiana latewood formation, but is dependent on edaphic conditions.

H2: Old trees, especially those with strip-bark, are more responsive to climatic variability than younger trees.

\subsection{Tree Rings and Climate}

Dendrochronology was developed by A.E. Douglass in the 1920 s as a means to accurately date trees and study the environmental influences on their growth. Most trees growing in locations with strong seasonality add only one ring per growing season. Variations in ring widths as well as other indices of tree growth are often related to climate (Stokes and Smiley 1968). Dendroclimatology compares individual tree-ring series to climate variables in order to 
draw inferences about past climate from tree-rings. Tree-ring analysis is particularly important in areas where the instrumental record is short or incomplete. In recent years dendroclimatology has adopted an array of statistical analyses to make the science more robust and objective (Fritts 1976). This is accomplished by creating a standardized chronology with unitless ring-width indices. Ring width indices (RWI) are useful because they remove the age effect of tree growth and influences from disturbance. These indices can be statistically correlated with environmental variables (Cook and Kairiukstis 1990; Villalba, Veblen, and Ogden 1994). By creating a standardized index for each series, relationships between radial growth and climate can be identified.

\subsection{Juniperus virginiana}

Previous analyses of $J$. virginiana have shown that individuals growing on dry rocky sites are likely to be limited by moisture availability (Hawley 1937; Larson 1997). But, J. virginiana exhibits two vastly different life histories, displaying an edaphic climax trajectory as well as a pioneer trajectory. Some individuals establish on steep rocky sites while others have been observed encroaching on habitat that has been disturbed either by grazing, logging, or farm field abandonment (Copenheaver et al. 2004). Those J. virginiana growing on limestone glades and barrens have similar characteristics to other long-lived species including the formation of stripbark, stunted growth form, and the inclusion of tree-ring anomalies (e.g. false rings) within annual growth rings. J. virginiana is an aggressive species that is relatively shade intolerant and, as a result, competes for resources across a wide range of habitats. Yet, where the species forms an edaphic climax community it has a competitive advantage under harsh environmental conditions and can persist on these sites where other species cannot (Small and Wentworth 1998). J. virginiana will actually raise the $\mathrm{pH}$ of the soil in which it grows by exchanging 
hydrogen ions with calcium ions, thus creating a more desirable habitat for itself while excluding other species (Read and Walker 1950). This dynamic is not fully understood and warrants further investigation, particularly in the context of species-specific longevity.

J. virginiana appears to be long-lived ( 200-800 years) on rocky limestone outcrops with little soil development (Read and Walker 1950; Larson et al. 1999). The direct causes of longevity are not well known, but the idea that $J$. virginiana has a competitive advantage on marginal sites implies a complex interaction between the species and the site-specific characteristics. It has also been observed that trees located on marginal sites exhibit a great deal of variability in growth form. For Pinus aristata Engelm., the formation of strip-bark allows the tree to maintain its growth even after a portion of the cambium has been damaged (LaMarche 1969). This may also be true for J. virginiana which, like other members of the Cupressaceae family, can also survive cambial dieback with strip-bark.

As with any species, J. virginiana responds best to drought stress at a well defined limit of its distribution (Fritts 1976), whether it is based on latitude, altitude, or edaphic conditions. Limited, but promising research has been conducted to test the efficiency of tree-ring series obtained from J. virginiana in dendrochronological analyses (see Guyette et al. 1980; Butler and Walsh 1988; Copenheaver et al. 2005; Edmonson 2006). J. virginiana is a good recorder of climatic variability, in that the results have been statistically significant. It has been shown that the mean sensitivity (the difference in ring width from one ring to the next adjacent ring; Fritts 1976) for edge and interior chronologies was 0.295 and 0.328 , respectively. These results, however, are somewhat problematic even though they are similar. Transitional zones between habitat types should be more responsive to climatic variation, because these locations are at the 
edge of a species' range. This could suggest that there are other factors influencing radial growth than just climatic variability.

Though few studies have explored the relationship between $J$. virginiana and climate or topography, several related species have been studied more extensively. Thuja occidentalis L., also in the Cupressaceae family, can grow on a broad range of sites across a wide environmental gradient (Tardif and Bergeron 1997). However, they are long-lived on rocky outcrops and cliff communities where there is poor soil development over carbonate strata (i.e. dolomitic limestone). Numerous studies have examined the growth habit of old-growth white cedar stands on the Niagara Escarpment as well as relict stands in Canada (see Kelly et al. 1992; Kelly and Larson 1997; Tardif and Bergeron 1997; Larson et al. 2000; Tardif and Stevenson 2001). As with $J$. virginiana, long-lived $T$. occidentalis displays a highly variable growth form. The form is characterized by stunted apical growth and cambial dieback ("strip-bark"). Strip-bark growth allows old trees to continue to grow while conserving some of their energy reserves for maintenance (LaMarche 1969; Kelly et al. 1992; Bunn et al. 2003). Radial growth of $T$. occidentalis is positively correlated with temperatures in November and December and negatively correlated with June maximum temperature the year the ring was formed (Tardif and Stevenson 2001).

J. occidentalis is closely related to J. virginiana, but grows on xeric sites in western North America. It has a high mean sensitivity (Knapp et al. 2002) suggesting that J. virginiana growing on moisture-limited sites might also be sensitive to climate. J. occidentalis, for example, grows on sites that receive less than 100mm of precipitation annually (Knapp et al. 2002). Climate reconstructions have been developed from J. occidentalis cores in the western United States (see Knapp et al. 2002). Ring widths were correlated with the current year's winter 
and spring precipitation. Series intercorrelation of $J$. occidentalis was high, but the response to climate deteriorated prior to 1750 . The chronologies created from western juniper cores displayed conflicting results when correlated with climatic variables. J. occidentalis growth was unresponsive to variability in the eastern portion of its range, but proved to be a good recorder of climate in the Pacific Northwest. These studies and those of Copenheaver et al. (2005) suggest that J. virginiana may serve as a good proxy for climate reconstructions in the Mid-Atlantic region.

\subsection{Edaphic and Site-Specific Influences}

The growth and distribution of vegetation is highly influenced by the characteristics of the underlying soil (Clarkson 1966). In fact, a combination of intra-site characteristics may influence the distribution and growth of tree species. Soil properties affect vegetation by controlling community structure, which is determined by a species' adaptation to the local limiting factor(s). One of the objectives of this research is to analyze the influence of the edaphic complex (the collection of soil properties at each tree) that may control the growth and climate response of individual J. virginiana (Beadle 1953). Variations in species distribution due to differences in edaphic characteristics have been observed in P. aristata (Marchand 1973). P. aristata is a climax species on thin, moisture-limited, carbonate soils. J. virginiana can also be a long-lived species and reach an edaphic climax on rocky outcrops of similar geologic composition.

Many old-growth habitats occur on steeper slopes where soils are poorly developed (Marchand 1973; Oberhuber et al. 1997). The study sites I sampled are also characterized by thin, poorly-developed, rocky soils (Kucera and Martin 1957; Bartgis 1993; Laughlin and Uhl 2003). Because these soils are thin and lack mature horizons, the water storage capacity is 
reduced, which influences the uptake of limiting nutrients such as potassium, calcium, phosphorus, magnesium, and nitrogen (Oberhuber and Kofler 2000). Because of this, it has been suggested that some species can adapt to growth-limiting sites because of the tendency for other highly competitive species to be excluded (Marchand 1973).

The effect of ecologically extreme site conditions on radial growth patterns in trees has been studied in other species, but not for J. virginiana (Oberhuber et al. 1997). Annual radial growth is dependent on the uptake of water and nutrients to facilitate in the metabolism of $\mathrm{CO}_{2}$ to produce glucose. But, for trees growing on rocky, nutrient-limited soils, growth may be stunted or even compromised when soil moisture is extremely low. The relationship between site-specific characteristics and radial growth has only recently been addressed and has yielded some confounding results. Dendroecological analyses of Scots pine (Pinus sylvestris L.) have been conducted in Austria (Oberhuber and Kofler 2000). The study sites, similar to the ones located in Smoke Hole Canyon, receive roughly $700 \mathrm{~mm}$ of annual precipitation and are located on thin, rocky, carbonate (dolomitic) soils. Geomorphic factors (such as aspect and slope gradient) can modify local plant communities by influencing micro-site climatic and edaphic conditions (Oberhuber and Kofler 2000).

Radial growth of silver fir (Abies alba Mill.) has also been correlated to climatic and sitespecific variables (Pinto et al. 2007). Sampling was conducted across an ecological gradient in order to make comparisons within and between distinct ecosystems. Radial growth was correlated with available water storage capacity and highly correlated with topography. The authors found that tree growth is influenced by nutrient limitation early in the life cycle and climatic variability later on (Pinto et al. 2007). This may be attributed to the decrease in root uptake as the tree ages. Because $J$. virginiana grows on similar sites, an analysis of climatic and 
site-specific limiting factors may yield significant insight into how they influence the radial growth of J. virginiana.

\section{Study Area}

J. virginiana has a broad distribution, extending across the eastern United States to the $100^{\text {th }}$ Meridian. The study area lies at the easternmost extent of the species' range (Little 1971; Figure 2.1). J. virginiana is found commonly on cedar glade, barren, and old-field sites throughout the eastern US, including the eastern panhandle of West Virginia (Baskin and Baskin 1986; Bartgis 1993), however, no old-fields were sampled as part of this study. Instead, only those stands where J. virginiana occurs as an edaphic climax were sampled for this study. Smoke Hole Canyon covers nearly $109 \mathrm{~km}^{2}$ within the Monongahela National Forest. The canyon is contained entirely within the Ridge and Valley physiographic province which is defined by a series of parallel ridges and valleys resulting from mid to late Paleozoic tectonic activity. The underlying geological structure trends from the southwest to the northeast and is bisected by the South Branch of the Potomac River (Gerritsen 1988). The relief varies throughout the province, but locally it changes abruptly producing steep slopes and rugged terrain.

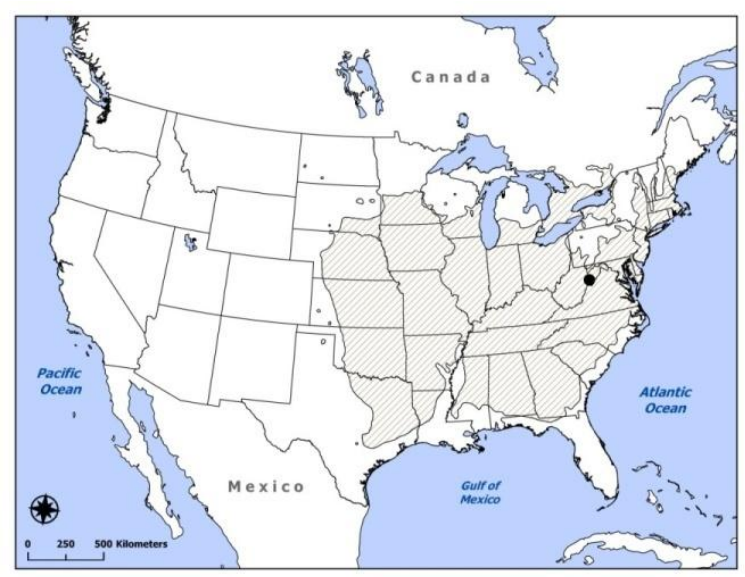

Figure 2.1: Distribution of Juniperus virginiana. 
Historically, mechanically resistant sandstone capped the ridge tops within Smoke Hole Canyon. Through successive faulting events, however, limestone strata were thrust overtop of the sandstone. Three separate stands of J. virginiana were sampled within the region (Figure 2.2; Table 2.1). Areas sampled include Big Bend South (BBS), Eagle Rock (EAR), and The Nature Conservancy (TNC). The study sites occur on gentle to steep south- and west-facing slopes with cherty Helderberg and argillaceous Tonoloway limestone parent material (Table 2.1; Sites 1973; Gerritsen 1988).

\begin{tabular}{|cccccc|}
\hline Site & Latitude $^{\circ} \mathbf{N}$ & Longitude $^{\circ} \mathbf{W}$ & Aspect & Max $_{\text {Elevation }} \mathbf{m}$ & Min $_{\text {Elevation }} \mathbf{m}$ \\
\hline BBS & $38^{\circ} 53^{\prime} 02^{\prime \prime}$ & $79^{\circ} 14^{\prime} 12^{\prime \prime}$ & $22-314^{\circ}$ & 655 & 625 \\
EAR & $38^{\circ} 49^{\prime} 42^{\prime \prime}$ & $79^{\circ} 17^{\prime} 02^{\prime \prime}$ & $164-300^{\circ}$ & 720 & 490 \\
TNC & $38^{\circ} 54^{\prime} 08^{\prime \prime}$ & $79^{\circ} 13^{\prime} 45^{\prime \prime}$ & $230-332^{\circ}$ & 610 & 570 \\
\hline Table 2.1: Topographic characteristics for the three tree-ring sites. \\
\hline
\end{tabular}

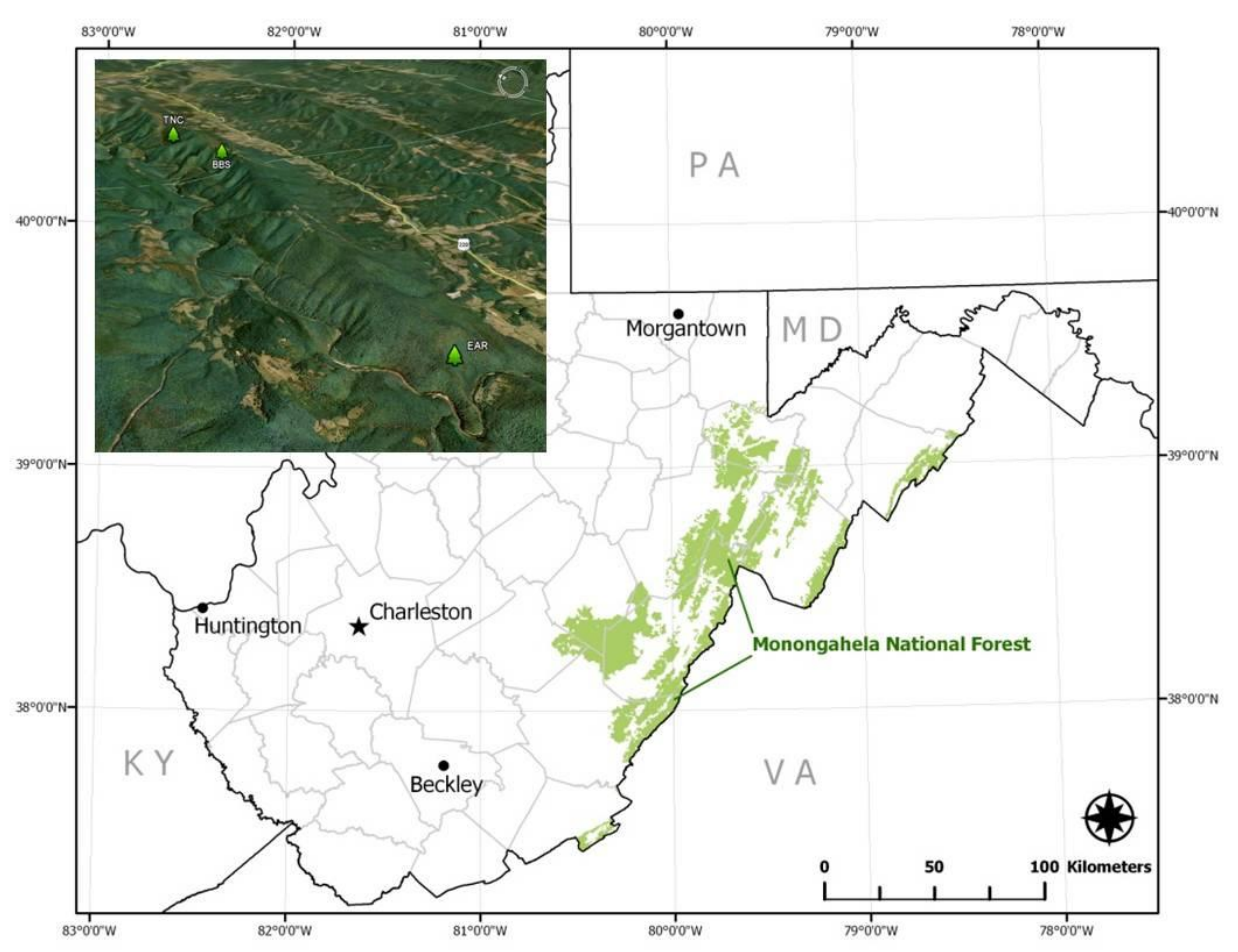

Figure 2.2: Study sites.

The Monongahela National Forest is characterized by a moist continental climate with hot summers and relatively cold winters (Clarkson 1966; McCay et al. 1997). Smoke Hole Canyon is located in the rain shadow of the Appalachian Mountains with an average 
precipitation of $<90 \mathrm{~cm} /$ year (Pyle et al. 1982). The study sites are some of the driest locations in the region suggesting that $J$. virginiana growing there may be sensitive to drought. The average monthly temperatures for January and July are $0^{\circ} \mathrm{C}$ and $23^{\circ} \mathrm{C}$, respectively. Smoke Hole Canyon lies entirely within Climate Division 6 in West Virginia (NOAA-NCDC).

\section{Methods}

\subsection{Tree-Ring Sampling}

Stands of old growth $J$. virginiana within Smoke Hole Canyon were identified using aerial photography, topographic maps, and field reconnaissance. In the field, boundaries were established for each site based on the presence/absence of J. virginiana. Once site boundaries had been established, a five meter buffer was added to reduce edge effect (Hurlbert 1984). A census of each site was done in which all $J$. virginiana meeting the following predefined criteria were sampled. Trees that were (1) greater than $15 \mathrm{~cm}$ in diameter, (2) safely accessible and (3) not rotten at the core were included in the study.

Trees that met the sampling criteria were indentified and cored. At each site, 80-100 trees were cored ( 2 cores per tree; Table 3.1). Because of the variability in the species' growth form, cores were removed from the most accessible portion of the tree or wherever strip-bark was encountered ( $10 \mathrm{~cm}$ to $2 \mathrm{~m})$. DBH for each tree was recorded and when strip-bark was present the width of living cambium was also measured. Slope, aspect, elevation, and XY coordinates were obtained for each tree (Table 3.2).

\begin{tabular}{|ccccc|}
\hline Site & $\begin{array}{c}\text { Number of Trees } \\
\text { Cored }\end{array}$ & Number of Cores & $\begin{array}{c}\text { Number of Trees } \\
\text { Included in Thesis }\end{array}$ & $\begin{array}{c}\text { Number of Cores } \\
\text { Included in Thesis }\end{array}$ \\
\hline BBS & 100 & 201 & 67 & 114 \\
EAR & 100 & 192 & 49 & 82 \\
TNC & 85 & 168 & 52 & 90 \\
\hline Table 3.1: Tree-ring sampling statistics for MA Thesis. & & \\
\hline
\end{tabular}




\subsection{Tree-Ring Analysis}

After the samples were returned to the lab, they were dried, mounted, and sanded according to standard dendrochronological methods (Stokes and Smiley 1968). Progressively finer grades of sandpaper (40-1000 grit) were used to surface the increment cores until the individual cells were visible under a stereomicroscope. Each increment core was scanned at 3200 dpi (dots per in $^{2}$ ) using an Epson Expression 10000XL flatbed scanner. WinDENDROTM was used to visually crossdate and measure each tree-ring series (Regent Instruments Canada Inc. 2008). WinDENDRO ${ }^{\mathrm{TM}}$ is a semi-automatic ring detection and analysis software package that relies on differences in light intensity between adjacent rings to locate ring boundaries. When ring anomalies (i.e. false rings) were encountered, manual adjustments were made to the boundaries to accurately define each ring as well as the earlywood/latewood boundary. False rings were identified as any density fluctuations within an individual ring that did not display the same characteristics as latewood. Total ring width (TRW), earlywood width (EWW), and latewood width (LWW) were measured to a precision of $0.001 \mathrm{~mm}$. I used digital skeleton plots that could be compared to a reference chronology created from independent samples. Two reference chronologies were loaded directly into WinDENDRO ${ }^{\mathrm{TM}}$ to crossdate (Ed Cook, TreeRing Laboratory, Lamont-Doherty Earth Observatory, personal communication; Leland 2009). Measurement files obtained from WinDENDRO ${ }^{\mathrm{TM}}$ were then converted to the Tucson (decadal) file format.

Crossdating was verified using the computer program COFECHA (Holmes 1983, Grissino-Mayer 2001). COFECHA is a quality control software package that statistically compares individual ring width measurements across all series. Once each core was measured, crossdated, and quality controlled, a calendar year was assigned to each tree-ring. Raw ring 
width measurements were then standardized using the computer program ARSTAN. A conservative detrending method (i.e. negative exponential, straight line, or negative slope) was used to remove growth and disturbance related trends (Fritts and Swetnam 1989). Series were then compiled into master chronologies for each site. In the one case where these detrending methods predicted values below zero (BBS037A was the only core meeting this criteria) a 100 year cubic smoothing spline was used. Two types of individual chronologies were developed for this study: the standard and residual chronologies. The standard chronology combines all detrended tree ring series together by calculating the arithmetic mean for each year. In addition, these master chronologies were examined for autocorrelation which can introduce unwanted noise into a dataset reducing the correlations with climatic variables. Autocorrelation often exists in time series data and represents a lag effect in which an observation is correlated with either past or future observations (Cook and Kairiuskstis 1990). ARSTAN was used to remove autocorrelation from each master tree ring series to create the residual chronologies.

Climatic data (temperature, precipitation, Palmer Drought Severity Index (PDSI)) were obtained from the National Climatic Data Center for the past 112 years (1895-2007). All climate data acquired comes from West Virginia's $6^{\text {th }}$ Climate Division which covers the Ridge and Valley physiographic province (NOAA-NCDC). PDSI was used as an index of drought conditions and is based on regional precipitation, temperature, and potential evapotranspiration patterns (Palmer 1965; Adams and Kolb 2005).

\subsection{Soil Sampling}

Soil samples were obtained from plots established around each J. virginiana tree cored in the field. The distance from the edge of the living tree crown was measured and used to delimit the plot radius (Zinke 1962; Boettcher and Kalisz 1990). Four sampling points were located at 
random distances along transects in upslope, down slope, and perpendicular to slope positions within each plot (Jackson 1958, Petersen and Calvin 1986). Soil cores were taken with a 2.54 $\mathrm{cm}$ diameter probe from the surface layer of soil, approximately $5 \mathrm{~cm}$ in depth. In rocky areas, it was often necessary to deviate from the sampling procedure in order to obtain enough soil to test in the laboratory (Page-Dumroese 1999). If this situation was encountered, a soil core was taken from the most accessible place nearest to the original sampling point. Some trees had no accessible soil within the plot radius. In those instances the sampling distance was recorded as " 0 " and no soil was collected. The four soil samples for each tree were then aggregated and placed in plastic bags to preserve field moisture conditions. Within each plot, depth to bedrock was measured at three random points using a tile probe $(105 \mathrm{~cm}$ long). The measurements were averaged resulting in one value per plot. In areas where sample trees were growing close to one another $(<80 \mathrm{~cm})$ only one plot radius was established and soil values were assigned to both trees (three instances).

\subsection{Soil Analysis}

The soil samples were weighed, placed in glass beakers, and, dried in an Isotemp ${ }^{\circledR} 655 \mathrm{~F}$ oven (Fisher Scientific) to a constant weight at $105^{\circ} \mathrm{C}$ for 24 hours (Blake and Hartge 1986, Birkeland 1999). After drying, the samples were weighed again. Soil moisture was then estimated by creating a ratio between the wet and dry soil weights. Dried soil samples were sent to the West Virginia University Soil Testing Laboratory located in the Department of Agronomy. Soil samples were analyzed only if their corresponding trees had been successfully crossdated. The Soil Testing Lab uses the Mehlich 1 Soil Test Extractant to determine the proportions of Magnesium (Mg), Phosphorus (P), Potassium (K), and Calcium (Ca) available in soil for ionic exchange. The Mehlich extractant method allows for soil nutrients to be separated from dried 
soil samples more quickly and cost effectively than other extraction methods (Mehlich 1984; Beck et al. 2004; USDA 2004). A subsample ( 2g) of dried soil was reserved to measure the relative percentages of organic Carbon (C) and Nitrogen (N). The soil samples were weighed to the nearest $0.01 \mathrm{mg}$ and a portion of each $(25-30 \mathrm{mg})$ was packed in aluminum tins. Every tenth sample was analyzed twice. A NC2500 Elemental Analyzer was used to combust and analyze each sample (NC2500 Elemental Analyzer, ThermoQuest Italia S.P.A., Italy). The standard Acetanilide $\left(\mathrm{CH}_{3} \mathrm{CONHC}_{5} \mathrm{H}_{6}\right)$ was used to calibrate the analyzer.

\subsection{Data Analysis}

ARSTAN was used to standardize the EWW and LWW chronologies in addition to the TRW chronology. Often latewood width is "pre-conditioned" by earlywood during the initial phase of growth (Meko and Baisan 2001). This was the case for all three sample sites: EWW and LWW were positively correlated $(r=0.14-0.33, p$-value $<0.05)$. A linear regression was performed where LWW was the predictand and EWW was the predictor. By using the residuals from the regression, the pre-conditioning was removed. A constant value of 1.0 was added to the residuals to restore the original mean resulting in an adjusted LWW index. All four tree-ring metrics (TRW, EWW, LWW, LWW adj) were then correlated with monthly PDSI, total monthly precipitation, and mean monthly temperature as well as seasonal PDSI, total precipitation, and monthly temperature (Table 4.2). The standardized chronology, for TRW, was also correlated with the climate variables (Table 4.3a, 4.3b, 4.3c). Seasonal categories were grouped as follows: winter - December, January, February; spring - March, April, May; summer - June, July, August, and fall - September, October, November. The correlation period extended from 1895 to 2007.

DendroClim 2002 (Biondi and Waikul 2004) was used to correlate the individual TRW residual site chronologies with monthly PDSI, total precipitation, and mean temperature. A 
period of 18 months (May of the previous year to October of the current year) was selected for the analysis. The correlation period was limited to 1896 to 2007 because an 18 month window covering portions of two years was used. Moving response function analysis was then performed in DendroClim 2002 to test the signal strength for all climate variables at each site. Response functions are multivariate estimates, derived from Principal Components Analysis (Fritts et al. 1971). Bootstrapped error estimates were then used to test for the significance of the response functions (Guiot 1991; Biondi and Waikul 2004). Response functions preserve the climatic signal present in each tree-ring series while reducing the influence of confounding variables (Fritts et al. 1971).

Exploratory data analysis was performed to investigate the relationship of tree morphology (age, DBH, and strip-bark) and soil chemistry with three metrics of sensitivity. These metrics include: series intercorrelation (SI), mean sensitivity (MS), and standard deviation (SD). SI is the measure of the signal strength (i.e. climate) preserved in each tree-ring series. SI is the average correlation of each tree ring series with the master chronology (Fritts 1976). To test the first hypothesis, correlation analysis was used to determine the relationship between the residual site chronologies and the climate data. To determine if local edaphic conditions influenced this relationship, scatter plots were made where SI was plotted on the y-axis and the soil variables $(\mathrm{pH}$, depth to bedrock, soil $\mathrm{P}, \mathrm{K}, \mathrm{Ca}, \mathrm{Mg}$, and $\% \mathrm{~N}$ ) were plotted on the $\mathrm{x}$-axis. These were used to graphically represent any influence the edaphic complex had on the series intercorrelation of individual tree-ring series. This procedure was repeated for the mean sensitivity and standard deviation (SD) for each site. MS is the average percent change from each annual ring measurement to the next year. MS is calculated with the following formula:

$$
M S=\frac{1}{(n-1)} \sum_{t=1}^{t=n-1}\left|\frac{2\left(x_{t+1}-x_{t}\right)}{\left(x_{t+1}+x_{t}\right)}\right|
$$


Where $x_{t}$ is each datum, $t$ is time, and the vertical lines represent the absolute value of the term contained within them.

To test the second hypothesis, a Student's t-test was used to determine if there was a significant difference between the June PDSI correlation coefficients of trees with strip-bark versus whole-bark trees (Rogerson 2006). June PDSI was selected because it was found to be the most important climatic variable influencing the radial growth of J. virginiana. The Student's t-test was used because the sample size and variance of between strip-bark and wholebark trees was significantly different.

\begin{tabular}{|c|c|c|c|}
\hline $\begin{array}{c}\text { Tree-Based Plots } \\
(\mathbf{n}=285)\end{array}$ & $\begin{array}{c}\text { Trees } \\
(\mathbf{n}=\mathbf{2 8 5})\end{array}$ & $\begin{array}{c}\text { Soil Variables } \\
(n=281)\end{array}$ & Climate Variables \\
\hline Elevation & $\overline{\mathrm{DBH}}$ & Depth to Bedrock & Mprecip \\
\hline Slope & NN - JUVI & $\%$ Soil Moisture & Sprecip \\
\hline \multirow[t]{6}{*}{ Aspect } & NN - Other & $\mathrm{pH}$ & Mtemp \\
\hline & SB:DC & $\%$ soil $\mathrm{N}$ & Stemp \\
\hline & TRW & Soil P & PDSI \\
\hline & EWW & Soil K & \\
\hline & LWW & Soil Mg & \\
\hline & $\mathrm{LWW}_{\mathrm{adj}}$ & Soil Ca & \\
\hline $\begin{array}{l}\text { Table 3.2: Data col } \\
\text { SB (strip bark); DC } \\
\text { width); LWW } \\
\text { precipitation); } \\
\text { Index }\end{array}$ & $\begin{array}{l}\text { study: DF } \\
\text { m); TRW } \\
\text { mood wi } \\
\text { mperature) }\end{array}$ & $\begin{array}{l}\text { t breast height); N] } \\
\text { lth); EWW (earlyw } \\
\text { (monthly preci } \\
\text { nal temperature); } \mathrm{P}\end{array}$ & $\begin{array}{l}\text { rest neighbor distance } \\
\text { idth); LWW (latewo } \\
\text { l); Sprecip (seasor } \\
\text { almer Drought Severi }\end{array}$ \\
\hline
\end{tabular}

Standardized index values were then used to perform regression analysis to test the significance $(p<0.05)$ between the relationship of individual tree growth and June PDSI. Trees that were found to have no significant response to June PDSI were separated from those with significant responses to growth. Student's t-tests (two-tailed) were then used to determine if there was a statistical difference in soil characteristics between the two groups (Table 4.4). 


\section{Results}

\subsection{Site Chronologies}

A total of 285 trees were sampled and returned to the laboratory for analysis (Table 3.1). After all cores were mounted and sanded they were pre-screened under the microscope. Cores with either missing segments (primarily due to rot) or growth anomalies were excluded from any further processing. Growth anomalies typically consisted of areas where several rings pinched together and could not be differentiated from one another. These anomalies may be the result of poor circuit uniformity. The final dataset for each site includes: 114, 82, and 90 crossdated cores for BBS, EAR, and TNC, respectively (Figures 4.1a, 4.1b, and 4.1c; Table 4.1).

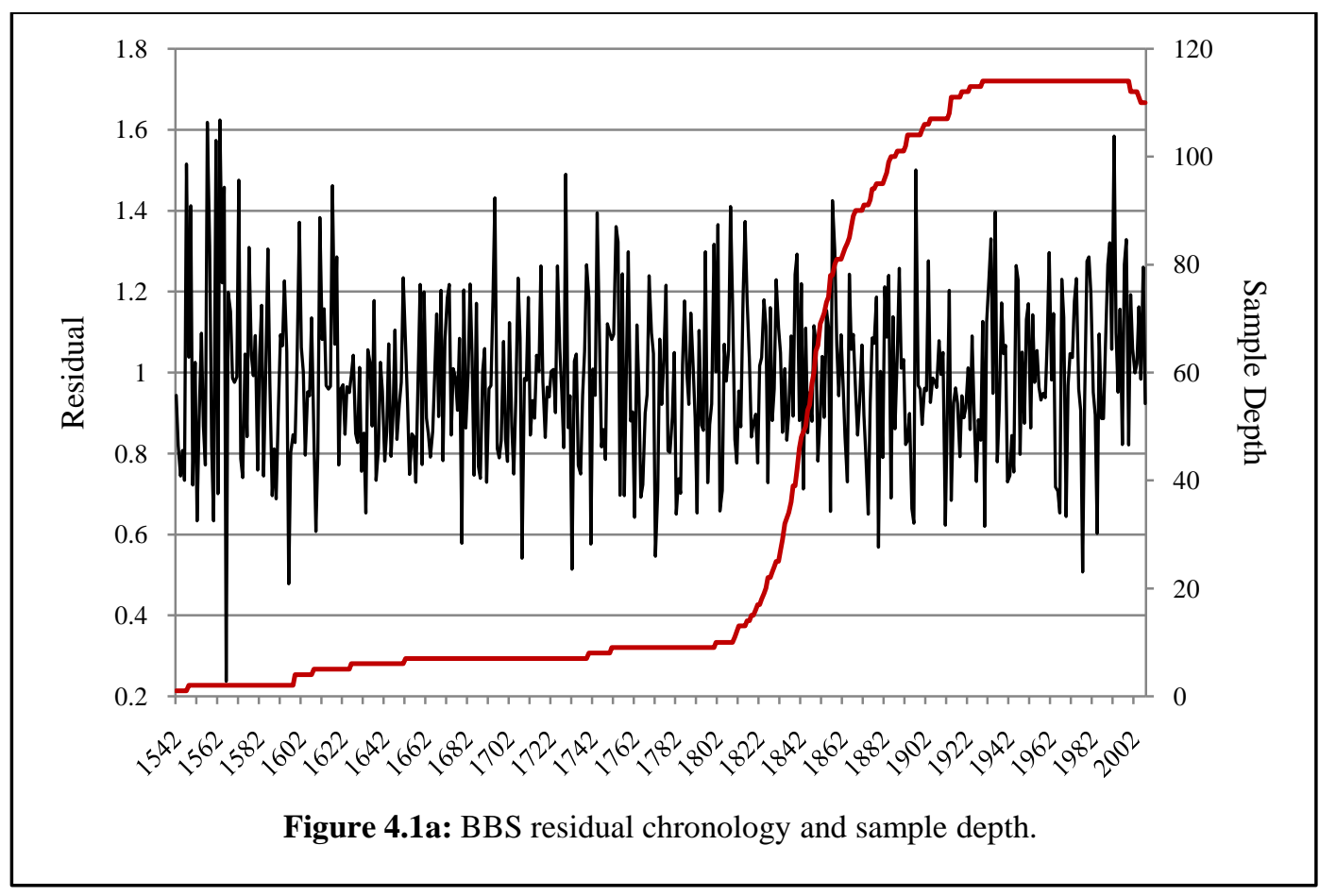



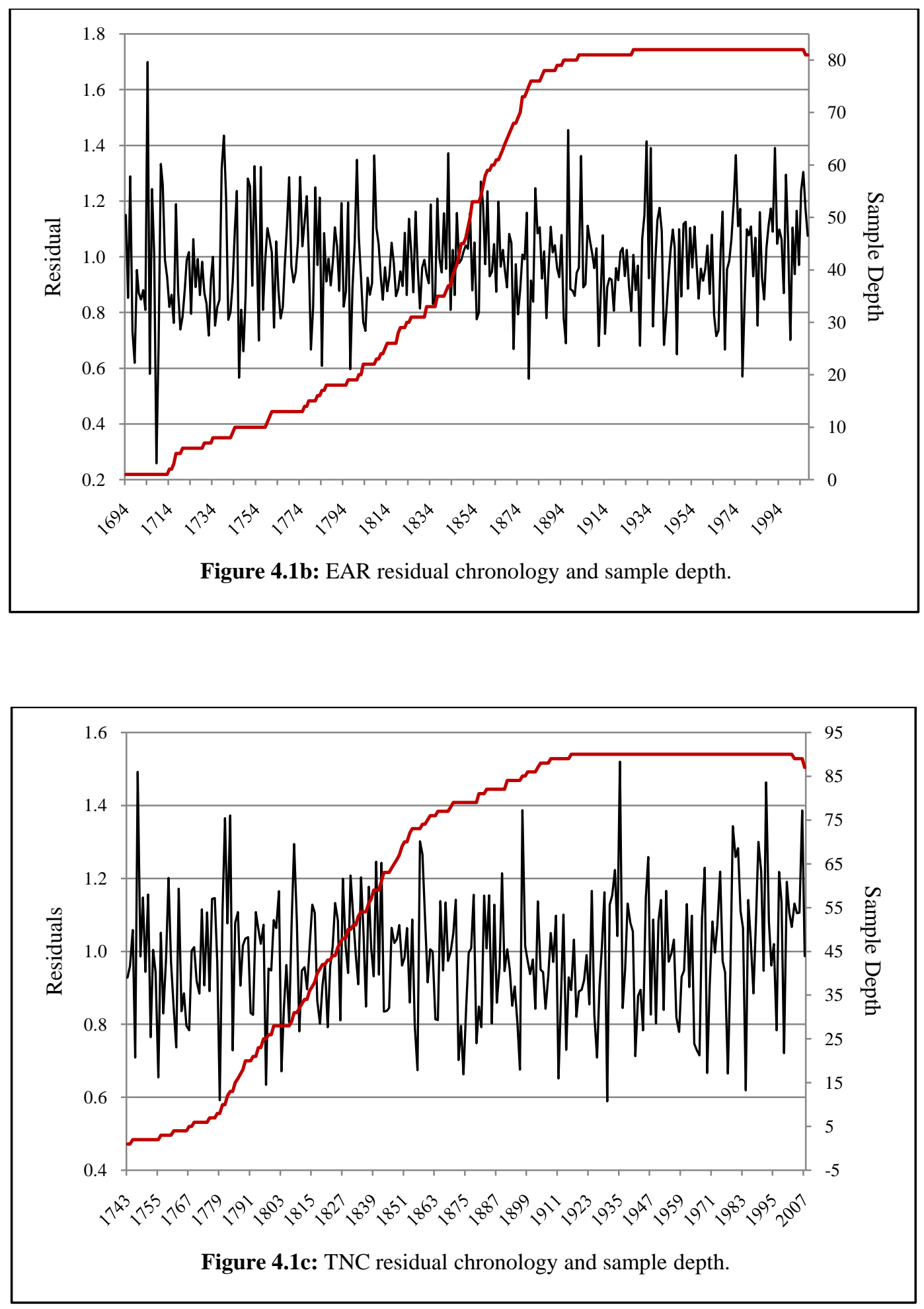
BBS had the longest record (465 years) though most trees' inner ring dates were between 1800 and 1950 (Figure 4.2). There were five outliers with inner dates ranging from 1540 to 1735 (Figure 4.2). EAR also has a long growth record (313 years), but with lower replication than the other two sites. Most inner ring dates at this site are between 1690 and 1890 (Figure 4.2). TNC has the shortest record (264 years), with inner ring dates occurring between 1740 and 1900 (Figure 4.2). The inner ring dates are only rough estimates of establishment because most trees were not cored near the base and cores did not always contain pith. Reported inner ring dates could be anywhere from 0-40 years away from the actual establishment of the trees. There are, however, several pulses of establishment at all three sites beginning in the late 18th and early 19th centuries.

\begin{tabular}{|lccc|}
\hline & BBS & EAR & TNC \\
\cline { 2 - 4 } Chronology Length & $1542-2007$ & $1694-2007$ & $1743-2007$ \\
Number of Trees & 67 & 49 & 52 \\
Number of Radii & 114 & 82 & 90 \\
Number of Rings & & 14,717 & 16,416 \\
in all Series & 19,496 & & \\
Number of Rings & & 14,697 & 16,414 \\
Crossdated & 19,490 & 78 yrs. $(1927-2005)$ & $86 y r s .(1916-2002)$ \\
Common Period & $70 y r s . ~(1929-1999)$ & 0.553 & 0.631 \\
Series Intercorrelation & 0.657 & $0.380-0.727$ & $0.422-0.763$ \\
S.I. Range & $0.470-0.806$ & 0.284 & 0.265 \\
Mean Sensitivity & 0.293 & 0.310 & 0.273 \\
\hline \multicolumn{1}{r}{ Standard Deviation } & 0.315 & & \\
\hline Table 4.1: COFECHA results for all three tree-ring sites. & & \\
\hline
\end{tabular}




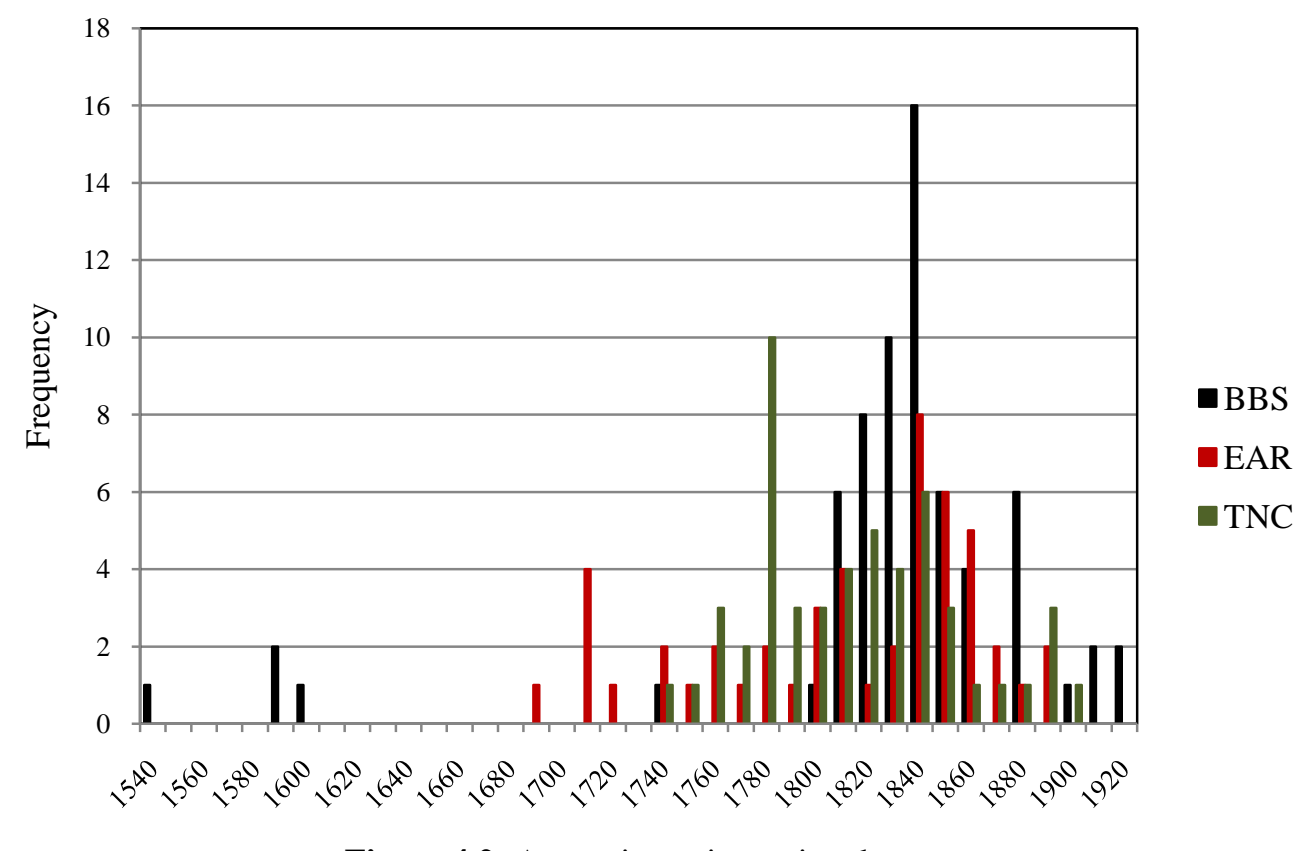

Figure 4.2: Approximate inner ring dates.

\subsection{Climate Correlations}

Residual chronologies were compared with monthly PDSI, precipitation, and temperature data (Tables 4.3a, 4.3b. and 4.3c). Replication was strong ( $\mathrm{x} \geq 80)$ for all three sites throughout the correlation period (1895-2007). June PDSI has the strongest correlation $(r=0.41-.0 .42, p<$ 0.05) with all three residual chronologies (Table 4.2). All sites (TRW and EWW only) were also positively correlated with May PDSI $(r=0.36-0.40, p<0.05)$ and precipitation $(r=0.34-0.42, p$ $<0.05)$. TRW and EWW were negatively correlated with May temperature $(r=-0.28-0.35, p<$ 0.05). TRW and EWW were also positively correlated with March temperature at all three sites $(r=0.33-0.36, p<0.05$; Appendix A). Though relationships are fairly consistent during the correlation period, the signal strength of the climate variables is increasing after $~ 1965$ (Figures 4.3a, 4.3b, and 4.3c; Appendix E). The standardized chronology was also used to correlate TRW values with the climate variables. The results of the correlation analysis were similar to those 
using the residual chronology (Table 4.3a, 4.3b, 4.3c). June PDSI had the strongest correlation with growth indices across all three sites $(r=0.37-0.43, p<0.05)$.

\begin{tabular}{|cccccc|}
\hline Site & $\boldsymbol{n}$ (years) $^{\text {a }}$ & \multicolumn{4}{c|}{ Correlation Coefficients* } \\
& & TRW & EWW & LWW & LWW $_{\text {adj }}$ \\
\cline { 3 - 6 } BBS & $112(1895-2007)$ & 0.42 & 0.42 & 0.18 & -0.01 \\
EAR & $112(1895-2007)$ & 0.42 & 0.41 & 0.13 & -0.20 \\
TNC & $112(1895-2007)$ & 0.41 & 0.40 & 0.27 & 0.17 \\
\hline \multicolumn{2}{l}{ Table 4.2: Correlation between all four tree-ring metrics and June PDSI for the three tree-ring sites in Smoke Hole } \\
\multicolumn{4}{l}{ Canyon, West Virginia. ${ }^{a}$ Number of years in the correlation period. ${ }^{*} p<0.05}$. \\
\hline
\end{tabular}

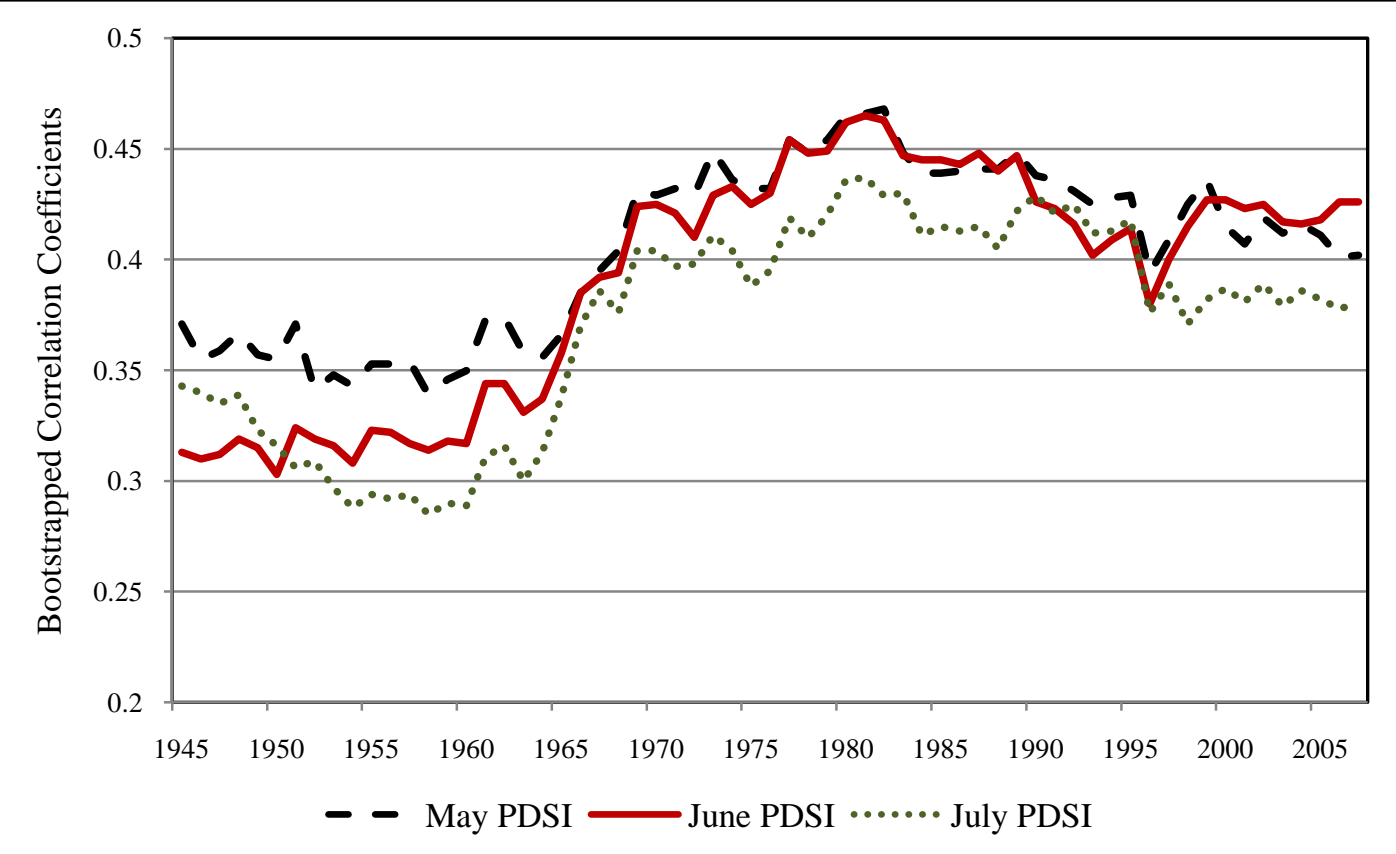

Figure 4.3a: Moving interval correlation analysis for BBS. 

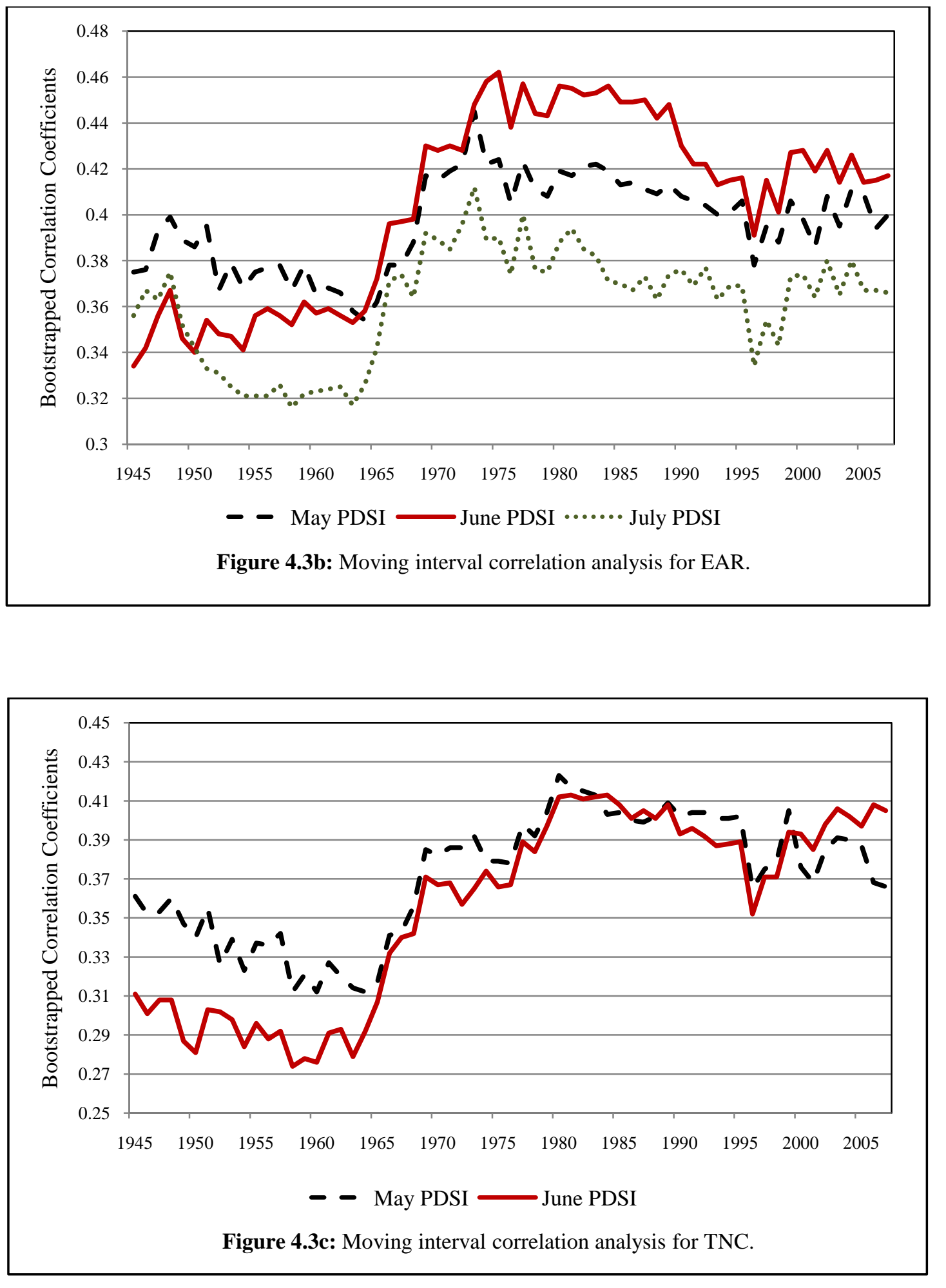


\begin{tabular}{|lccc|ccc|}
\hline & \multicolumn{3}{c|}{ Standard Chronology } & \multicolumn{3}{c|}{ Residual Chronology } \\
\cline { 2 - 7 } January & PDSI & PRECIP & TEMP & PDSI & PRECIP & TEMP \\
\cline { 2 - 7 } February & 0.14 & 0.00 & $\mathbf{0 . 2 4}$ & 0.08 & -0.06 & $\mathbf{0 . 2 3}$ \\
March & 0.17 & 0.07 & $\mathbf{0 . 1 9}$ & 0.13 & 0.09 & 0.14 \\
April & $\mathbf{0 . 2 8}$ & 0.13 & $\mathbf{0 . 2 9}$ & $\mathbf{0 . 1 9}$ & 0.03 & $\mathbf{0 . 3 3}$ \\
May & $\mathbf{0 . 2 4}$ & 0.05 & 0.10 & 0.18 & 0.00 & 0.07 \\
June & $\mathbf{0 . 3 9}$ & $\mathbf{0 . 3 2}$ & -0.2 & $\mathbf{0 . 4 0}$ & $\mathbf{0 . 4 1}$ & $\mathbf{- 0 . 3 0}$ \\
July & $\mathbf{0 . 4 3}$ & 0.14 & -0.15 & $\mathbf{0 . 4 2}$ & 0.13 & $\mathbf{- 0 . 2 2}$ \\
August & $\mathbf{0 . 3 6}$ & 0.03 & -0.01 & $\mathbf{0 . 3 8}$ & 0.06 & -0.06 \\
September & $\mathbf{0 . 2 2}$ & -0.09 & -0.09 & $\mathbf{0 . 2 4}$ & -0.09 & -0.17 \\
October & $\mathbf{0 . 1 9}$ & 0.10 & -0.08 & $\mathbf{0 . 1 9}$ & 0.05 & -0.06 \\
November & 0.15 & -0.07 & 0.02 & 0.13 & -0.08 & 0.02 \\
December & 0.17 & 0.13 & 0.06 & 0.16 & 0.08 & 0.03 \\
Winter & 0.13 & 0.04 & 0.01 & 0.09 & 0.00 & -0.04 \\
Spring & $\mathbf{0 . 1 9}$ & 0.07 & $\mathbf{0 . 2 4}$ & 0.13 & 0.02 & 0.18 \\
Summer & $\mathbf{0 . 3 2}$ & 0.31 & 0.13 & $\mathbf{0 . 2 7}$ & $\mathbf{0 . 2 9}$ & 0.12 \\
Fall & $\mathbf{0 . 3 6}$ & 0.02 & -0.12 & $\mathbf{0 . 3 7}$ & 0.04 & $\mathbf{- 0 . 2 2}$ \\
\hline Table 4.3a: BBS correlation coefficients for two chronologies. Coefficients shown in bold are significantly \\
correlated $(p<0.05)$.
\end{tabular}

\begin{tabular}{|lccc|ccc|}
\hline \multirow{2}{*}{ January } & \multicolumn{3}{c|}{ Standard Chronology } & \multicolumn{3}{c|}{ Residual Chronology } \\
\cline { 2 - 7 } February & PDSI & PRECIP & TEMP & PDSI & PRECIP & TEMP \\
\cline { 2 - 7 } March & $\mathbf{0 . 2 4}$ & -0.02 & $\mathbf{0 . 2 2}$ & 0.18 & -0.11 & $\mathbf{0 . 2 3}$ \\
April & $\mathbf{0 . 2 3}$ & 0.02 & $\mathbf{0 . 2 2}$ & $\mathbf{0 . 2 0}$ & 0.07 & $\mathbf{0 . 2 3}$ \\
May & $\mathbf{0 . 3 1}$ & 0.13 & $\mathbf{0 . 3 2}$ & $\mathbf{0 . 2 4}$ & 0.06 & $\mathbf{0 . 3 6}$ \\
June & $\mathbf{0 . 2 5}$ & 0.08 & 0.04 & $\mathbf{0 . 2 3}$ & 0.06 & 0.02 \\
July & $\mathbf{0 . 3 4}$ & $\mathbf{0 . 2 2}$ & $\mathbf{- 0 . 2 1}$ & $\mathbf{0 . 3 9}$ & $\mathbf{0 . 3 4}$ & $\mathbf{- 0 . 2 8}$ \\
August & $\mathbf{0 . 3 9}$ & 0.13 & -0.06 & $\mathbf{0 . 4 2}$ & 0.12 & -0.15 \\
September & $\mathbf{0 . 3 2}$ & 0.00 & 0.04 & $\mathbf{0 . 3 6}$ & 0.01 & -0.02 \\
October & $\mathbf{0 . 2 3}$ & -0.01 & -0.03 & $\mathbf{0 . 2 5}$ & -0.04 & -0.14 \\
November & $\mathbf{0 . 2 1}$ & 0.11 & -0.06 & $\mathbf{0 . 2 0}$ & 0.06 & -0.07 \\
December & $\mathbf{0 . 2 2}$ & 0.02 & -0.04 & $\mathbf{0 . 2 0}$ & 0.02 & -0.01 \\
Winter & $\mathbf{0 . 2 1}$ & $\mathbf{0 . 1 9}$ & 0.05 & $\mathbf{0 . 2 0}$ & 0.13 & 0.01 \\
Spring & $\mathbf{0 . 1 9}$ & 0.06 & 0.01 & 0.17 & 0.06 & -0.07 \\
Summer & $\mathbf{0 . 2 8}$ & 0.03 & $\mathbf{0 . 2 4}$ & $\mathbf{0 . 2 3}$ & 0.01 & $\mathbf{0 . 2 2}$ \\
Fall & $\mathbf{0 . 3 2}$ & $\mathbf{0 . 2 7}$ & 0.15 & $\mathbf{0 . 3 1}$ & $\mathbf{0 . 3 0}$ & 0.13 \\
\hline Table 4.3b: EAR correlation coefficients for two chronologies. Coefficients shown in bold are significantly \\
correlated $(p<0.05)$.
\end{tabular}




\begin{tabular}{|lccc|ccc|}
\hline \multirow{2}{*}{ January } & \multicolumn{3}{c|}{ Standard Chronology } & \multicolumn{3}{c|}{ Residual Chronology } \\
\cline { 2 - 7 } February & PDSI & PRECIP & TEMP & PDSI & PRECIP & TEMP \\
\cline { 2 - 7 } March & 0.11 & -0.04 & 0.18 & 0.05 & -0.09 & 0.16 \\
April & 0.14 & 0.04 & 0.14 & 0.09 & 0.05 & 0.08 \\
May & $\mathbf{0 . 2 3}$ & 0.07 & $\mathbf{0 . 3 2}$ & 0.14 & 0.00 & $\mathbf{0 . 3 6}$ \\
June & $\mathbf{0 . 1 9}$ & 0.07 & 0.08 & 0.13 & 0.01 & 0.04 \\
July & $\mathbf{0 . 3 6}$ & $\mathbf{0 . 3 5}$ & $\mathbf{- 0 . 2 7}$ & $\mathbf{0 . 3 6}$ & 0.42 & $\mathbf{- 0 . 3 5}$ \\
August & $\mathbf{0 . 4 0}$ & 0.13 & -0.08 & $\mathbf{0 . 4 0}$ & 0.15 & $\mathbf{- 0 . 1 9}$ \\
September & $\mathbf{0 . 3 4}$ & 0.03 & 0.05 & $\mathbf{0 . 3 5}$ & 0.02 & -0.04 \\
October & $\mathbf{0 . 2 3}$ & -0.04 & -0.01 & $\mathbf{0 . 2 4}$ & -0.07 & -0.11 \\
November & $\mathbf{0 . 2 3}$ & 0.11 & -0.12 & $\mathbf{0 . 2 2}$ & 0.08 & -0.12 \\
December & $\mathbf{0 . 1 9}$ & -0.02 & -0.01 & 0.17 & -0.04 & 0.00 \\
Winter & $\mathbf{0 . 2 2}$ & 0.21 & 0.12 & $\mathbf{0 . 2 0}$ & 0.13 & 0.09 \\
Spring & 0.13 & -0.03 & 0.02 & 0.09 & -0.05 & -0.04 \\
Summer & 0.17 & -0.01 & $\mathbf{0 . 1 9}$ & 0.10 & -0.06 & 0.11 \\
Fall & $\mathbf{0 . 2 7}$ & $\mathbf{0 . 3 1}$ & 0.13 & $\mathbf{0 . 2 3}$ & $\mathbf{0 . 2 8}$ & 0.11 \\
\hline Table 4.3c: TNC correlation coefficients for two chronologies. Coefficients shown in bold are significantly \\
correlated $(p<0.05)$.
\end{tabular}

\subsection{Strip-bark: Relationship with Climate Sensitivity}

Of the 168 trees included in this study only 33 had strip-bark. All of these strip-bark trees were greater than 155 years old with the exception of one (TNC054, 103 years). BBS had some of the oldest strip-bark trees (160-465 years), EAR had trees ranging from 162-313 years old, and TNC was similar in age to EAR (103-251 years). T-tests were used to determine if strip-bark trees were more sensitive to June PDSI than whole-bark trees. The tests showed that all three sites were had different sample means for the strip-bark and whole-bark trees. At BBS, however, strip-bark trees were more responsive to June PDSI than whole-bark trees (Table 4.4). The SI and MS for BBS strip-bark trees are 0.631 and 0.303, respectively. Whole-bark trees had a SI of 0.669 and a MS of 0.290. 


\begin{tabular}{|ccccccc|}
\hline Site & $\begin{array}{c}\boldsymbol{n} \text { Strip- } \\
\text { bark }\end{array}$ & $\begin{array}{c}\boldsymbol{n} \text { Whole- } \\
\text { bark }\end{array}$ & $\boldsymbol{t}$ value & $\begin{array}{c}\text { Mean June } \\
\text { PDSI } \\
\text { C.C. }- \text { SB }\end{array}$ & $\begin{array}{c}\text { Mean June } \\
\text { PDSI } \\
\text { C.C. }- \text { WB }\end{array}$ & $\begin{array}{c}\text { Two-tail critical } \\
\boldsymbol{t} \text { value; }(\boldsymbol{p})\end{array}$ \\
\hline BBS & 9 & 58 & 2.72 & 0.33 & 0.26 & $2.13(0.02)$ \\
EAR & 13 & 36 & 1.18 & 0.26 & 0.21 & $2.10(0.25)$ \\
TNC & 11 & 41 & 1.75 & 0.31 & 0.24 & $2.12(0.10)$ \\
\hline Table 4.4: Two-tail $t$-tests comparing the difference in strip-bark and whole-bark tree response to June PDSI. \\
\hline
\end{tabular}

\subsection{Tree age and DBH: Relationship with Climate Sensitivity}

Individual trees from each study site were separated into two groups based on whether or not trees were significantly correlated with June PDSI (Table 4.5). T-tests were used to test whether individual tree age and diameter varied significantly between the two groups. At BBS both variables, tree age and $\mathrm{DBH}$, surpassed the two-tail statistical threshold. Trees with significant correlations to June PDSI were older and had larger mean DBHs. Tree age at EAR was the only variable to exceed the two-tail threshold. At TNC trees with a larger mean DBH had significant correlations to June PDSI.

\begin{tabular}{|c|c|c|c|c|}
\hline Site & $n \leq 0.05$ & $n>0.05$ & $\begin{array}{c}\text { Mean June } \\
\text { PDSI } \\
\text { C.C. } \leq \mathbf{0 . 0 5}\end{array}$ & $\begin{array}{c}\text { Mean June } \\
\text { PDSI } \\
\text { C.C. }>0.05\end{array}$ \\
\hline BBS & 55 & 12 & 0.30 & 0.11 \\
\hline EAR & 31 & 18 & 0.29 & 0.12 \\
\hline TNC & 39 & 13 & 0.31 & 0.11 \\
\hline
\end{tabular}

\subsection{Soil Chemistry Effects on Tree Sensitivity to Climate}

\section{$\underline{\mathrm{BBS}}$}

At BBS, soil $\mathrm{pH}$ has a complex non-linear relationship with sensitivity to climate (Figure 4.4). Individual core $\mathrm{SI}$ is lowest at extreme $\mathrm{pH}$ values $(<6.6$ and $>7.5)$. The majority of trees growing between a $\mathrm{pH}$ of 6.6-7.4 have the highest SI values (SI > 0.600). Depth to bedrock had negative linear relationship with SI, indicating that trees with higher sensitivity are growing on shallower soils. The majority of responsive trees were observed growing on soil $10-20 \mathrm{~cm}$ deep 
(Figure 4.5). There was a modest positive linear trend when soil P was compared with SI, yet no other apparent relationships exist between individual core sensitivity at BBS and the remaining soil nutrients (Appendix C).

The relationships between individual core sensitivity and soil nutrients were slightly different when MS was used as the measure of sensitivity. Soil pH again followed a non-linear trend, but sensitive trees $(\mathrm{MS}>0.40)$ are growing on soils with a $\mathrm{pH}$ of 6.6-7.2. Depth to bedrock had a weaker relationship than the one observed for SI. As with SI, there were weak to nonexistent relationships between MS and the rest of the soil nutrients. When SD was used as the metric of sensitivity, the relationships were similar to those observed between MS and the edaphic variables.

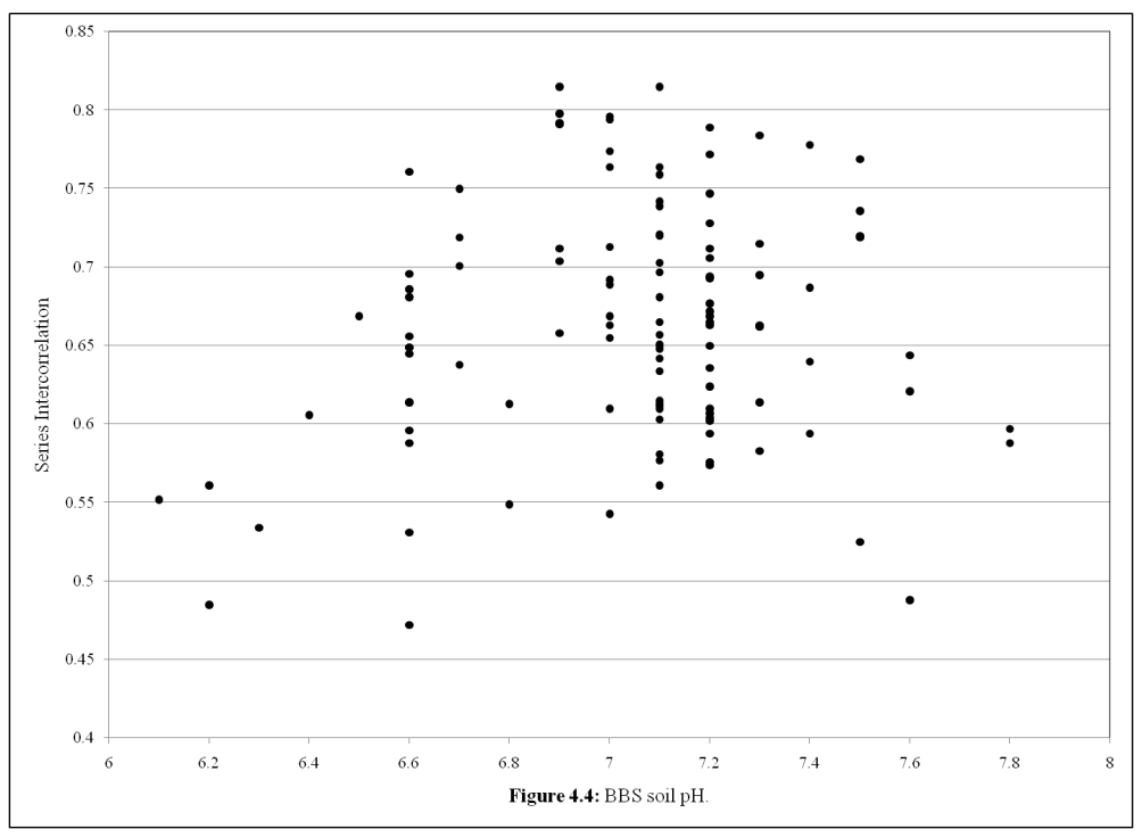




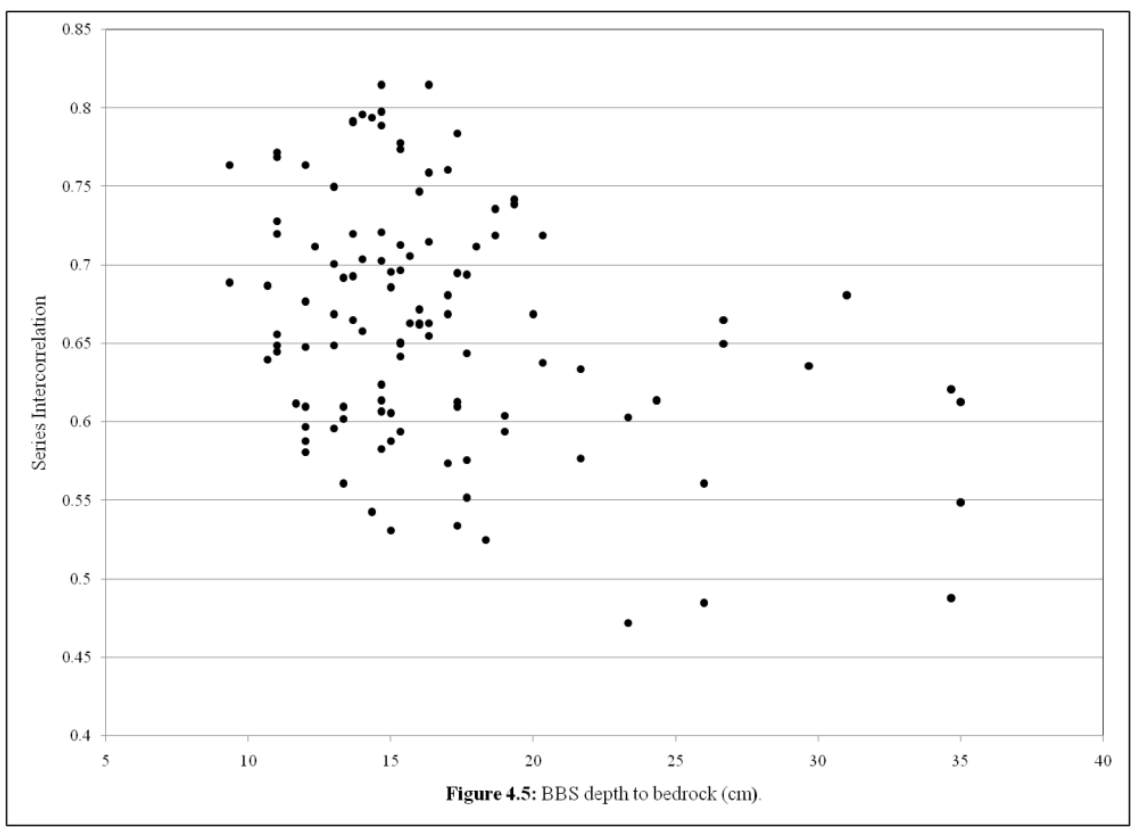

$\underline{\text { EAR }}$

There was not a coherent relationship between soil $\mathrm{pH}$ and SI at EAR, but the pattern was not as complex as the one observed at BBS (Figure 4.6). Depth to bedrock does not have the same negative linear relationship observed at BBS (Figure 4.7). Trees with a SI > 0.600 are growing on a broad range of soil depths $(10-30 \mathrm{~cm}$ deep). Yet, there are also less responsive trees (SI $<0.450)$ growing on shallower soils. There are no relationships between SI and the remaining soil variables $(\mathrm{P}, \mathrm{K}, \mathrm{Mg}, \mathrm{Ca}$, and $\mathrm{N}$; Appendix $\mathrm{C})$. $\mathrm{MS}$ has a slightly stronger relationship than SI when compared against soil $\mathrm{pH}$, while SD had the strongest relationship of the three metrics. There was a noticeably stronger relationship between MS/SD and depth to bedrock. The majority of cores with a MS/SD $>0.40$ are growing on soil $10-15 \mathrm{~cm}$. While generally stronger than the relationship with SI, MS and SD did not have strong relationships with soil $\mathrm{P}, \mathrm{K}, \mathrm{Mg}, \mathrm{Ca}$, or $\mathrm{N}$. 

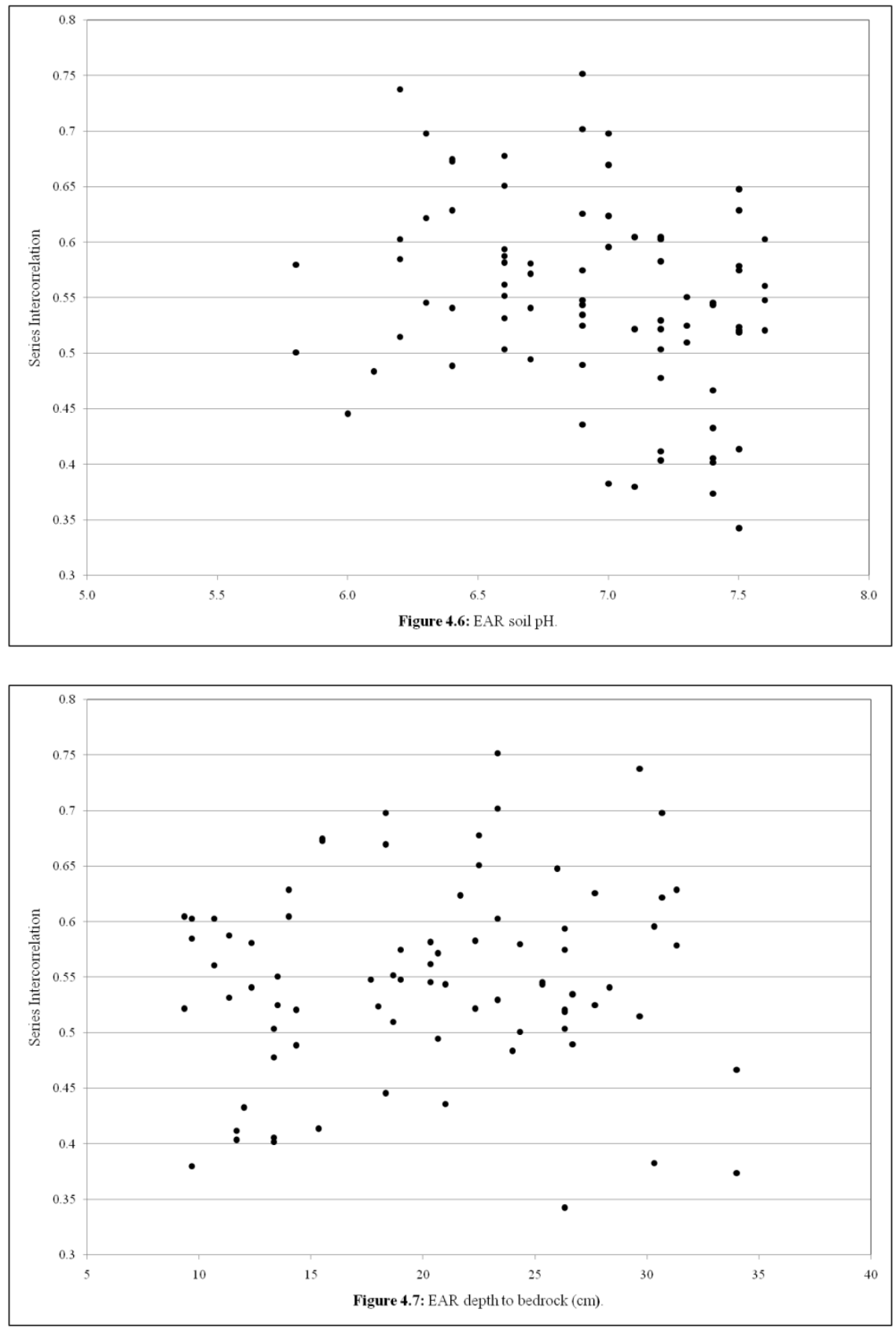

$\underline{\text { TNC }}$

At TNC there was not a strong relationship between SI and soil $\mathrm{pH}$ (Figure 4.8). There were, however, three outlying values that appeared to weaken the pattern. The relationship was only slightly better when these outliers were removed. There was no discernible pattern when SI was compared with depth to bedrock (Figure 4.9). Soil nutrients (P, Mg, Ca, and N) had modest 
positive relationships with SI, but $\mathrm{K}$ had a slightly stronger positive association (Appendix C). Like BBS, when MS and SD were used as the metrics of sensitivity, the relationships were only slightly stronger. It is also interesting to note that, when TNC was separated based on each tree's correlation with June PDSI, soil Mg concentrations were higher for those trees significantly associated with the drought metric.
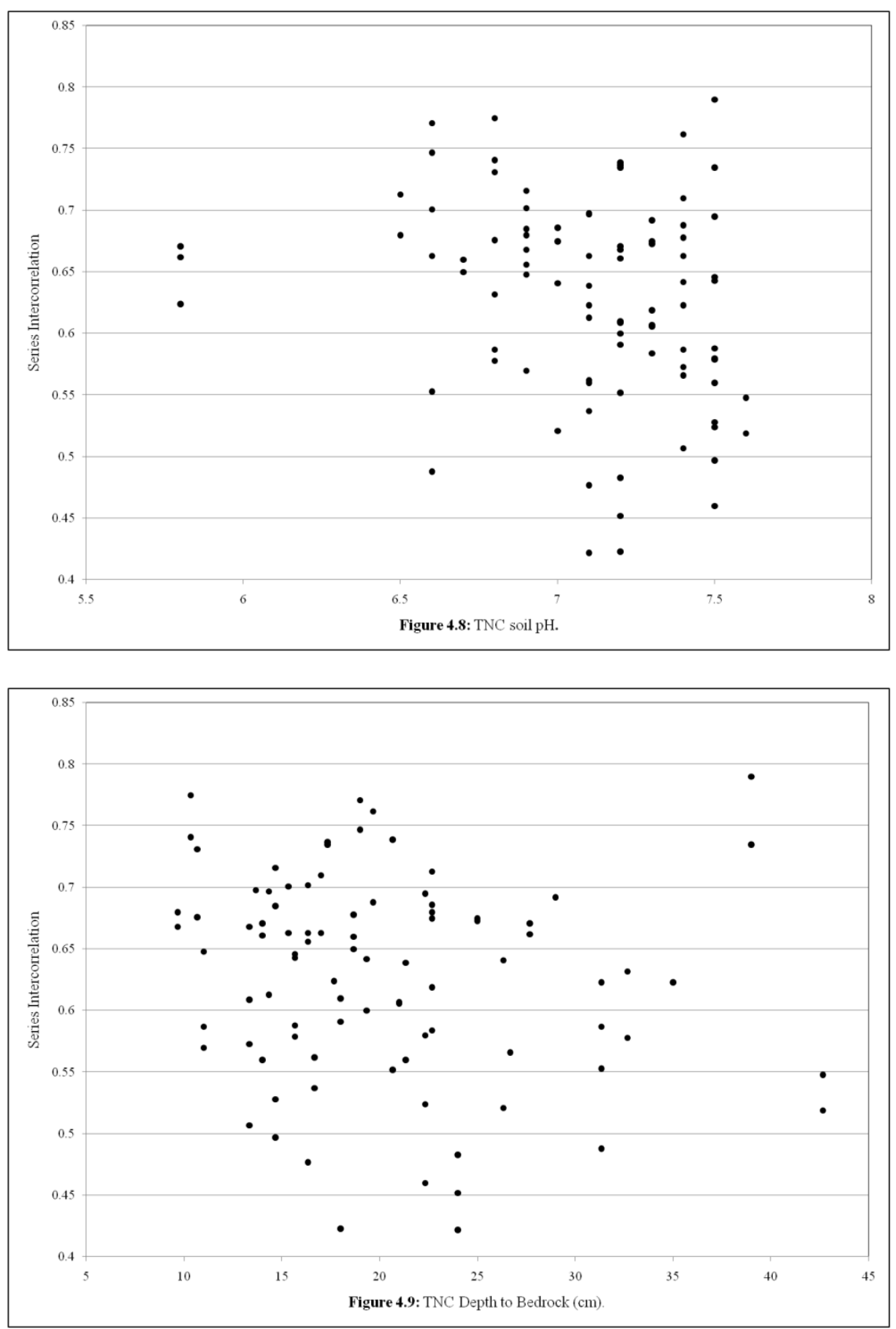


\section{Discussion}

\subsection{Relationship to Climate}

Consistent with my first hypothesis, summer drought, centered on June PDSI, is the most significant driver of TRW in $J$. virginiana, though other climatic variables are also moderately correlated with indices of growth. The residual chronologies were positively and significantly correlated with May, June, and July PDSI consistent with previous studies of J. virginiana on xeric sites (Hawley 1937, Larson 1997). However, inconsistent with my first hypothesis, I did not observe any clear interactions with the edaphic complex. For individual trees and site chronologies, correlations with PDSI are greatest in June (Tables 4.3a, 4.3b, and 4.3c; Appendix B) when temperatures are approaching their maximum, suggesting that potential evapotranspiration is limiting water availability. Temperature, however, reaches its maximum in July when precipitation declines. Because monthly PDSI is dependent on the previous month's moisture availability, the three consecutive months with positive correlations with PDSI could be a function of temporal autocorrelation in PDSI rather than direct relationships with growth

Growth at all three sites is also positively correlated with May precipitation $(r>0.34)$ and negatively correlated with May temperature $(r<-0.28)$. The combination of drier and warmer conditions in May leads to decreased tree growth for that year. May weather conditions could initiate a reduction in growth that persists throughout the remainder of the growing season. March temperature is, however, positively correlated with growth $(r>0.33)$. This would imply that $J$. virginiana growth is pre-conditioned by warm temperatures in March, perhaps indicating that these trees are photosynthesizing before other species. Correlations between TRW and the standard chronology were consistent with the residual chronology. 
In direct contradiction to part of the first working hypothesis, latewood width has only a modest relationship with climatic variability. J. virginiana is constrained by summer drought, but EWW is the metric most affected by a severe drop in moisture availability. Latewood formation may be controlled by short-duration weather events that initiate a reduction in vascular activity (Edmonson 2006). Intra-annual variability may also be responsible for controlling the formation of false rings within J. virginiana. False rings often occur in the later stages of growth and have similar characteristics to latewood. Near the end of the growing season, cells begin to reduce in size and cell walls thicken. This marks formation of latewood and the end of the growing season for trees, but if mid-growing season drought persists long enough J. virginiana will begin to reduce cell size until climatic conditions are favorable for growth again. It is this intra-annual variability that leads to the formation of false rings. The presence of common false rings across the chronology warrants further investigation of seasonal changes in weather patterns since false ring chronologies may contain potentially important climate information (Wimmer, Strumia, and Holawe 2000; Masiokas and Villalba 2004). Masiokas and Villalba (2004) also suggest that the formation of false rings may be a function of tree-age and site conditions. Further investigations of $J$. virginiana false rings may yield important information on intra-annual variability and lead to fine scale climate reconstructions.

The growth response to June PDSI was also compared across full-bark and strip-bark trees at each site. BBS was the only site that showed a significant difference between the two groups, though all sites showed strip-bark trees to be more responsive. This suggests that, at least for this site, trees with strip-bark characteristics respond differently than those with fullbark. Bunn et al. (2003) found that the differences in growth rates between strip-bark and wholebark trees were attributed to soil moisture. Furthermore, Bunn et al. observed that the 
distribution of strip-bark trees was not random across the study site, but clustered by a proxy for soil moisture. The authors concluded that, while the data highlighted the importance of microsite variability, strip-bark could not be assumed to be a key characteristic appropriate for climate reconstructions. My results are equivocal on this point. Additional analysis of strip-bark trees at the study sites is needed to compare with these results. Strip-bark is not only a physiological response to adverse ecological conditions, but can be a result of exogenous physical factors (e.g. rock fall or broken limbs). My study suggests that at least some J. virginiana with strip-bark are more responsive to drought and have the potential to be a valuable source for climatic information.

\subsection{Soil Chemistry and Tree Sensitivity}

The relationship between tree growth/sensitivity and soil chemistry is complex. Because this study did not include trees growing on old field sites, samples were not obtained across the full range of ecological conditions for J. virginiana. Due to the xeric nature of the study sites, however, nutrient availability most likely is not the predominant factor limiting radial growth. Water is a fundamental component for plant processes at all scales. If, at any point, a plant is exposed to shortages in water availability (water stress) it will interrupt functions necessary for growth and reproduction (Mooney, Winner, and Pell 1991). J. virginiana experience varying levels of water stress throughout the growing season. Thus, as water availability decreases and plants are more stressed, concentrations of $\mathrm{N}, \mathrm{Mg}^{2+}$, and $\mathrm{K}^{+}$tend to decrease with reductions in leaf water potential (Osonubi et al. 1988). If this is the case with J. virginiana then the observed results may confirm that water stress truly is driving growth/sensitivity.

Sedimentary rocks (e.g. limestone and sandstone) and their subsequent soils have moderate to rapid permeability and enhance runoff at these sites which could drain water in the 
upper reaches of the soil horizons at a faster rate than can be used by J. virginiana (Harmon 1981). Because J. virginiana is dependent on moisture availability, seasonal interruptions of moisture could be constraining annual growth (and potentially causing false ring formation). Thus, the influence of soils on tree growth may be modulated by the lack of soil water (due to permeability) at these sites rather than soil chemistry specifically. Consequently, individuals might not be limited by cation/anion exchange because they are not receiving enough of their primary limiting factor, water.

For this study, it was necessary to identify a well-defined gradient in the field across which there would be variations in tree growth. Each site, however, is relatively small making it difficult to identify areas where there are significant differences in soil conditions. The sites are also topographically discontinuous. They are characterized by moderate to steep slopes and are bisected by cliff faces. These factors could contribute to an incomplete record of ecological variability at my study sites. By not sampling old-field sites with J. virginiana, a component of the species' growing environment was excluded from the study. Old-fields tend to have deeper soils capable of retaining more water. In turn, increased water availability could alter the relationship between tree growth/sensitivity and soil nutrients. Copenheaver et al. (2005), however, observed conditions that conflict with these assumptions. Interior stands of $J$. virginiana were found to be more sensitive than trees growing at the forest edge. As the study points out, this could result from changes in stand density which would mask the true connections between growth and climate. Variability in tree sensitivity may be the result of $J$. virginiana's ability to encroach into surrounding habitats.

This study also looked at the relationship between depth to bedrock and three different tree-ring sensitivity metrics. It has long been assumed that trees growing on shallower soils are 
more sensitive to climatic conditions (see Fritts 1976). My data, however, does not entirely support this assumption. While a weak relationship between soil depth and sensitivity exists for J. virginiana, sensitive trees can be observed across a broad range of soil depths (Appendix C). The lack of a coherent relationship between depth and sensitivity may arise because it is difficult to accurately sample soil depth on steep rock slopes. J. virginiana take advantage of cracks in the bedrock where soil accumulates or can extend a taproot to take advantage of soil water at greater depths than can be measured in the field. Other measurements of physical soil properties could have been useful in identifying the relationship between water stress and sensitivity. Water holding capacity, bulk density, and permeability may have proven to be valuable measures of the moisture available to each tree. Yet, these metrics would be subject to the same challenges as depth to bedrock: the soil measured may not be the source of the moisture available to each tree.

There are a number of other factors (physiological and abiotic) that can control variability in a tree's response to climate. J. virginiana has the ability to photosynthesize early in the growing season, before deciduous over story trees begin to produce leaves (Van Haverbeke and Read 1976). This adaptation allows the species to initiate growth before the canopy fills and blocks off sunlight and may explain a portion of the correlation with early season May precipitation and March and May temperature. Competition among stands of J. virginiana growing in closed canopy forest could also impact individual tree sensitivity to climate. I did not sample trees within closed canopy stands so this assumption was not tested. Yet, if $J$. virginiana has the ability to photosynthesize at relatively low temperatures, then results similar to Copenheaver et al. (2005) would suggest that competition is not a predominant mechanism driving tree sensitivity. 


\section{Conclusions}

\subsection{Climate Response}

J. virginiana radial growth is positively correlated with PDSI for May, June, and July across all sites. These months are characterized by high insolation and slight decreases in precipitation resulting in a water deficit. The extent of soil drying was not been analyzed, but could be enhanced by local edaphic conditions at the study sites. Growth indices and PDSI are only moderately correlated, however, suggesting that another mechanism may be responsible for driving the relationship between climate sensitivity and site specific conditions. An understanding of the physiology of $J$. virginiana is a necessary component for climate reconstructions. Further analysis of individual trees physiological response to moisture stress could be used to strengthen correlations with climate. Strip-bark, or cambial die-back, is one such potential mechanism J. virginiana uses to cope with water deficits. A thorough investigation of strip-bark versus whole-bark trees could highlight this mechanism. This would allow investigators to determine whether or not drought tolerant species such as $J$. virginiana have different reactions to moisture stress across a broad edaphic gradient.

Tree-ring metrics (TRW and EWW) are also positively correlated with March temperature. Warmer temperatures in early spring could indicate the species' ability to rapidly begin photosynthesis and initiate growth before surrounding competitors. A complex association exists between tree sensitivity, May precipitation, and May temperature as well. The relationship can be summarized by the following model:

$$
\text { Growth } \uparrow=\operatorname{May}_{\mathrm{P}} \uparrow+\operatorname{May}_{\mathrm{T}} \downarrow
$$


Wetter cooler May conditions leads to increased wood production throughout the growing season. An increase in precipitation during and prior to the period of pronounced drought could moderate tree growth.

\subsection{Strip-bark, Tree Age, and Size}

J. virginiana has the potential to be a major source of information for past climatic variability in the Eastern United States. If left undisturbed, trees can grow to great ages on isolated rocky outcrops. When combined with remnant wood, it is possible to create $>1,000$ year chronologies from J. virginiana growth. It is possible to crossdate trees of this species, but particular attention must be given to the physiological responses $J$. virginiana has to climate. The formation of strip-bark is an important indicator of tree sensitivity. It is uncertain, however, if strip-bark trees at the study sites provide the best record of climatic variability. Tree age is another important biotic factor influencing climate sensitivity. Older trees were shown to be more responsive to June PDSI and significantly so at BBS and EAR. Trees with larger DBH also had higher correlations with June PDSI.

\subsection{Lack of Relationships with Soil Metrics}

Site selection is essential for the dendroclimatological investigation of J. virginiana. Trees often establish on abandoned farm fields where soil tends to be deeper and better defined. Rocky outcrops and steep slopes, however, have proven to be the areas where long-lived trees are found. This research, however, suggests that targeting areas with shallow well drained soils will not always yield the best trees for climate analysis. The study sites have a unique combination of characteristics that amplify soil water loss. Thin rocky soils overlay limestone substrates in areas that tend to be moderately steep to steep and have southwesterly facing aspects. These conditions promote increased percolation and evaporation. Yet, increased 
moisture stress may not be the only driver of climate sensitivity. Phenotypic variation could account for differences in individualistic response to climate.

\subsection{Future Research}

False rings were common to the tree-ring series investigated in this study. While WinDENDRO ${ }^{\mathrm{TM}}$ offered an efficient way to crossdate individual tree-ring series, some cores had to be scrutinized closely under a stereomicroscope. The anatomy of false rings in J. virginiana is often similar to the structure of latewood, thus individual cores often had to be observed at higher magnification in order to distinguish between the two. The commonality of false rings within J. virginiana warrants additional investigation as they may be a recorder of intra-annual climatic variability (Wimmer, Strumia, and Holawe 2000). The relationship between strip-bark trees and climatic variability needs to be tested further to identify potential linkages to sensitivity. Strip-bark trees at BBS were more responsive to drought indicating that this relationship might be observed at other sites. Also, a detailed analysis of the spatial distributions of individuals could highlight clusters of trees growing across edaphic gradients. 


\section{References}

Adams, H. D. and T. E. Kolb. 2005. Tree growth response to drought and temperature in a mountain landscape in northern Arizona, USA. Journal of Biogeography. 32 (9): 1629-1640.

Bartgis, R. L. 1993. The limestone glades and barrens of West Virginia. Castanea. 58 (2): 68-89.

Baskin, J. M., and C. C. Baskin. 1986. Distribution and geographical/evolutionary relationships of cedar glade endemics in southeastern United States. ASB Bulletin 33: 138-154.

Beadle, N. C. W. 1953. The edaphic factor in plant ecology with a special note on soil phosphates. Ecology. 34 (2): 426-428.

Beck, M. A., L. W. Zelazny, W.L. Daniels, and G.L. Mullins. 2004. Using the Mehlich-1 extract to estimate soil phosphorus saturation for environmental risk assessment. Soil Science Society of America Journal. 68: 1762-1771.

Biondi, F. and K. Waikul. 2004. DENDROCLIM2002: a C++ program for statistical calibration of climate signals in tree-ring chronologies. Computers \& Geosciences. 30: 303-311.

Birkeland, P. W. 1999. Soils and Geomorphology. 3rd ed. NY: Oxford University Press. 430p.

Blake, G. R. and K. H. Hartge. 1986. Bulk Density. In Methods of Soil Analysis Part I-Physical and Mineralogical Methods. 2nd ed. ed. A. Klute, 363-382. Madison, WI: American Society of Agronomy, Soil Science Society of America.

Boettcher, S. E. and P. J. Kalisz. 1990. Single-tree influence on soil properties in the mountains of eastern Kentucky. Ecology. 71 (4): 1365-1372.

Bunn, A. G., R. L. Lawrence, L. A. Waggoner, and L. J. Graumlich. 2003. Spatial variation in distribution and growth patterns of old growth strip-bark pines. Arctic, Antarctic, and Alpine Research. 35 (3): 323-330.

Butler, D. R. and S. J. Walsh. 1988. The use of eastern redcedar in a tree-ring study in Oklahoma. Prairie Naturalist. 20 (1): 47-56.

Clarkson, R. B. 1966. The vascular flora of the Monongahela National Forest, West Virginia. Castanea. 31 (1): 1-119.

Cook, E. R. and L. A. Kairiukstis. 1990. Methods of Dendrochronology Applications in the Environmental Sciences. Dordrecht, Amsterdam: Kluwer Academic Publishers.

Copenheaver, C.A., N.E. Fuhrman, L.S. Gellerstedt, and P.A. Gellerstedt. 2004. Tree encroachment in forest openings: a case study from Buffalo Mountain, Virginia. Castanea. 69 (4): 297-308.

Copenheaver, C. A., K. H. Kyle, G. N. Stevens, and M. H. Kamp. 2005. “Comparing Juniperus virginiana tree-ring chronologies from forest edge vs. forest interior positions in the Cedars Natural Area Preserve in Virginia, USA." Dendrochronologia. 23: 39-45.

Currey, D. R. 1965. An ancient bristlecone pine stand in eastern Nevada. Ecology. 46 (4): 564566.

Edmondson, J.R. 2006. An ancient red cedar woodland in the Oklahoma Cross Timbers. AR: University of Arkansas. 60p. Honors thesis.

Fritts, H. C., T. J. Blasing, B. P. Hayden, and J. E. Kutzbach. 1971. Multivariate techniques for specifying tree-growth and climate relationships and for reconstructing anomalies in paleoclimate. Journal of Applied Meteorology. 10 (5): 845-863,

Fritts, H. C. 1976. Tree Rings and Climate. Caldwell, NJ: The Blackburn Press. 567p.

Fritts, H. C. and T. W. Swetnam. 1989. Dendroecology: a tool for evaluating variations in past and present forest environments. Advances in Ecological Research. 19: 111-188. 
Gerritsen, S. S. 1988. Structural analysis of the silurian-devonian cover in the Smoke Holes, WV. MS Thesis: West Virginia University. 195p.

Grissino-Mayer, H. D. 2001. Evaluating crossdating accuracy: a manual and tutorial for the computer program COFECHA. Tree-Ring Research. 57: 206-221.

Guiot, J. 1991. The bootstrapped response function. Tree-Ring Bulletin. 51: 39-41.

Guyette, R., E. A. McGinnes, Jr., G. E. Probasco, and K. E. Evans. 1980. A climate history of Boone County, Missouri, from tree-ring analysis of eastern redcedar. Wood and Fiber. 12 (1): 17-28.

Harmon, P.J. 1981. The vascular flora of the ridge of North Fork Mountain Grant and Pendleton Counties, West Virginia. Carbondale, IL: Southern Illinois University. 408p. Master's thesis.

Hawley, F. M. 1937. Relationship of southern cedar growth to precipitation and run off. Ecology. 18 (3): 398-405.

Holmes, R. L. 1983. Computer-assisted quality control in tree-ring dating and measurement. Tree-Ring Bulletin. 44: 69-75.

Hurlbert, S. H. 1984. Pseudoreplication and the design of ecological field experiments. Ecological Monographs. 54 (2): 187-211.

Jackson, M. L. 1958. Soil Chemical Analysis. Englewood Cliffs, NJ: Prentice-Hall, Inc. 498p.

Kelly, P. E., E. R. Cook, and D. W. Larson. 1992. Constrained growth, cambial mortality, and dendrochronology of ancient Thuja occidentalis. International Journal of Plant Sciences. 153 (1): 117-127.

Kelly, P. E. and D. W. Larson. 1997. Dendroecological analysis of the population dynamics of an old-growth forest on cliff-faces of the Niagara Escarpment, Canada. Journal of Ecology. 85: 467-478.

Knapp, P. A., H. D. Grissino-Mayer, and P. T. Soulé. 2002. Climatic regionalization and the spatio-temporal occurrence of extreme single-year drought events (1500-1998) in the Interior Pacific Northwest, USA. Quaternary Research. 58: 226-233.

Kucera, C. L. and S. C. Martin. 1957. Vegetation and soil relationships in the glade region of the southwestern Missouri Ozarks. Ecology. 38 (2): 285-291.

LaMarche, V. C. 1969. Environment in relation to age of bristlecone pines. Ecology. 50 (1): 53 59.

Larson, D. W. 1997. Dendroecological potential of Juniperus virginiana L. growing on cliffs in Western Virginia. Banisteria. 10: 13-18.

Larson, D. W., U. Matthes, J. A. Gerrath, J. M. Gerrath, J. C. Nekola, G. L. Walker, S. Porembski, A. Charlton, and N. W. K. Larson. 1999. Ancient stunted trees on cliffs. Nature. 398: 382-383.

Larson, D. W, U. Matthes, J. A. Gerrath, N. W. K. Larson, J. M. Gerrath, J. C. Nekola, G. L. Walker, S. Porembski, and A. Charlton. 2000. Evidence for the widespread occurrence of ancient forests on cliffs. Journal of Biogeography. 27 (2): 319-331.

Laughlin, D. C. and C. F. Uhl. 2003. The xeric limestone prairies of Pennsylvania. Castanea. 68 (4): 300-316.

Leland, C. 2009. Tree-ring applications for climate reconstruction using eastern redcedar: an exploratory study. Morgantown, WV: West Virginia University. 13p. Honors thesis.

Little, E. L., Jr. 1971. Atlas of United States trees, volume 1, conifers and important hardwoods. U.S. Department of Agriculture: Miscellaneous Publication 1146, 9p., 200 maps.

Marchand, D. E. 1973. Edaphic control of plant distribution in the White Mountains, eastern California. Ecology. 54 (2): 233-250. 
Masiokas, M. and R. Villalba. 2004. Climatic significance of intra-annual bands in the wood of Nothofagus pumilio in southern Patagonia. Trees. 18: 696-704.

McCay, D. H., M. D. Abrams, and T. E. DeMeo. 1997. Gradient analysis of secondary forests of eastern West Virginia. Journal of the Torrey Botanical Society. 124 (2): 160-173.

Mehlich, A. 1984. Mehlich 3 soil test extractant: a modification of Mehlich 2 extractant. Communications in Soil Science Plant Analysis. 15 (12): 1409-1416.

Meko, D. M. and C. H. Baisan. 2001. Pilot study of latewood-width of conifers as an indicator of variability of summer rainfall in the North American monsoon region. International Journal of Climatology. 21: 697-708.

Miles, D. H. and M. J. Worthington. 1998. Sonora Pass junipers from California USA: construction of a 3,500-year chronology. In Stravinskiene, V. and R. Juknys, (eds) Dendrochronology and Environmental Trends - Proceedings of the International Conference 17-21 June 1998, Kaunas, Lithuania. Vytautas Magnas University.

Mooney, H. A., W. E. Winner, and E. Chu. Eds. 1991. Response of plants to multiple stresses. San Diego, CA: Academic Press, Inc. 422p.

NOAA-NCDC. 2007. National Climatic Data Center. Available at http://www.ncdc.noaa.gov/oa/ncdc.html (last accessed 15 March 2009).

Oberhuber, W., K. Pagitz, and K. Nicolussi. 1997. Subalpine tree growth on serpentine soil: a dendroecological analysis. Plant Ecology. 130: 213-221.

Oberhuber, W. and W. Kofler. 2000. Topographic influences on radial growth of Scots pine (Pinus sylvestris L.) at small spatial scales. Plant Ecology. 146: 231-240.

Osonubi, O., R. Oren, K. S. Werk, E. -D. Schulze, and H. Heilmeier. 1988. Performance of two Picea abies (L.) Karst. stands at different stages of decline. IV. Xylem sap concentrations of magnesium, calcium, potassium, and nitrogen. Oecologia. 77: 1-6.

Page-Dumroese, D. S., M. F. Jurgensen, R. E. Brown, and G. D. Mroz. 1999. Comparison of methods for determining bulk densities of rocky forest soils. Soil Science Society of America Journal. 63: 379-383.

Palmer, W. C. 1965. Meteorological Drought. Research Paper No. 45. US Weather Bureau, Washington, DC. 64p.

Petersen, R. G. and L. D. Calvin. 1986. Sampling. In Methods of Soil Analysis Part I-Physical and Mineralogical Methods. 2nd ed. ed. A. Klute, 33-51. Madison, WI: American Society of Agronomy, Soil Science Society of America.

Pinto, P. E., J. C. Gégout, J. C. Hervé, and J. F. Dhôte. 2007. Changed in environmental controls on the growth of Abies alba Mill. In the Vosges Mountains, north-eastern France, during the 20th century. Global Ecology and Biogeography. 16: 472-484.

Pyle, R. E. et al. 1982. Soil survey of Randolph County area, main part, West Virginia. USDA Soil Conservation Service, Washington, DC.

Read, R. A. and L. C. Walker. 1950. Influence of eastern redcedar on soil in Connecticut pine plantations. Journal of Forestry. 48: 337-339.

Regent Instruments Canada Inc. 2008. WinDENDRO for tree-ring analysis.

Rogerson, P. A. 2006. Statistical Methods for Geography A Student's Guide. 2nd ed. Los Angeles: SAGE Publications.

Schulman, E. 1954. Longevity under adversity in conifers. Science. 119 (3091): 396-399.

Sites, R. S. 1973. Geology of the Smoke Hole region of West Virginia. Southern Geology.153167. 
Small, C. J. and T. R. Wentworth. 1998. Characterization of montane cedar-hardwood woodland in the Piedmont and Blue Ridge provinces of North Carolina. Castanea. 63 (3): 241-261.

Stephenson, N. L. 1990. Climatic control of vegetation distribution: the role of the water balance. The American Naturalist. 135 (5): 649-670.

Stokes, M. A. and T. L. Smiley. 1968. An Introduction to Tree-Ring Dating. Chicago: University of Chicago Press. 73p.

Tardif, J. and Y. Bergeron. 1997. Comparative dendroclimatological analysis of tow black ash and tow white cedar populations from contrasting sites in the Lake Duparquet region, northwestern Quebec. Canadian Journal of Forest Research. 27: 108-116.

Tardif, J. and D. Stevenson. 2001. Radial growth-climate association of Thuja occidentalis L. at the northwestern limit of its distribution, Manitoba, Canada. Dendrochronologia. 19 (2): 179-187.

USDA-NRCS. 2004. Soil survey laboratory methods manual. Rebecca Burt (ed.). Soil Survey Investigations Report No. 42, Version 4. USDA. 735p.

Van Haverbeke, D. F. and R. A. Read. 1976. Genetics of eastern redcedar. USDA Forest Service. $17 \mathrm{p}$.

Villalba, R., T. T. Veblen, and J. Ogden. 1994. Climatic influences on the growth of subalpine trees in the Colorado Front Range. Ecology. 75 (5): 1450-1462.

Wimmer, R., G. Strumia, and F. Holawe. 2000. Use of false rings in Austrian pine to reconstruct early growing season precipitation. Canadian Journal of Forest Research. 30: 1691-1697.

Zinke, P. J. 1962. The pattern of influence of individual forest trees on soil properties. Ecology. 43 (1): 130-133. 
Appendix A: Correlation Coefficients for BBS Residual Chronology

\begin{tabular}{|c|c|c|c|c|c|c|c|c|c|c|c|c|}
\hline & \multicolumn{4}{|c|}{ PDSI } & \multicolumn{4}{|c|}{ Precipitation } & \multicolumn{4}{|c|}{ Temperature } \\
\hline & TRW & EWW & LWW & $\mathrm{LWW}_{\text {adj }}$ & TRW & EWW & LWW & $\mathrm{LWW}_{\text {adj }}$ & TRW & EWW & LWW & $\mathrm{LWW}_{\mathrm{adj}}$ \\
\hline January & 0.08 & 0.08 & 0.14 & 0.12 & -0.06 & -0.06 & 0.04 & 0.08 & 0.23 & 0.23 & 0.24 & 0.16 \\
\hline February & 0.13 & 0.13 & 0.14 & 0.09 & 0.09 & 0.09 & -0.02 & -0.07 & 0.14 & 0.15 & -0.04 & -0.12 \\
\hline March & 0.19 & 0.18 & 0.17 & 0.11 & 0.03 & 0.03 & 0.12 & 0.13 & $\mathbf{0 . 3 3}$ & 0.33 & 0.12 & -0.03 \\
\hline April & 0.18 & 0.18 & 0.16 & 0.10 & 0.00 & 0.00 & -0.02 & -0.02 & 0.07 & 0.07 & -0.11 & -0.17 \\
\hline May & 0.40 & 0.40 & 0.24 & 0.08 & 0.41 & 0.41 & 0.17 & -0.01 & -0.30 & -0.30 & -0.10 & 0.04 \\
\hline June & 0.42 & 0.42 & 0.18 & -0.01 & 0.13 & 0.13 & -0.03 & -0.11 & -0.22 & -0.22 & 0.04 & 0.17 \\
\hline July & 0.38 & 0.38 & 0.14 & -0.03 & 0.06 & 0.06 & -0.07 & -0.12 & -0.06 & -0.06 & -0.06 & -0.04 \\
\hline August & 0.24 & 0.24 & 0.07 & -0.04 & -0.09 & -0.09 & -0.10 & -0.07 & -0.17 & -0.16 & 0.00 & 0.09 \\
\hline September & 0.19 & 0.19 & 0.07 & -0.01 & 0.05 & 0.05 & 0.07 & 0.06 & -0.06 & -0.06 & -0.02 & 0.00 \\
\hline October & 0.13 & 0.13 & 0.02 & -0.05 & -0.08 & -0.08 & -0.09 & -0.06 & 0.02 & 0.02 & 0.11 & 0.12 \\
\hline November & 0.16 & 0.16 & 0.02 & -0.05 & 0.08 & 0.08 & 0.00 & -0.05 & 0.03 & 0.03 & -0.12 & -0.16 \\
\hline December & 0.09 & 0.09 & 0.05 & 0.02 & 0.00 & 0.00 & 0.10 & 0.12 & -0.04 & -0.04 & 0.01 & 0.04 \\
\hline Winter & 0.13 & 0.13 & 0.14 & 0.10 & 0.02 & 0.02 & 0.08 & 0.08 & 0.18 & 0.19 & 0.12 & 0.05 \\
\hline Spring & 0.27 & 0.27 & 0.21 & 0.10 & 0.29 & 0.29 & 0.17 & 0.05 & 0.12 & 0.12 & -0.02 & -0.09 \\
\hline Summer & 0.37 & 0.37 & 0.14 & -0.03 & 0.04 & 0.04 & -0.12 & -0.16 & -0.22 & -0.22 & 0.00 & 0.11 \\
\hline Fall & 0.17 & 0.17 & 0.04 & -0.04 & 0.02 & 0.02 & -0.02 & -0.03 & 0.00 & 0.00 & -0.02 & -0.03 \\
\hline
\end{tabular}


Appendix A: Correlation Coefficients for EAR Residual Chronology

\begin{tabular}{|c|c|c|c|c|c|c|c|c|c|c|c|c|}
\hline & \multicolumn{4}{|c|}{ PDSI } & \multicolumn{4}{|c|}{ Precipitation } & \multicolumn{4}{|c|}{ Temperature } \\
\hline & TRW & EWW & LWW & $\mathrm{LWW}_{\text {adj }}$ & TRW & EWW & LWW & $\mathrm{LWW}_{\text {adj }}$ & TRW & EWW & LWW & $\mathrm{LWW}_{\mathrm{ad}}$ \\
\hline January & 0.18 & 0.17 & 0.08 & -0.06 & -0.11 & -0.11 & 0.02 & 0.11 & 0.23 & 0.24 & 0.13 & -0.05 \\
\hline February & 0.20 & 0.20 & 0.05 & -0.11 & 0.07 & 0.07 & -0.11 & -0.17 & 0.23 & 0.23 & 0.11 & -0.07 \\
\hline March & 0.24 & 0.24 & 0.05 & -0.15 & 0.06 & 0.07 & 0.05 & 0.00 & 0.36 & 0.36 & 0.17 & -0.12 \\
\hline April & 0.23 & 0.23 & 0.12 & -0.06 & 0.06 & 0.06 & 0.03 & -0.02 & 0.02 & 0.01 & -0.10 & -0.11 \\
\hline May & 0.39 & 0.39 & 0.24 & -0.06 & 0.34 & 0.34 & 0.23 & -0.03 & -0.28 & -0.28 & -0.09 & 0.13 \\
\hline June & 0.42 & 0.41 & 0.13 & -0.20 & 0.12 & 0.12 & -0.06 & -0.17 & -0.15 & -0.15 & -0.10 & 0.02 \\
\hline July & 0.36 & 0.36 & 0.09 & -0.20 & 0.01 & 0.01 & -0.03 & -0.04 & -0.02 & -0.02 & 0.08 & 0.10 \\
\hline August & 0.25 & 0.25 & 0.14 & -0.05 & -0.04 & -0.05 & 0.08 & 0.13 & -0.14 & -0.14 & -0.07 & 0.04 \\
\hline September & 0.20 & 0.20 & 0.06 & -0.10 & 0.06 & 0.06 & -0.06 & -0.11 & -0.07 & -0.07 & -0.05 & 0.00 \\
\hline October & 0.20 & 0.19 & 0.06 & -0.10 & 0.02 & 0.02 & 0.04 & 0.03 & -0.01 & -0.01 & 0.02 & 0.03 \\
\hline November & 0.20 & 0.20 & 0.04 & -0.12 & 0.13 & 0.14 & -0.05 & -0.17 & 0.01 & 0.01 & -0.08 & -0.10 \\
\hline December & 0.17 & 0.17 & 0.06 & 0.07 & 0.06 & 0.06 & 0.07 & 0.03 & -0.07 & -0.08 & 0.04 & 0.10 \\
\hline Winter & 0.23 & 0.23 & 0.08 & -0.10 & 0.01 & 0.01 & -0.01 & -0.02 & 0.22 & 0.22 & 0.14 & -0.02 \\
\hline Spring & 0.31 & 0.30 & 0.14 & -0.09 & 0.30 & 0.30 & 0.20 & -0.03 & 0.13 & 0.13 & 0.03 & -0.08 \\
\hline Summer & 0.36 & 0.36 & 0.13 & -0.16 & 0.04 & 0.03 & 0.01 & -0.02 & -0.16 & -0.16 & -0.05 & 0.08 \\
\hline Fall & 0.21 & 0.21 & 0.05 & -0.12 & 0.11 & 0.11 & -0.04 & -0.13 & -0.04 & -0.04 & -0.07 & -0.04 \\
\hline
\end{tabular}


Appendix A: Correlation Coefficients for TNC Residual Chronology

\begin{tabular}{|c|c|c|c|c|c|c|c|c|c|c|c|c|}
\hline & \multicolumn{4}{|c|}{ PDSI } & \multicolumn{4}{|c|}{ Precipitation } & \multicolumn{4}{|c|}{ Temperature } \\
\hline & TRW & EWW & LWW & $\mathrm{LWW}_{\text {adj }}$ & TRW & EWW & LWW & $\mathrm{LWW}_{\text {adj }}$ & TRW & EWW & LWW & $\mathrm{LWW}_{\mathrm{ad}}$ \\
\hline January & 0.05 & 0.05 & 0.14 & 0.13 & -0.09 & -0.09 & 0.09 & 0.13 & 0.16 & 0.16 & 0.15 & 0.11 \\
\hline February & 0.09 & 0.09 & 0.13 & 0.11 & 0.05 & 0.05 & -0.01 & -0.03 & 0.08 & 0.09 & -0.02 & -0.05 \\
\hline March & 0.14 & 0.14 & 0.16 & 0.13 & 0.00 & 0.00 & 0.01 & 0.01 & 0.36 & 0.36 & 0.22 & 0.12 \\
\hline April & 0.13 & 0.13 & 0.17 & 0.14 & 0.01 & 0.01 & -0.02 & -0.02 & 0.04 & 0.04 & 0.06 & 0.05 \\
\hline May & 0.36 & 0.36 & 0.27 & 0.18 & 0.42 & 0.42 & 0.25 & 0.13 & -0.35 & -0.35 & -0.08 & 0.03 \\
\hline June & 0.40 & 0.40 & 0.27 & 0.16 & 0.15 & 0.15 & 0.08 & 0.04 & -0.19 & -0.19 & -0.05 & 0.01 \\
\hline July & 0.35 & 0.35 & 0.21 & 0.11 & 0.02 & 0.02 & -0.06 & -0.08 & -0.04 & -0.05 & 0.09 & 0.12 \\
\hline August & 0.24 & 0.23 & 0.24 & 0.19 & -0.07 & -0.07 & 0.13 & 0.17 & -0.11 & -0.11 & -0.03 & 0.00 \\
\hline September & 0.22 & 0.22 & 0.17 & 0.11 & 0.08 & 0.08 & 0.03 & 0.01 & -0.12 & -0.12 & -0.13 & -0.10 \\
\hline October & 0.17 & 0.17 & 0.13 & 0.08 & -0.04 & -0.04 & 0.01 & 0.02 & 0.00 & 0.00 & 0.08 & 0.09 \\
\hline November & 0.20 & 0.20 & 0.16 & 0.11 & 0.13 & 0.13 & 0.09 & 0.05 & 0.09 & 0.09 & 0.06 & 0.04 \\
\hline December & 0.09 & 0.09 & 0.09 & 0.06 & -0.05 & -0.06 & 0.05 & 0.08 & -0.04 & -0.04 & 0.00 & 0.01 \\
\hline Winter & 0.10 & 0.10 & 0.15 & 0.13 & -0.06 & -0.06 & 0.08 & 0.11 & 0.11 & 0.11 & 0.07 & 0.04 \\
\hline Spring & 0.23 & 0.22 & 0.21 & 0.16 & 0.28 & 0.28 & 0.16 & 0.08 & 0.11 & 0.11 & 0.15 & 0.14 \\
\hline Summer & 0.35 & 0.35 & 0.26 & 0.17 & 0.04 & 0.04 & 0.10 & 0.09 & -0.18 & -0.18 & 0.00 & 0.06 \\
\hline Fall & 0.21 & 0.21 & 0.16 & 0.11 & 0.09 & 0.09 & 0.07 & 0.04 & 0.00 & 0.00 & 0.02 & 0.02 \\
\hline
\end{tabular}


Appendix B: Individual Tree Correlation Coefficients for BBS Standardized Chronology

\begin{tabular}{|c|c|c|c|c|c|c|}
\hline & May PDSI & June PDSI & July PDSI & May Precip & March Temp & May Temp \\
\hline BBS001 & 0.13 & 0.22 & 0.16 & 0.08 & 0.14 & -0.09 \\
\hline BBS002 & 0.12 & 0.16 & 0.09 & 0.12 & 0.16 & -0.19 \\
\hline BBS003 & 0.27 & 0.33 & 0.27 & 0.21 & 0.41 & -0.19 \\
\hline BBS004 & 0.04 & 0.14 & 0.19 & 0.08 & 0.20 & -0.07 \\
\hline BBS008 & 0.13 & 0.21 & 0.16 & 0.07 & 0.19 & -0.10 \\
\hline BBS009 & 0.16 & 0.21 & 0.15 & 0.31 & 0.06 & -0.10 \\
\hline BBS010 & 0.34 & 0.38 & 0.30 & 0.22 & 0.19 & -0.02 \\
\hline BBS011 & 0.08 & 0.18 & 0.11 & 0.03 & 0.08 & -0.11 \\
\hline BBS013 & 0.24 & 0.31 & 0.33 & 0.31 & 0.25 & -0.10 \\
\hline BBS014 & 0.13 & 0.22 & 0.22 & 0.07 & 0.18 & -0.05 \\
\hline BBS015 & 0.29 & 0.35 & 0.29 & 0.16 & 0.29 & -0.22 \\
\hline BBS016 & 0.06 & 0.12 & 0.11 & 0.17 & 0.20 & -0.09 \\
\hline BBS017 & 0.21 & 0.22 & 0.16 & 0.22 & 0.17 & -0.12 \\
\hline BBS018 & 0.28 & 0.30 & 0.24 & 0.30 & 0.17 & -0.19 \\
\hline BBS019 & 0.33 & 0.35 & 0.28 & 0.21 & 0.34 & -0.12 \\
\hline BBS020 & 0.06 & 0.13 & 0.10 & 0.14 & 0.16 & -0.09 \\
\hline BBS021 & 0.32 & 0.31 & 0.25 & 0.35 & 0.14 & -0.17 \\
\hline BBS023 & 0.28 & 0.24 & 0.23 & 0.22 & 0.02 & -0.16 \\
\hline BBS024 & 0.28 & 0.28 & 0.26 & 0.26 & 0.14 & -0.10 \\
\hline BBS026 & 0.11 & 0.08 & 0.09 & 0.06 & 0.17 & -0.05 \\
\hline BBS027 & 0.26 & 0.31 & 0.24 & 0.27 & 0.37 & -0.17 \\
\hline BBS029 & 0.34 & 0.33 & 0.33 & 0.40 & 0.09 & -0.16 \\
\hline BBS030 & 0.26 & 0.29 & 0.28 & 0.27 & 0.15 & -0.21 \\
\hline BBS032 & 0.21 & 0.23 & 0.21 & 0.20 & 0.14 & -0.18 \\
\hline BBS033 & 0.38 & 0.42 & 0.34 & 0.14 & 0.29 & -0.15 \\
\hline BBS034 & 0.22 & 0.26 & 0.19 & 0.22 & 0.31 & -0.23 \\
\hline BBS035 & 0.25 & 0.29 & 0.25 & 0.25 & 0.28 & -0.11 \\
\hline BBS036 & 0.20 & 0.24 & 0.21 & 0.26 & 0.23 & -0.15 \\
\hline BBS037 & 0.29 & 0.28 & 0.21 & 0.30 & 0.23 & -0.19 \\
\hline BBS038 & 0.23 & 0.20 & 0.14 & 0.16 & 0.11 & -0.18 \\
\hline BBS039 & -0.07 & -0.06 & -0.07 & 0.02 & 0.01 & -0.13 \\
\hline BBS042 & 0.20 & 0.25 & 0.21 & 0.13 & 0.19 & -0.09 \\
\hline BBS044 & 0.22 & 0.21 & 0.24 & 0.23 & 0.04 & -0.09 \\
\hline BBS046 & 0.26 & 0.28 & 0.25 & 0.21 & 0.07 & -0.21 \\
\hline BBS047 & 0.24 & 0.24 & 0.23 & 0.26 & 0.13 & -0.14 \\
\hline BBS048 & 0.28 & 0.28 & 0.28 & 0.22 & 0.10 & -0.12 \\
\hline BBS049 & 0.26 & 0.26 & 0.20 & 0.21 & 0.14 & -0.15 \\
\hline BBS053 & 0.26 & 0.31 & 0.27 & 0.22 & 0.21 & -0.21 \\
\hline BBS055 & 0.35 & 0.40 & 0.33 & 0.31 & 0.26 & -0.35 \\
\hline BBS057 & 0.39 & 0.45 & 0.37 & 0.30 & 0.17 & -0.17 \\
\hline
\end{tabular}




\begin{tabular}{|c|c|c|c|c|c|c|}
\hline BBS061 & 0.25 & 0.22 & 0.17 & 0.29 & 0.22 & -0.15 \\
\hline BBS062 & 0.22 & 0.21 & 0.18 & 0.19 & 0.13 & -0.18 \\
\hline BBS063 & 0.34 & 0.39 & 0.36 & 0.30 & 0.33 & -0.17 \\
\hline BBS064 & 0.25 & 0.18 & 0.18 & 0.30 & 0.13 & -0.06 \\
\hline BBS065 & 0.32 & 0.36 & 0.35 & 0.29 & 0.15 & -0.14 \\
\hline BBS068 & 0.19 & 0.24 & 0.22 & 0.15 & 0.18 & -0.14 \\
\hline BBS070 & 0.32 & 0.35 & 0.32 & 0.22 & 0.22 & -0.13 \\
\hline BBS071 & 0.40 & 0.38 & 0.36 & 0.32 & 0.27 & -0.24 \\
\hline BBS073 & 0.33 & 0.35 & 0.30 & 0.27 & 0.10 & -0.22 \\
\hline BBS075 & 0.14 & 0.12 & 0.08 & 0.17 & 0.22 & -0.07 \\
\hline BBS080 & 0.06 & 0.10 & 0.02 & -0.07 & 0.07 & -0.17 \\
\hline BBS083 & 0.17 & 0.15 & 0.27 & 0.25 & 0.12 & -0.18 \\
\hline BBS084 & 0.24 & 0.31 & 0.27 & 0.20 & 0.18 & -0.17 \\
\hline BBS085 & 0.34 & 0.32 & 0.26 & 0.29 & 0.18 & -0.27 \\
\hline BBS086 & 0.09 & 0.07 & 0.06 & 0.14 & 0.14 & -0.14 \\
\hline BBS087 & 0.36 & 0.43 & 0.35 & 0.16 & 0.32 & -0.20 \\
\hline BBS088 & 0.31 & 0.33 & 0.26 & 0.19 & 0.17 & -0.15 \\
\hline BBS089 & 0.29 & 0.26 & 0.25 & 0.35 & 0.23 & -0.22 \\
\hline BBS090 & 0.37 & 0.43 & 0.34 & 0.14 & 0.18 & -0.21 \\
\hline BBS091 & 0.19 & 0.19 & 0.13 & 0.23 & 0.07 & -0.12 \\
\hline BBS093 & 0.18 & 0.21 & 0.21 & 0.09 & 0.18 & -0.11 \\
\hline BBS094 & 0.32 & 0.35 & 0.32 & 0.14 & 0.21 & -0.29 \\
\hline BBS095 & 0.39 & 0.35 & 0.29 & $\mathbf{0 . 3 3}$ & 0.21 & -0.19 \\
\hline BBS096 & 0.33 & 0.49 & 0.50 & 0.18 & 0.27 & -0.17 \\
\hline BBS097 & 0.19 & 0.27 & 0.21 & 0.03 & 0.25 & -0.29 \\
\hline BBS099 & 0.29 & 0.35 & 0.31 & 0.17 & 0.25 & -0.31 \\
\hline BBS100 & 0.17 & 0.27 & 0.19 & 0.08 & 0.37 & -0.18 \\
\hline
\end{tabular}


Appendix B: Individual Tree Correlation Coefficients for EAR Standardized Chronology

\begin{tabular}{|c|c|c|c|c|c|c|}
\hline & May PDSI & June PDSI & July PDSI & May Precip & March Temp & May Temp \\
\hline EAR004 & 0.11 & 0.08 & 0.10 & 0.07 & 0.21 & 0.08 \\
\hline EAR006 & 0.19 & 0.14 & 0.16 & 0.16 & 0.10 & -0.03 \\
\hline EAR008 & 0.36 & 0.42 & 0.38 & 0.28 & 0.21 & -0.10 \\
\hline EAR009 & -0.01 & 0.04 & 0.03 & -0.03 & 0.15 & -0.03 \\
\hline EAR011 & 0.09 & 0.16 & 0.13 & 0.12 & 0.15 & -0.01 \\
\hline EAR012 & 0.08 & 0.12 & 0.14 & -0.04 & 0.14 & -0.03 \\
\hline EAR014 & 0.22 & 0.26 & 0.20 & 0.17 & 0.12 & -0.13 \\
\hline EAR015 & 0.24 & 0.27 & 0.26 & 0.18 & 0.16 & -0.12 \\
\hline EAR016 & 0.13 & 0.17 & 0.16 & -0.01 & 0.20 & -0.09 \\
\hline EAR020 & 0.19 & 0.16 & 0.18 & 0.24 & 0.13 & -0.10 \\
\hline EAR024 & 0.21 & 0.20 & 0.08 & 0.04 & 0.11 & -0.08 \\
\hline EAR025 & 0.37 & 0.35 & 0.28 & 0.22 & 0.22 & -0.08 \\
\hline EAR026 & 0.13 & 0.20 & 0.18 & 0.06 & 0.18 & -0.07 \\
\hline EAR027 & 0.19 & 0.16 & 0.11 & 0.16 & 0.19 & -0.13 \\
\hline EAR030 & 0.33 & 0.35 & 0.28 & 0.25 & 0.16 & -0.13 \\
\hline EAR031 & 0.32 & 0.32 & 0.22 & 0.14 & 0.13 & -0.14 \\
\hline EAR032 & 0.09 & 0.06 & 0.03 & 0.00 & 0.16 & -0.08 \\
\hline EAR033 & 0.08 & 0.11 & 0.09 & -0.09 & 0.23 & -0.05 \\
\hline EAR034 & 0.24 & 0.25 & 0.18 & 0.08 & 0.16 & -0.21 \\
\hline EAR035 & 0.14 & 0.17 & 0.16 & -0.02 & 0.17 & -0.21 \\
\hline EAR036 & 0.18 & 0.22 & 0.14 & 0.08 & 0.18 & -0.11 \\
\hline EAR037 & 0.26 & 0.30 & 0.26 & 0.16 & 0.17 & -0.12 \\
\hline EAR042 & 0.23 & 0.27 & 0.17 & 0.15 & 0.32 & -0.16 \\
\hline EAR043 & 0.20 & 0.15 & 0.09 & 0.09 & 0.39 & -0.19 \\
\hline EAR045 & 0.20 & 0.21 & 0.11 & 0.23 & 0.22 & -0.15 \\
\hline EAR046 & 0.19 & 0.21 & 0.18 & 0.10 & 0.30 & -0.16 \\
\hline EAR049 & -0.08 & -0.04 & -0.10 & -0.07 & 0.08 & -0.14 \\
\hline EAR056 & 0.33 & 0.40 & 0.30 & 0.20 & 0.16 & -0.19 \\
\hline EAR060 & 0.32 & 0.33 & 0.25 & 0.16 & 0.28 & -0.09 \\
\hline EAR062 & 0.31 & 0.35 & 0.22 & 0.13 & 0.22 & -0.11 \\
\hline EAR063 & 0.18 & 0.19 & 0.12 & 0.17 & 0.18 & -0.13 \\
\hline EAR068 & 0.17 & 0.15 & 0.13 & 0.11 & 0.21 & -0.09 \\
\hline EAR069 & 0.31 & 0.35 & 0.31 & 0.20 & 0.17 & -0.23 \\
\hline EAR070 & 0.15 & 0.15 & 0.14 & 0.09 & 0.13 & -0.05 \\
\hline EAR072 & 0.25 & 0.33 & 0.27 & 0.17 & 0.20 & -0.09 \\
\hline EAR074 & 0.22 & 0.26 & 0.19 & 0.13 & 0.19 & -0.09 \\
\hline EAR077 & 0.06 & 0.09 & 0.12 & 0.13 & 0.13 & -0.04 \\
\hline EAR080 & 0.18 & 0.19 & 0.21 & 0.23 & 0.17 & -0.07 \\
\hline EAR082 & 0.14 & 0.22 & 0.22 & 0.13 & 0.12 & -0.09 \\
\hline EAR084 & 0.00 & 0.10 & 0.12 & 0.07 & 0.15 & -0.10 \\
\hline
\end{tabular}




\begin{tabular}{|l|llllll|} 
EAR085 & $\mathbf{0 . 2 0}$ & $\mathbf{0 . 2 2}$ & $\mathbf{0 . 2 0}$ & $\mathbf{0 . 2 6}$ & 0.06 & $\mathbf{- 0 . 3 1}$ \\
EAR086 & 0.10 & 0.16 & $\mathbf{0 . 2 1}$ & 0.10 & $\mathbf{0 . 2 7}$ & -0.08 \\
EAR087 & $\mathbf{0 . 2 0}$ & $\mathbf{0 . 2 5}$ & $\mathbf{0 . 2 5}$ & 0.14 & $\mathbf{0 . 2 2}$ & $\mathbf{- 0 . 2 3}$ \\
EAR088 & $\mathbf{0 . 2 5}$ & $\mathbf{0 . 2 6}$ & $\mathbf{0 . 2 5}$ & $\mathbf{0 . 2 0}$ & $\mathbf{0 . 2 4}$ & -0.08 \\
EAR089 & $\mathbf{0 . 2 8}$ & $\mathbf{0 . 2 9}$ & $\mathbf{0 . 2 7}$ & 0.14 & $\mathbf{0 . 3 6}$ & -0.18 \\
EAR094 & $\mathbf{0 . 2 4}$ & $\mathbf{0 . 2 0}$ & $\mathbf{0 . 2 2}$ & $\mathbf{0 . 2 8}$ & $\mathbf{0 . 1 9}$ & $\mathbf{- 0 . 2 5}$ \\
EAR096 & $\mathbf{0 . 4 8}$ & $\mathbf{0 . 5 3}$ & $\mathbf{0 . 4 3}$ & $\mathbf{0 . 2 6}$ & $\mathbf{0 . 3 4}$ & $\mathbf{- 0 . 2 0}$ \\
EAR099 & $\mathbf{0 . 3 1}$ & $\mathbf{0 . 3 2}$ & $\mathbf{0 . 2 5}$ & $\mathbf{0 . 1 9}$ & 0.13 & -0.14 \\
EAR100 & $\mathbf{0 . 3 7}$ & $\mathbf{0 . 4 5}$ & $\mathbf{0 . 4 1}$ & $\mathbf{0 . 2 3}$ & $\mathbf{0 . 3 3}$ & $\mathbf{- 0 . 2 3}$ \\
\hline
\end{tabular}


Appendix B: Individual Tree Correlation Coefficients for TNC Standardized Chronology

\begin{tabular}{|c|c|c|c|c|c|c|}
\hline & May PDSI & June PDSI & July PDSI & May Precip & March Temp & May Temp \\
\hline TNC001 & 0.25 & 0.30 & 0.19 & 0.24 & 0.21 & -0.22 \\
\hline TNC002 & 0.10 & 0.17 & 0.09 & 0.12 & 0.20 & -0.15 \\
\hline TNC003 & -0.09 & -0.09 & -0.10 & 0.03 & 0.02 & -0.11 \\
\hline TNC005 & 0.06 & 0.10 & 0.08 & 0.11 & 0.20 & -0.18 \\
\hline TNC006 & 0.12 & 0.22 & 0.13 & 0.04 & 0.30 & -0.24 \\
\hline TNC007 & 0.13 & 0.11 & 0.05 & 0.10 & 0.22 & -0.18 \\
\hline TNC008 & 0.18 & 0.26 & 0.19 & 0.10 & 0.31 & -0.28 \\
\hline TNC009 & 0.15 & 0.16 & 0.13 & 0.19 & 0.24 & -0.04 \\
\hline TNC010 & -0.01 & 0.03 & 0.02 & 0.01 & 0.26 & -0.32 \\
\hline TNC011 & 0.07 & 0.08 & 0.05 & 0.12 & 0.25 & -0.19 \\
\hline TNC012 & 0.26 & 0.28 & 0.20 & 0.32 & 0.25 & -0.29 \\
\hline TNC013 & 0.25 & 0.30 & 0.23 & 0.22 & 0.22 & -0.10 \\
\hline TNC014 & 0.29 & 0.30 & 0.27 & 0.30 & 0.21 & -0.16 \\
\hline TNC015 & 0.35 & 0.37 & 0.33 & 0.33 & 0.20 & -0.12 \\
\hline TNC016 & 0.26 & 0.24 & 0.21 & 0.34 & 0.24 & -0.11 \\
\hline TNC017 & 0.26 & 0.30 & 0.24 & 0.30 & 0.27 & -0.22 \\
\hline TNC019 & 0.30 & 0.31 & 0.30 & 0.27 & 0.12 & -0.15 \\
\hline TNC021 & 0.22 & 0.26 & 0.24 & 0.25 & 0.25 & -0.14 \\
\hline TNC023 & 0.16 & 0.22 & 0.19 & 0.17 & 0.24 & -0.15 \\
\hline TNC024 & 0.18 & 0.18 & 0.16 & 0.27 & 0.18 & -0.12 \\
\hline TNC026 & 0.27 & 0.27 & 0.17 & 0.28 & 0.20 & -0.15 \\
\hline TNC027 & 0.26 & 0.35 & 0.23 & 0.09 & 0.21 & -0.16 \\
\hline TNC029 & 0.23 & 0.27 & 0.23 & 0.21 & 0.30 & -0.18 \\
\hline TNC030 & 0.41 & 0.42 & 0.35 & 0.33 & 0.25 & -0.30 \\
\hline TNC032 & 0.12 & 0.15 & 0.17 & 0.22 & 0.24 & -0.17 \\
\hline TNC034 & 0.31 & 0.37 & 0.34 & 0.34 & 0.32 & -0.22 \\
\hline TNC035 & 0.34 & 0.44 & 0.36 & 0.19 & 0.16 & -0.22 \\
\hline TNC039 & 0.33 & 0.30 & 0.30 & 0.25 & 0.19 & -0.14 \\
\hline TNC041 & 0.31 & 0.34 & 0.29 & 0.29 & 0.12 & -0.08 \\
\hline TNC045 & 0.28 & 0.30 & 0.28 & 0.26 & 0.15 & -0.15 \\
\hline TNC048 & 0.41 & 0.42 & 0.33 & 0.24 & 0.18 & -0.27 \\
\hline TNC049 & 0.26 & 0.27 & 0.24 & 0.26 & 0.10 & -0.21 \\
\hline TNC050 & 0.33 & 0.32 & 0.29 & 0.25 & 0.23 & -0.18 \\
\hline TNC052 & 0.30 & 0.39 & 0.33 & 0.23 & 0.35 & -0.15 \\
\hline TNC054 & 0.16 & 0.28 & 0.29 & 0.04 & 0.18 & -0.09 \\
\hline TNC055 & 0.32 & 0.33 & 0.26 & 0.32 & 0.23 & -0.19 \\
\hline TNC056 & 0.01 & 0.10 & 0.09 & -0.04 & 0.18 & -0.13 \\
\hline TNC057 & 0.13 & 0.23 & 0.15 & 0.06 & 0.12 & -0.17 \\
\hline TNC063 & 0.19 & 0.28 & 0.25 & 0.20 & 0.27 & -0.17 \\
\hline TNC066 & 0.23 & 0.30 & 0.29 & 0.23 & 0.16 & -0.12 \\
\hline
\end{tabular}




\begin{tabular}{|l|llllll|} 
TNC067 & 0.15 & 0.12 & 0.10 & $\mathbf{0 . 3 5}$ & $\mathbf{0 . 2 1}$ & $\mathbf{- 0 . 2 3}$ \\
TNC069 & 0.17 & $\mathbf{0 . 2 0}$ & $\mathbf{0 . 2 3}$ & $\mathbf{0 . 2 3}$ & 0.15 & $\mathbf{- 0 . 1 9}$ \\
TNC070 & 0.18 & 0.18 & 0.17 & $\mathbf{0 . 4 3}$ & 0.14 & $\mathbf{- 0 . 2 2}$ \\
TNC073 & $\mathbf{0 . 1 9}$ & 0.16 & 0.16 & $\mathbf{0 . 2 1}$ & 0.15 & -0.13 \\
TNC076 & $\mathbf{0 . 2 2}$ & $\mathbf{0 . 2 5}$ & $\mathbf{0 . 1 9}$ & $\mathbf{0 . 3 4}$ & 0.18 & -0.11 \\
TNC077 & $\mathbf{0 . 3 1}$ & $\mathbf{0 . 3 9}$ & $\mathbf{0 . 3 8}$ & $\mathbf{0 . 2 6}$ & 0.17 & -0.15 \\
TNC079 & $\mathbf{0 . 2 3}$ & $\mathbf{0 . 3 1}$ & $\mathbf{0 . 2 9}$ & $\mathbf{0 . 2 7}$ & $\mathbf{0 . 2 4}$ & -0.16 \\
TNC080 & 0.16 & $\mathbf{0 . 2 5}$ & $\mathbf{0 . 2 4}$ & $\mathbf{0 . 2 4}$ & 0.13 & -0.13 \\
TNC082 & $\mathbf{0 . 2 6}$ & $\mathbf{0 . 3 4}$ & $\mathbf{0 . 3 3}$ & $\mathbf{0 . 3 2}$ & 0.18 & -0.18 \\
TNC083 & 0.17 & $\mathbf{0 . 2 6}$ & $\mathbf{0 . 2 3}$ & 0.08 & $\mathbf{0 . 2 1}$ & -0.13 \\
TNC084 & $\mathbf{0 . 3 9}$ & $\mathbf{0 . 4 1}$ & $\mathbf{0 . 3 5}$ & 0.17 & 0.17 & -0.16 \\
TNC085 & $\mathbf{0 . 2 8}$ & $\mathbf{0 . 3 2}$ & $\mathbf{0 . 2 8}$ & 0.07 & $\mathbf{0 . 2 7}$ & $\mathbf{- 0 . 2 3}$ \\
\hline
\end{tabular}


Appendix C: Scatter Plots of Soil Chemistry vs. Sensitivity Metrics
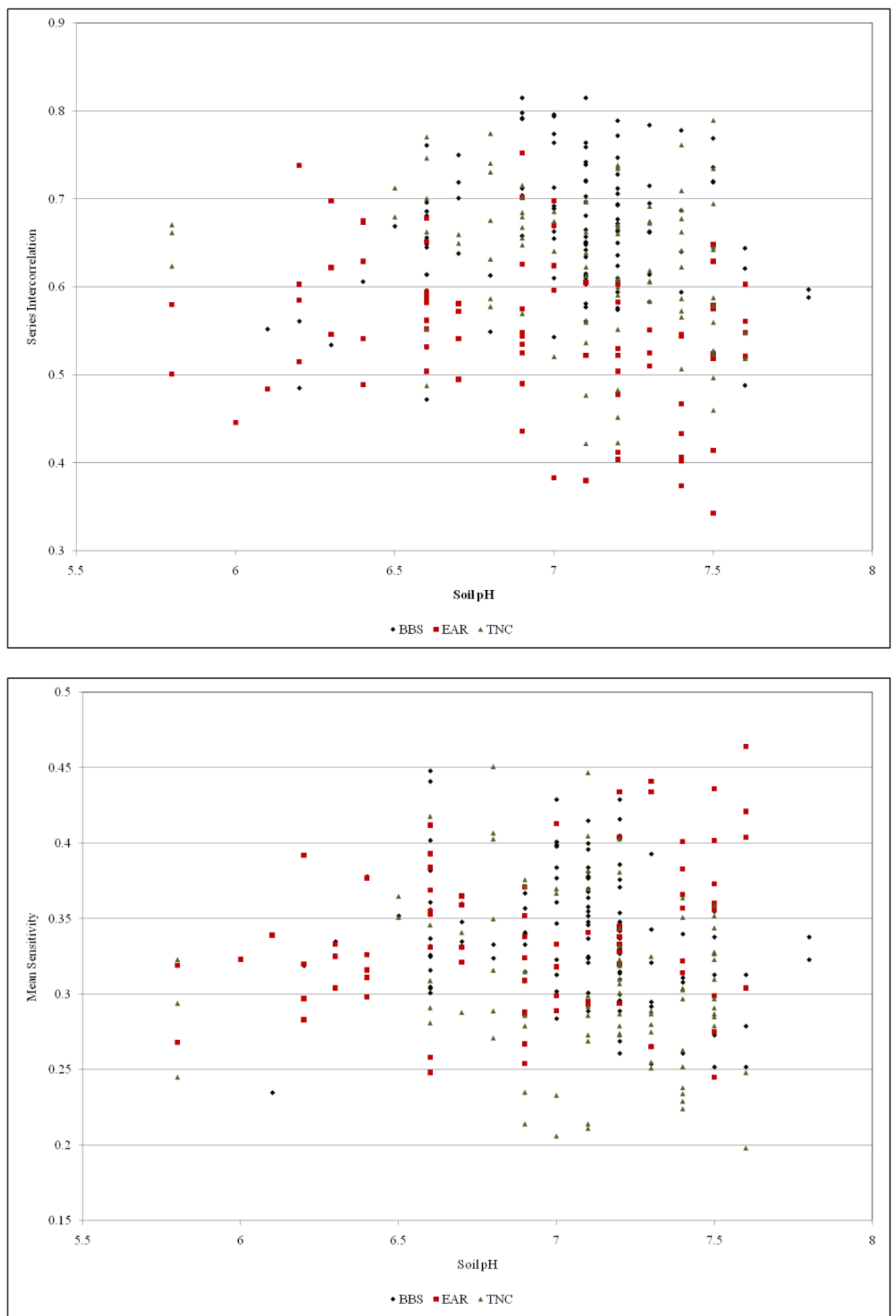

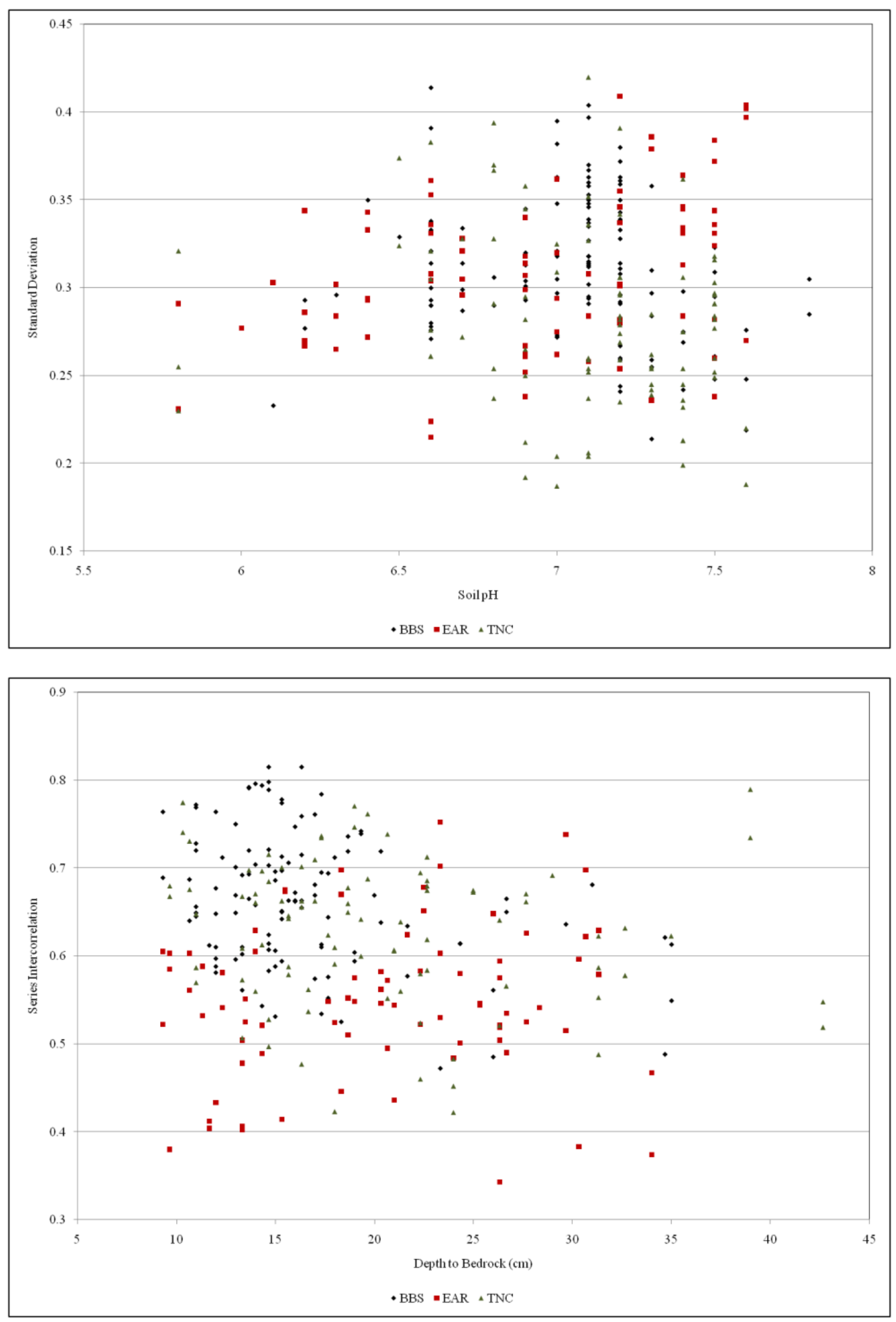

53 

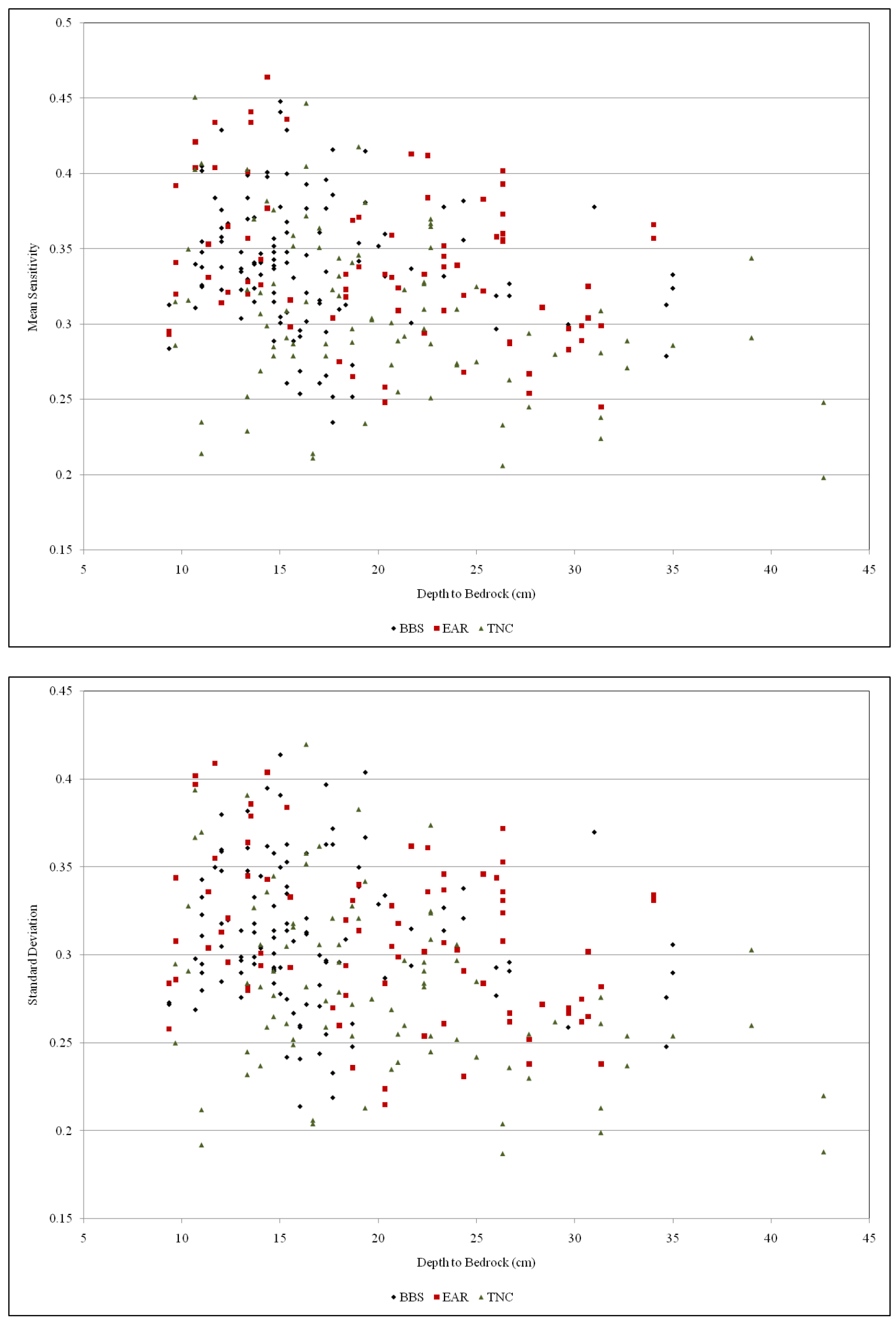

54 

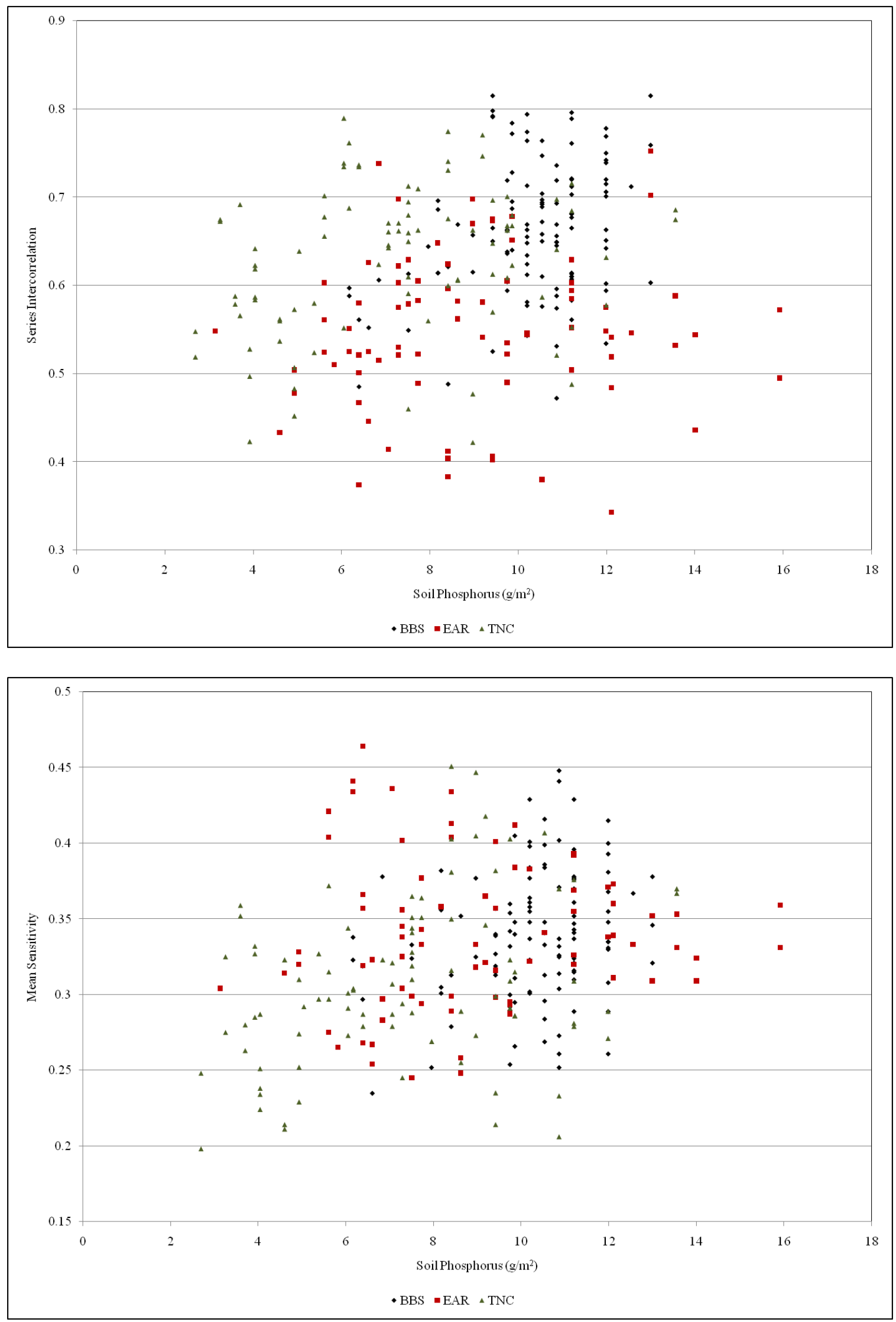

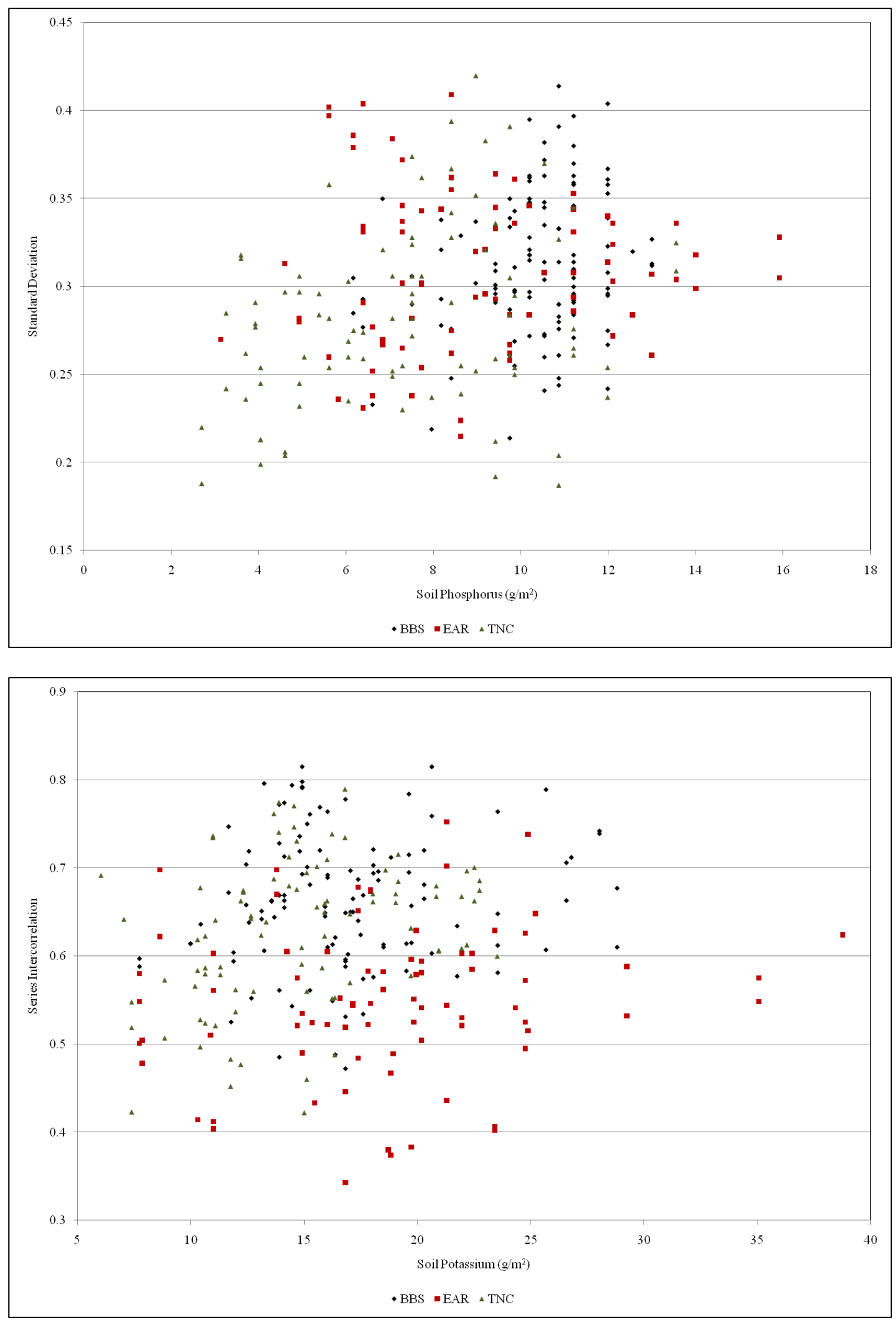

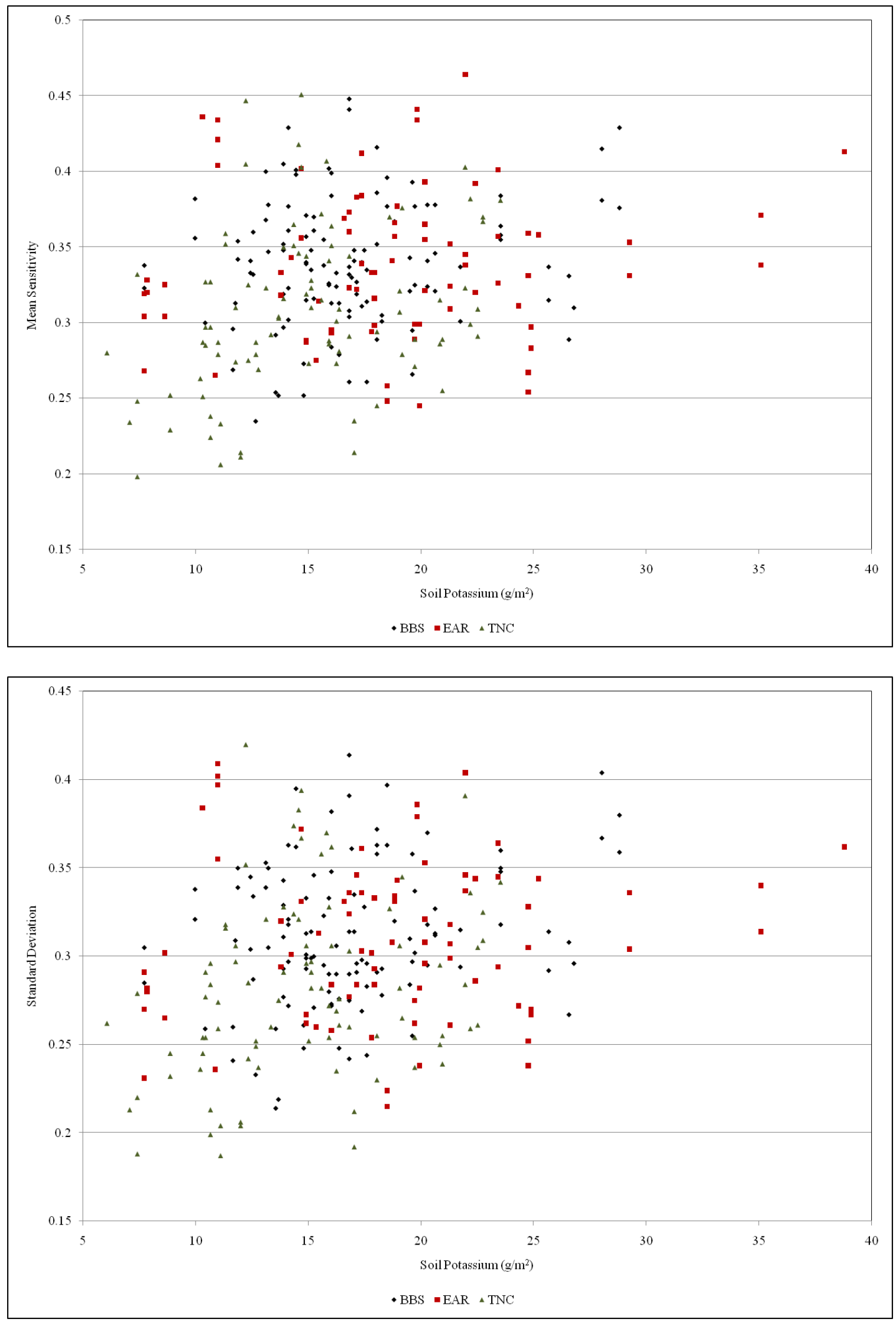

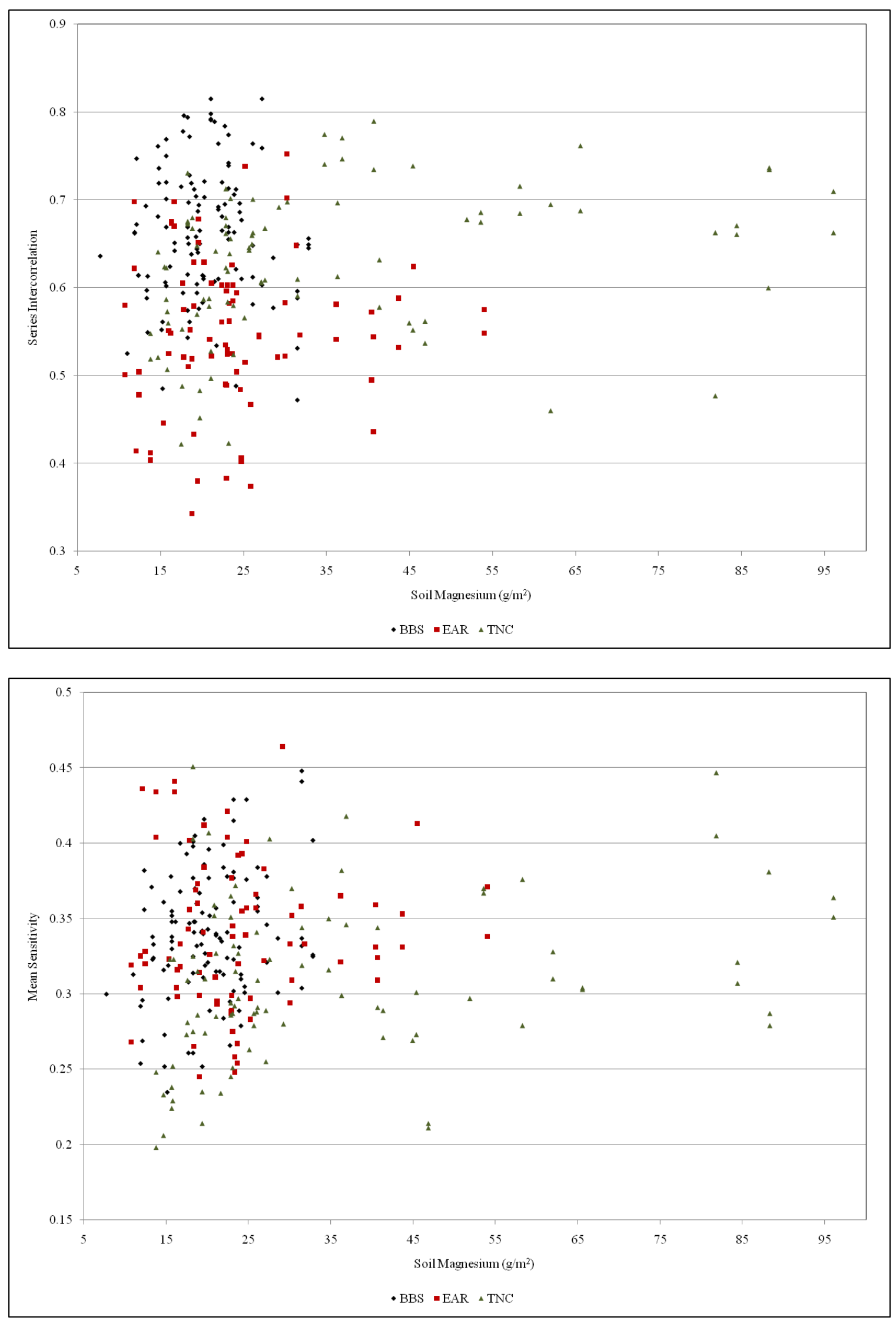

58 

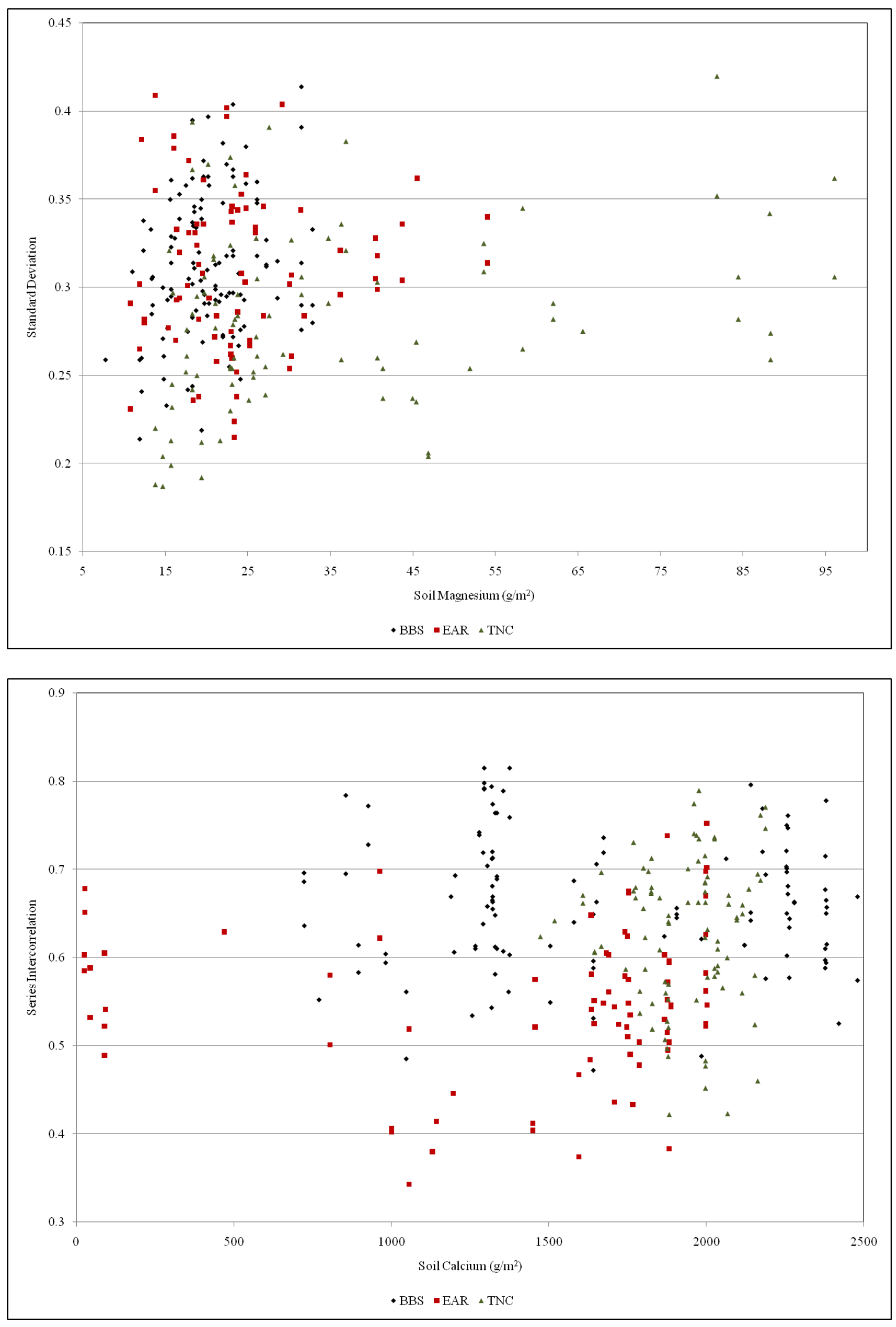

59 

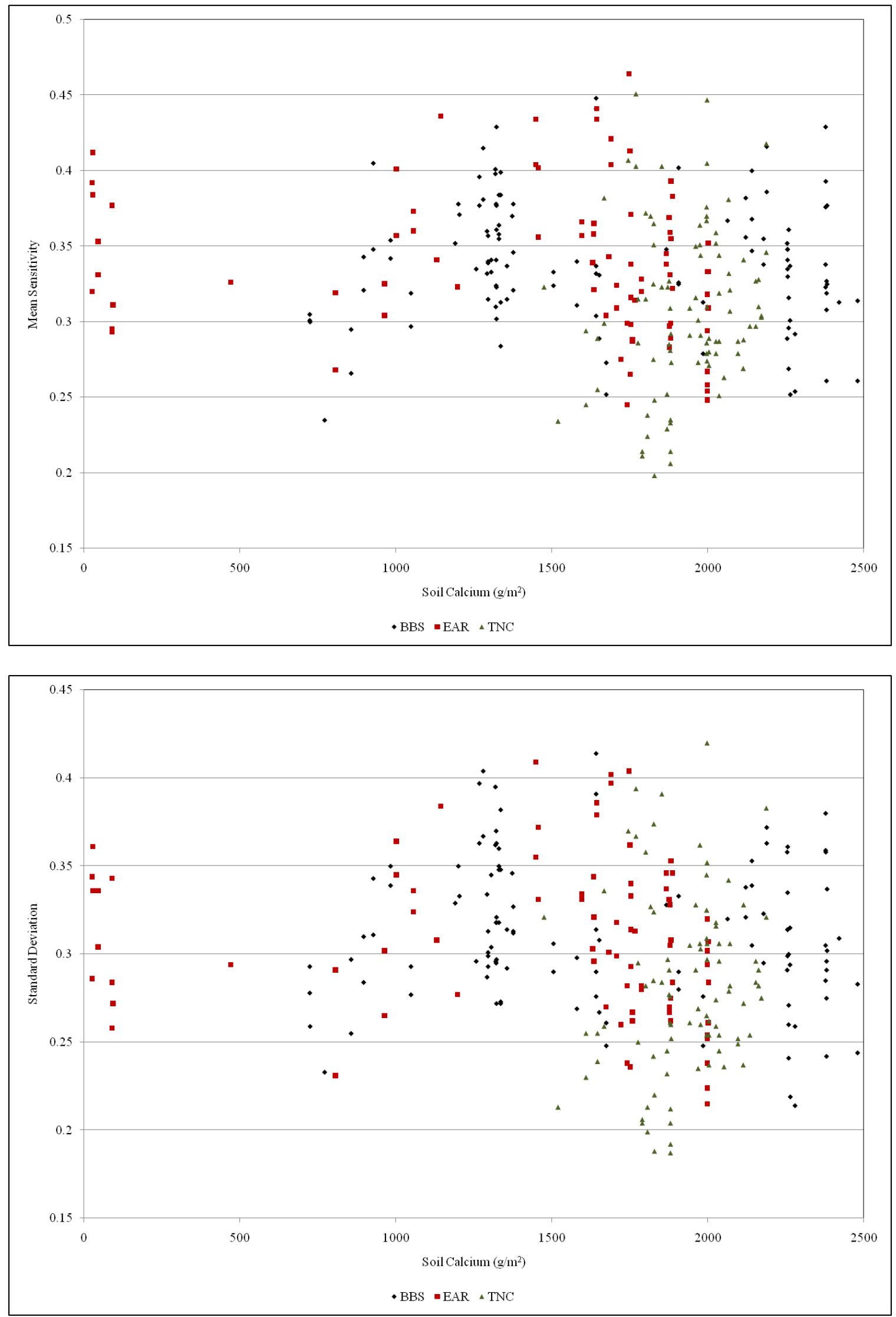

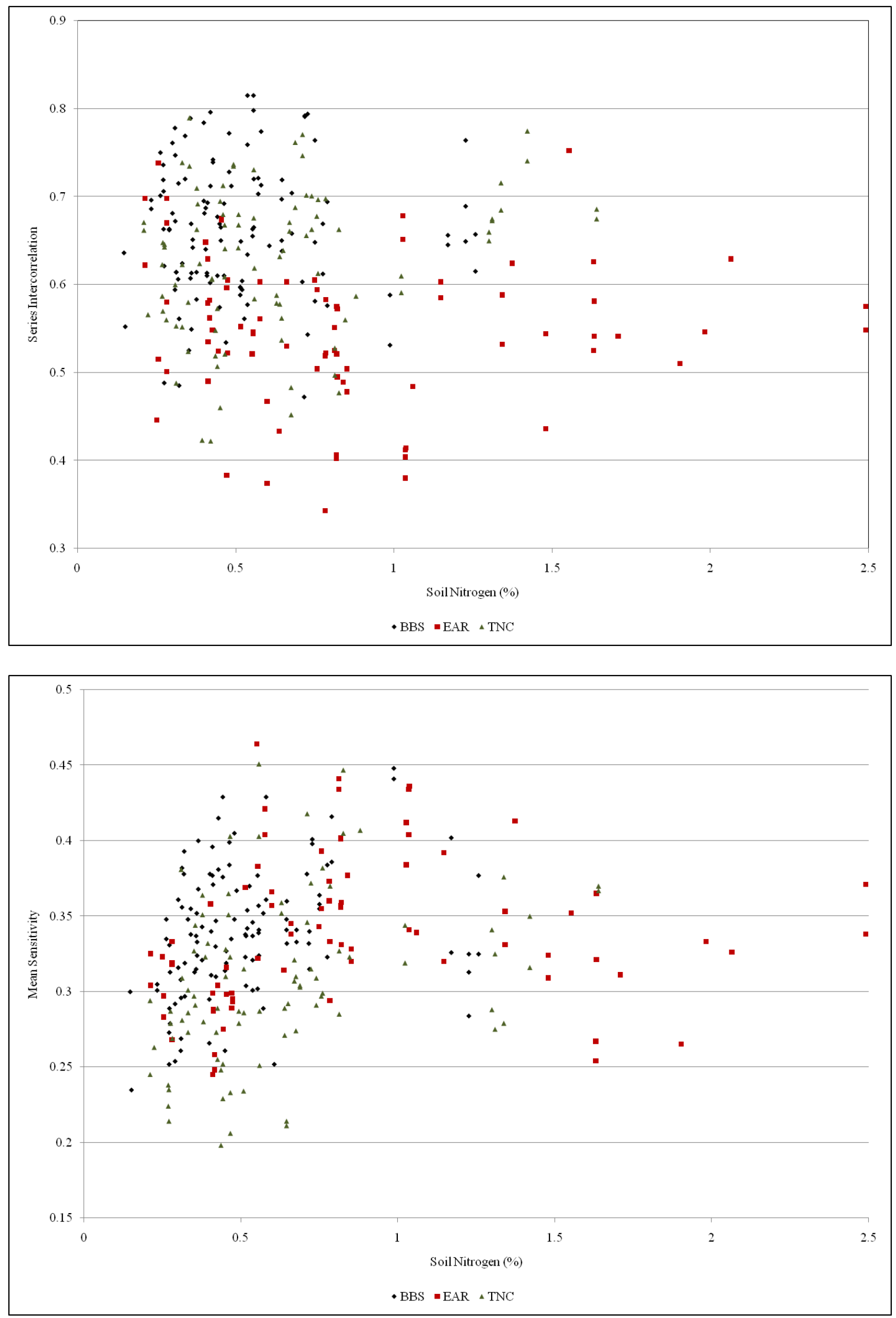


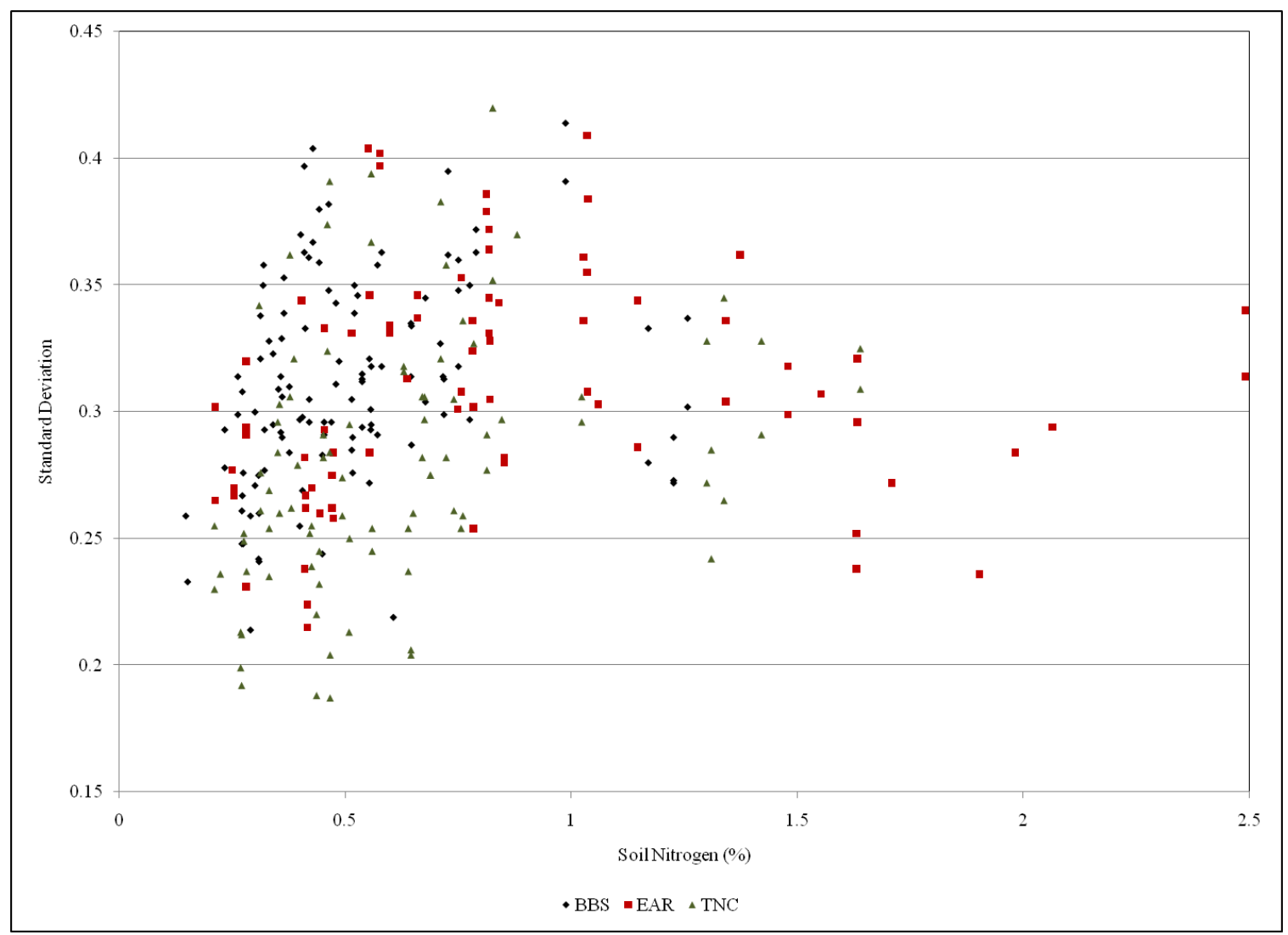


Appendix D: Scatter Plots of Soil Chemistry vs. June PDSI Correlations
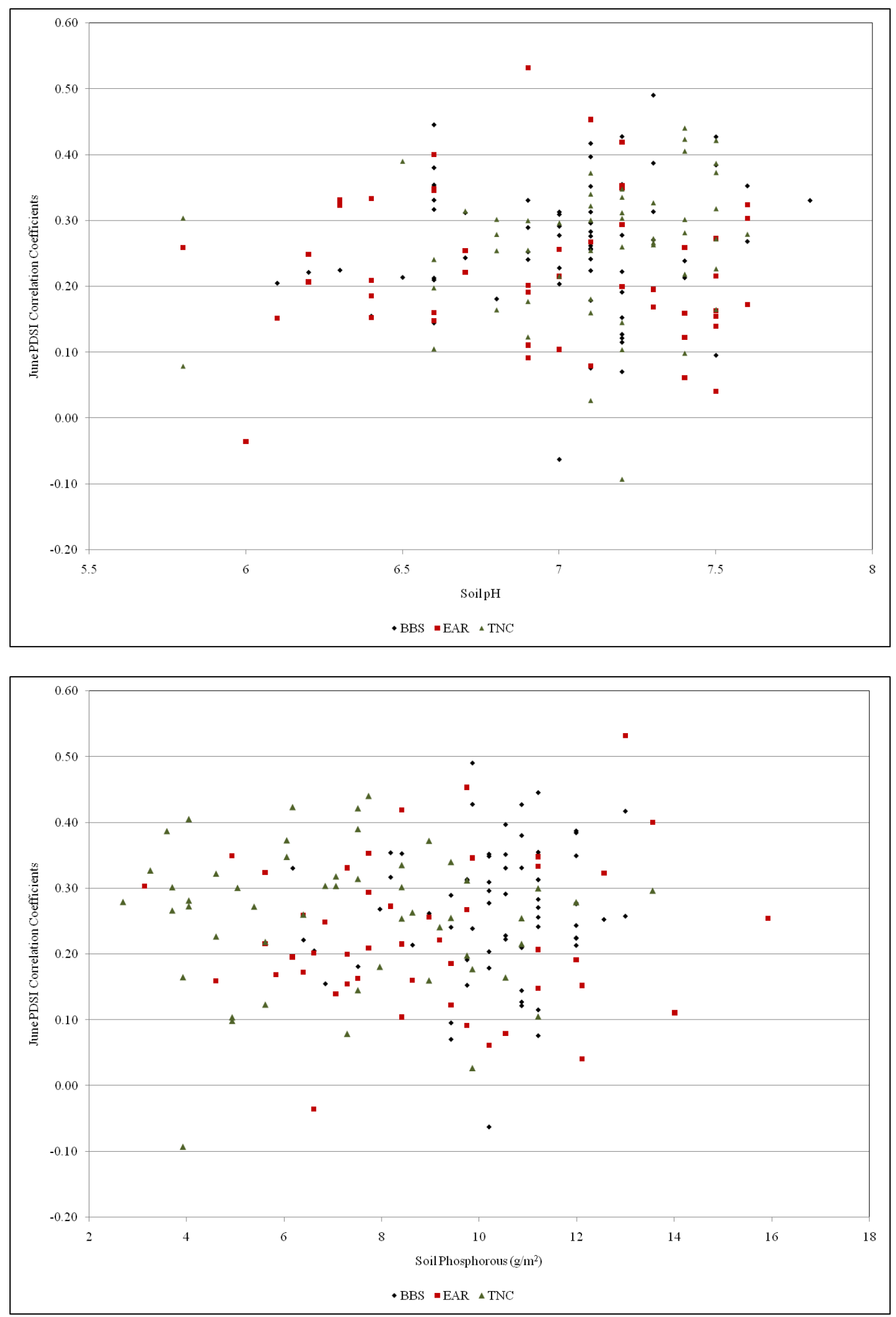

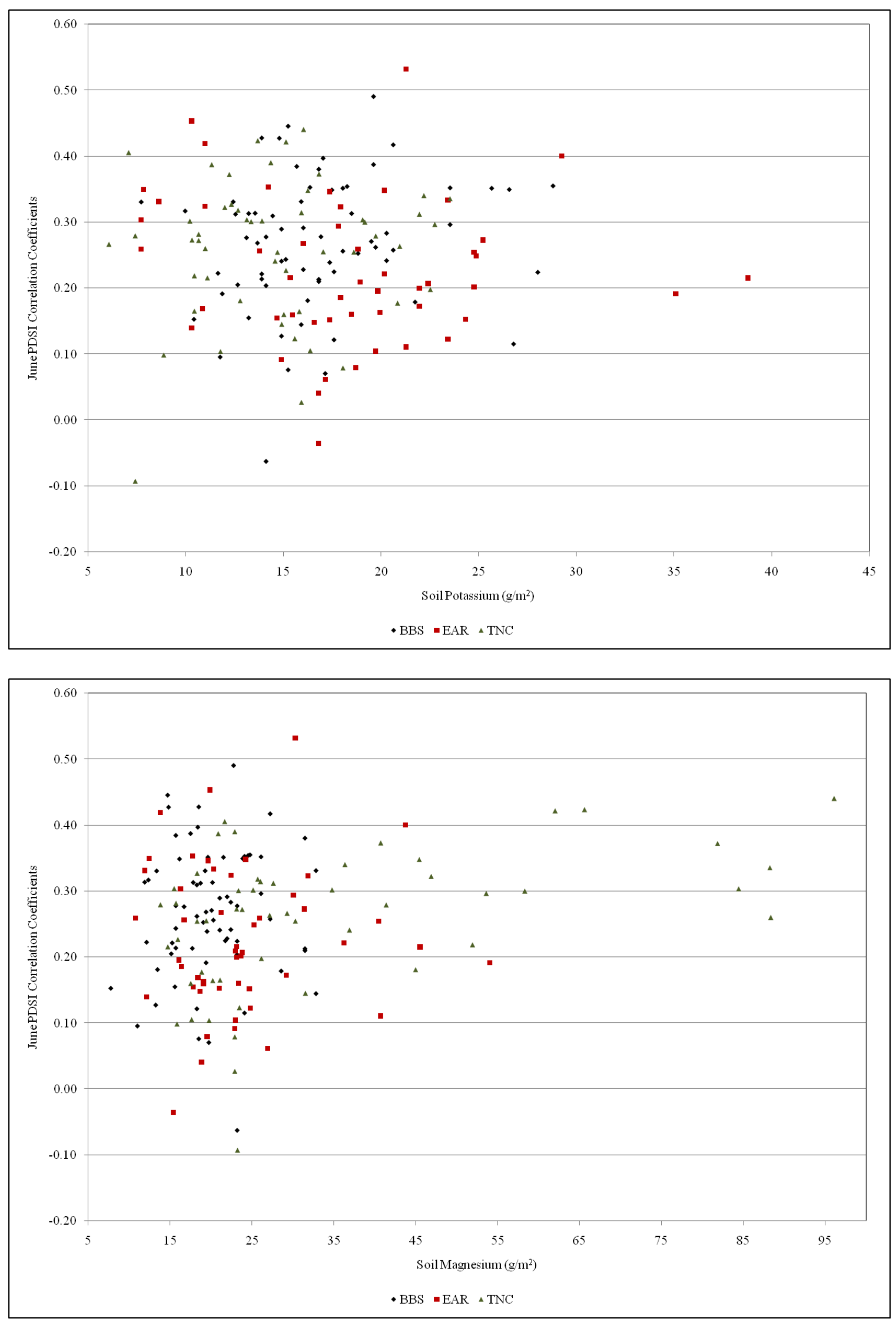

64 

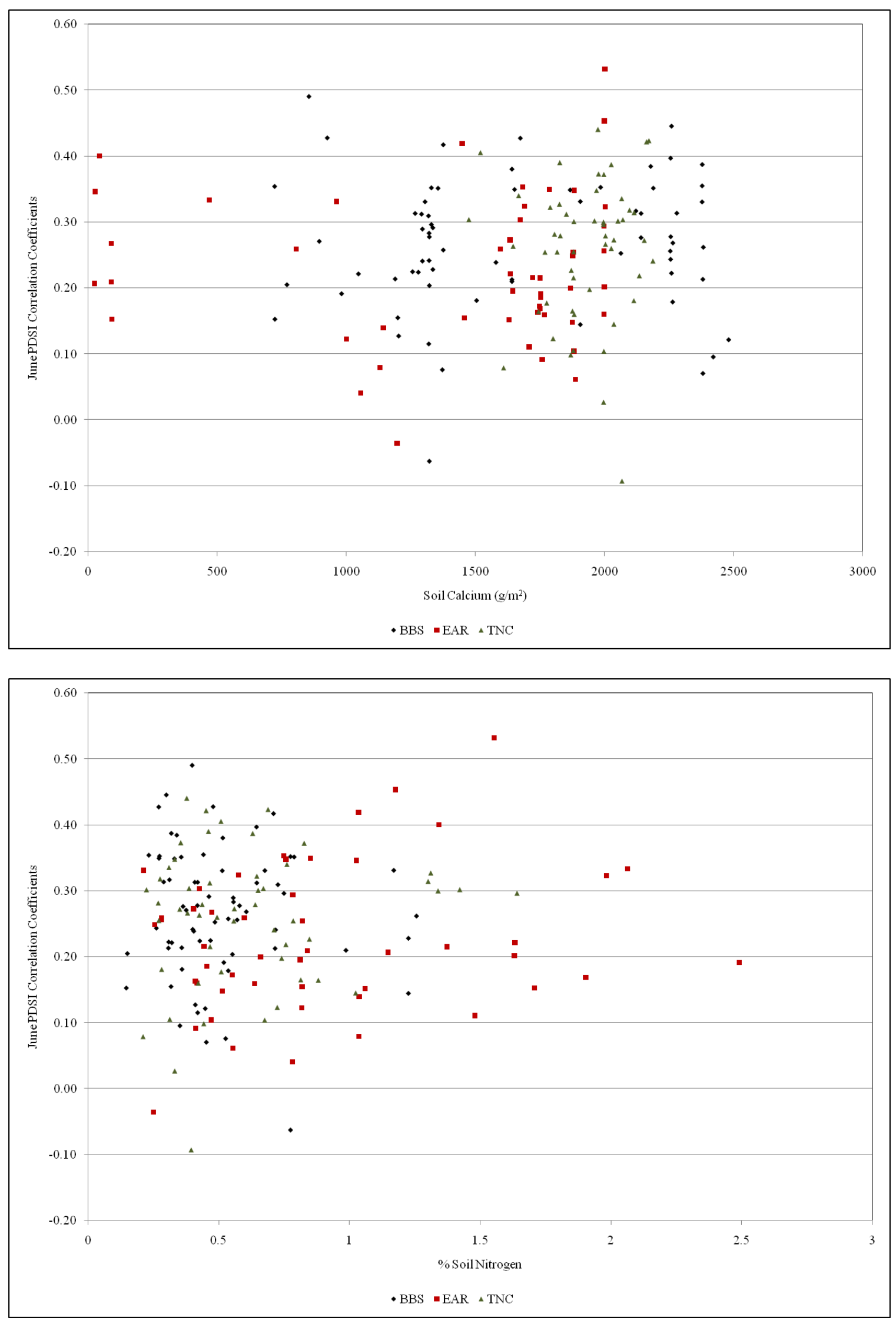

65 
Appendix E: Moving Interval Correlation Values - 50 Year Window
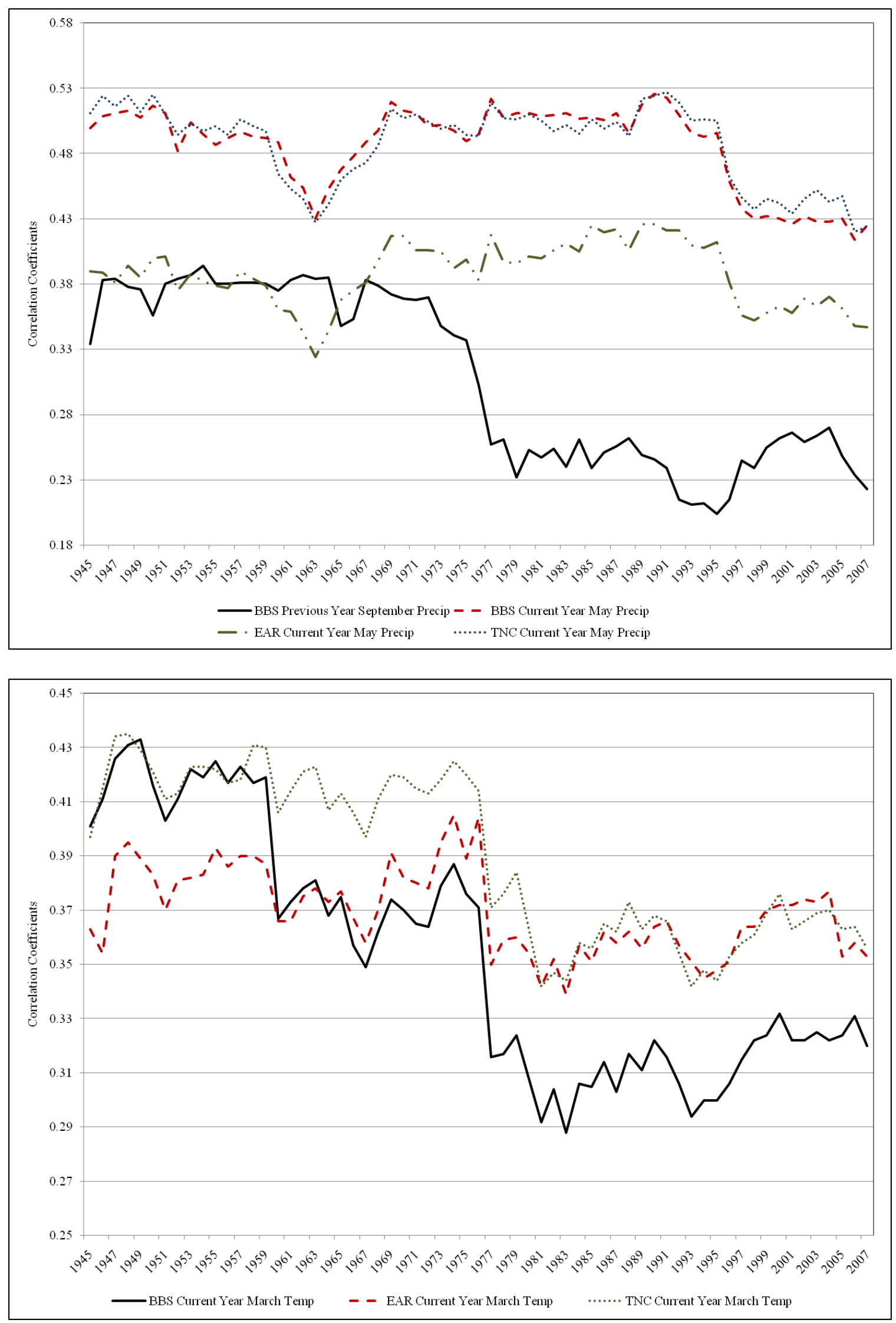


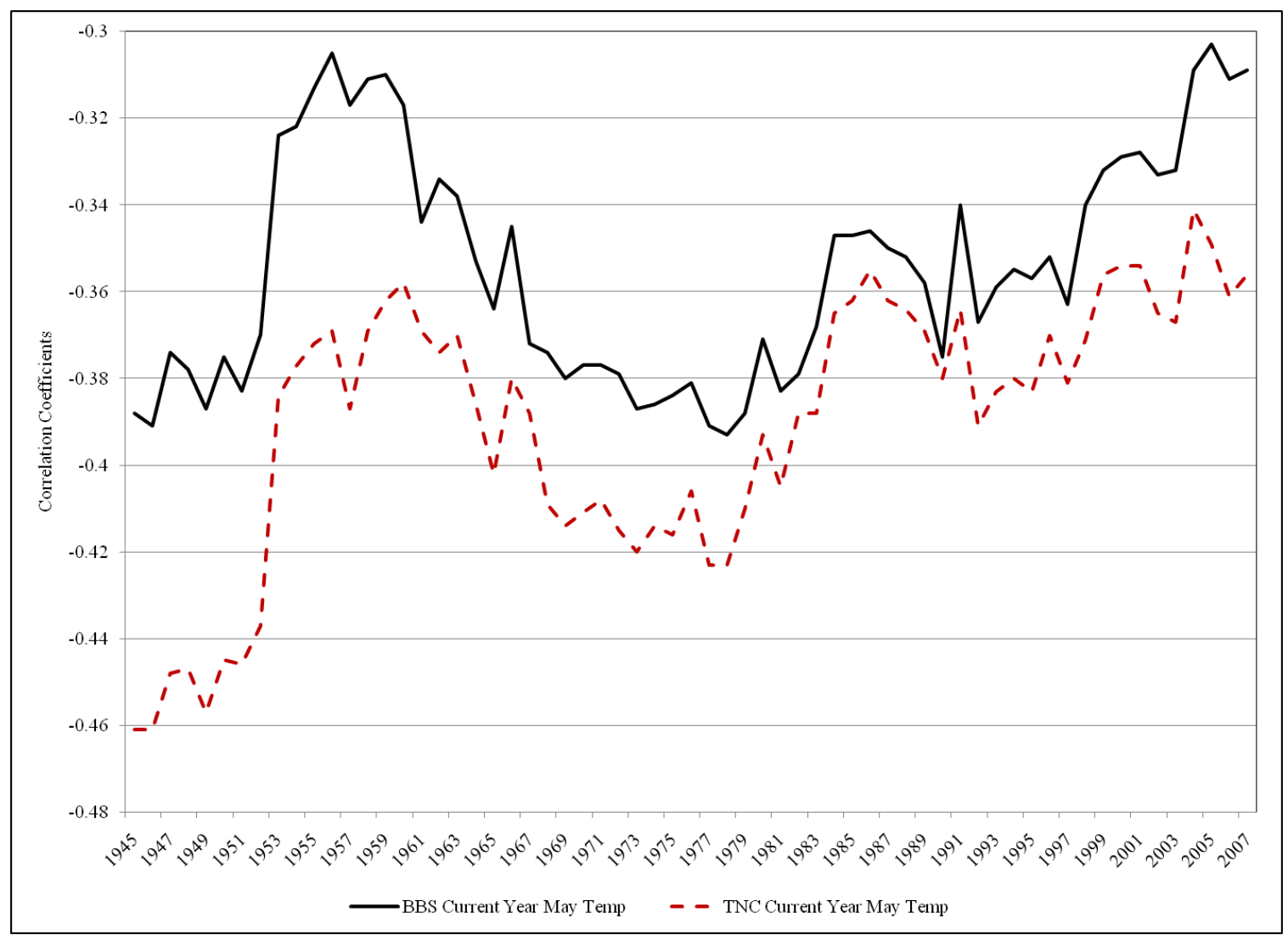

John

Unvesisty thataic

$\mathrm{H}$. 